\title{
PROBABILIDADE DOS ERROS TIPO I E II DOS TESTES \\ PARA DELINEAMENTO CROSS-OVER $2 \times 2$ DE RESPOSTAS BINÁRIAS: ESTIMAÇÃO \\ PELO MÉTODO DE MONTE CARLO
}

\author{
ANTONIO LUIZ RODRIGUES JÚNIOR \\ Cirurgião Dentista
}

Orientadora: Profa.Dra.Clarice B.G.Demétrio

\begin{abstract}
Dissertaçāo apresentada à Escola Superior de Agricultura "Luiz de Queiróz", da Universidade de São Paulo, para obtençāo do título de Mestre em Agronomia. Área de Concentraçāo: Estatistica e Experimentaçāo Agronômica.
\end{abstract}

\section{PIRACICABA}

Estado de São Paulo - Brasil

novembro de 1994 
Ficha catalogratica preparada pela Seça de Livros da Divisao de Bitbiateca e Documentaçăo - FCLOfUSF

\footnotetext{
Fiodrigues Juniar, Antonio Luiz Fófop Frobabilidade das erros tipo I e Il dos testes para
delineamento cross-over $2 \times 2$ de respostas tinarias es timaço pelo metodo de Monte Carlo. Firacicaba, 1995 88p.

Diss. (MEstre) - ESALQ

Eibliografia.

1. Andidse estatistica 2. Deirreamento de evperimen to 3. Metodo Monte Carlo 4. Simulaçăo I. Escola Supe rior de fgricultura luiz de Gueifoz, Firacicata 


\section{PROBABILIDADE DOS ERROS TIPO I E II DOS TESTES \\ PARA DELINEAMENTO CROSS-OVER $2 \times 2$ DE \\ RESPOSTAS BINÁRIAS: ESTIMAÇÃO \\ PELO MÉTODO DE MONTE CARLO}

\section{ANTONIO LUIZ RODRIGUES JÚNIOR}

Aprovada em 13/02/1995

COMISSÃO JULGADORA:

Profa.Dra. Clarice Borges Garcia Demétrio ESALQ/USP

Prof.Dr. Irineu Umberto Packer ESALQ/USP

Profa.Dra. Leonor de Castro Monteiro Loffredo FOAr/UNESP

Prof.Dr. Sérgio do Nascimento Kronka FCV/UNESP

Prof.Dr. Décio Barbin ESALQ/USP

Parictarcia Boffes Dennétrio Profa.Dra. Clarice B.G. Demétrio 
Assim, pelos olhos, o amor atinge o coraçấ:

Pois os olhos sajo os espióes do coração.

$E$ vão investigando

$O$ que agradaria a este possuir.

E quando entram em pleno acordo

E, firmes, os trés em um só se harmonizam,

Nesse instante nasce o amor perfeito, nasce

Daquilo que os olhos tornaram bem-vindo ao coraçáo.

O amor náo pode nascer nem ter início senâo

Por esse movimento originado do pendor natural.

Pela graça e o comando

Dos très, e do prazer deles,

Nasce o amor, cuja clara esperança

Segue dando conforto aos seus amigos.

Pois, como sabem todos os amantes

Verdadeiros, o amor é bondade perfeita,

Oriunda - ninguém duvida - do coraçáo e dos olhos.

Os olhos o fazem florecer; o coraçâo o amadurece:

Amor, fruto da semente pelos três plantada.

Guiraut de Borneilh (1138-1200?)

... para Mônica. 


\section{Agradecimentos}

Ao Departamento de Matemática e Estatística da ESALQ/USP, por propiciar o aprendizado de um Cirurgião Dentista nos conhecimentos de Estatística.

À minha Orientadora, pelo estímulo durante este processo de formação.

Ao Professor Humberto de Campos, pelas sugestões relevantes.

À Faculdade de Odontologia de Araraquara - UNESP, em especial às integrantes da área de Bioestatística e Metodologia Científica - Leonor e Lúcia, por apoiarem o meu desenvolvimento profissional. 


\section{CURRICULUM VITAE}

Antonio Luiz Rodrigues Júnior, nascido em 22/jul/62, em Pirassununga - SP.

formaçấo universitária:

cirurgião dentista, pela FOP - UNICAMP em 1985; especialista em saúde pública, pela CEDAS - São Camilo em 1992.

publicaçòes:

Benelli, E.M.; Serra, M.C.; Cury, J.A.; Rodrigues Jr., A.L. In situ anticariogenic potential of glass ionomer cement. Caries Res 27: 280-4, 1993.

Rodrigues Jr., A.L.\& Cury, J.A. Principles of statistical quality control applied to fluoride determination routine. J.Dent.Res. 71(4): 9731, 1991.

Rodrigues Jr., A.L. Aplicação de testes de hipótese à exames laboratoriais que utilizam controle estatístico de qualidade. In: Congresso Brasileiro de Epidemiologia, II, Belo Horizonte, 1992 Anais p.46.

atividades profissionais:

clínico geral de fevereiro de 1986 a fevereiro de 1987;

técnico especializado em programação de computadores, na FOP UNICAMP, de março de 1987 a março de 1989.

clínico geral, na prefeitura municipal de Sumaré - SP, de dezembro de 1989 a março de 1990.

docente da FOAr - UNESP, na disciplina de Bioestatística e Metodologia Científica, desde agosto de 1990. 


\section{SUMÁRIO}

CONTEÚDO

página

LISTA DE TABELAS . . . . . . . . . . . . . . . . . . . iii

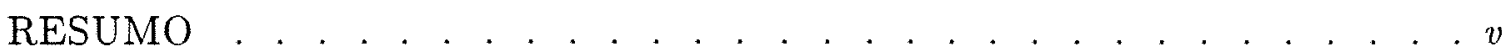

SUMMARY ..................... vii

1. INTRODUÇÃO . . . . . . . . . . . . . . . . . 1

2. REVISÃO DE LITERATURA . . . . . . . . . . . . . . . . . . 4

2.1. Variável Aleatória Binária . . . . . . . . . . . . . . . 10

2.2. Modelo Logístico . . . . . . . . . . . . . . . . . . . . . 13

2.3. Tabelas de Contingência . . . . . . . . . . . . . . . . . 15

2.3.1. Independência . . . . . . . . . . . . . . . . . . . 16

2.3.2. Homogeneidade de Proporçôes . . . . . . . . . . . . 18

2.4. Modelos Log-Lineares . . . . . . . . . . . . . . . . . . . 21

2.5. O Delineamento "Cross-Over" $2 \times 2$. . . . . . . . . . 25

2.6. Análise do Delineamento . . . . . . . . . . . . . . . . . 30

2.6.1. Teste de McNemar . . . . . . . . . . . . . . . . . 30

2.6.2. Teste de Mainland-Gart . . . . . . . . . . . . . 32

2.6.3. Teste Exato de Fisher . . . . . . . . . . . . . . . 39

2.6.4. Testes Não-Condicionais . . . . . . . . . . . . . . 35

2.6.5. Teste de Prescott . . . . . . . . . . . . . . . . . 36

2.6.6. Teste para Interaçấo Tratamento×período . . . . . . . 39

2.6.7. Teste de Tratamentos usando o Primeiro Período . . . . 40 
3. METODOLOGIA . . . . . . . . . . . . . . . 41

3.1. Método de Monte Carlo . . . . . . . . . . . . . . . . . . 42

3.2. Programaçâa do Computador . . . . . . . . . . . . . . . 47

3.2.1. Software XOVER . . . . . . . . . . . . . 47

3.2.2. Software SIMXOVER . . . . . . . . . . . . . . . 49

4. RESUlTADOS \& DISCUSSÃO . . . . . . . . . . . . 52

5. CONCLUSÕES . . . . . . . . . . . . . . . 59

6. REFERÊNCIAS BIBLIOGRÁFICAS . . . . . . . . . . . . 61 APÊNDICE A . . . . . . . . . . . . . . . . 65 APÊNDICE B . . . . . . . . . . . . . . . . 67 APÊNDICE C . . . . . . . . . . . . . . . . . . . 80 


\section{LISTA DE TABELAS}

CONTEÚDO

página

TABELA 1: Esquema de uma tabela de contingência genérica, de dupla entrada, usada na análise de dados categorizados . . . . . . . 16

TABELA 2: Esquema da tabela de contingência $2 \times 2$, utilizada quando as duas variáveis são binárias . . . . . . . . . . . . . . . . . 18

TABELA 3: Esquema da tabela de contingência $2 \times 2$, considerando as probabilidades condicionais, em um estudo prospectivo (por exemplo) com totais marginais da variável $\mathbf{U}$ conhecidos. . . . . . . . . 20

TABELA 4: Esquema da tabela de contingência $2 \times 2$, considerando as probabilidades condicionais, em um estudo retrospectivo com totais marginais da variável $\mathrm{V}$ conhecidos. . . . . . . . . . . . . . 20

TABELA 5: Representação da tabela de contingência $2 \times 2$, onde as células foram obtidas pelo modelo log-linear. . . . . . . . . . . . . 23

TABELA 6: Representação esquemática da tabela de contingência $2 \times 2$, mostrando a matriz de freqüências $\left(n_{i j}\right)$ e as probabilidades $\left(\pi_{i j}\right)$ do delineamento "Cross-Over". . . . . . . . . . . . . . . 25

TABELA 7: Tabela de contingência utilizada por GART (1969), que considera somente os pares em que $Y_{1} \neq Y_{2}$. . . . . . . . . . . . 26

TABELA 8: Representação esquemática da tabela de contingência $2 \times 2$, onde os elementos foram obtidos pela proposta de ZIMMERMANN \& RAHLFS. (1978) . . . . . . . . . . . . . . . . . . . 28

TABELA 9: Esquema da tabela utilizada pelo teste PRESCOTT, onde são agrupados os pares de respostas binárias iguais . . . . . . . . 37 
TABELA 10: Representação esquemática dos dados utilizados no teste de tratamentos, considerando o primeiro periodo . . . . . . . . . 40

TABELA 11: Parâmetros $\left(\pi_{i j}\right)$ utilizados no Método de Monte Carlo, para gerar as simulaçôes do delineamento "Cross-Over" . . . . . . 44

TABELA 12: Relação dos testes estatísticos utilizados na análise de delineamentos "Cross-Over" $2 \times 2$, onde constam a hipótese nula, o teste e as restriçôes . . . . . . . . . . . . . . . . . . . 46

TABELA 13: Valores absolutos de amostras simuladas com resultados menores que 0.05. . . . . . . . . . . . . . . . . . . . . 53

TABELA 14: Estimativas de sensibilidade dos testes estudados, em função dos efeitos de tratamentos $\left(\lambda_{i}^{T}\right)$ e do tamanho da amostra $\left(n_{i}\right)$. . 54

TABELA 15: Estimativas percentuais (\%) de sensibilidade dos testes, em funçẫo do efeito da interação $\left(\lambda_{i j}^{T P}\right)$ e do tamanho da amostra $\left(n_{i .}\right)$, dos testes de tratamentos . . . . . . . . . . . . . . . . . 55

TABELA 16: Estimativas percentuais (\%) de especificidade dos testes, em funçâo do efeito da interação $\left(\lambda_{i j}^{T P}\right)$ e do tamanho da amostra $\left(n_{i}\right)$, dos testes de tratamentos . . . . . . . . . . . . . . . . 57

TABELA 17: Parâmetros usados nas simulaçôes, para interação tratamento $\times$ periodo $\left(\lambda^{T P}\right)$ e para tratamentos $\left(\lambda^{T}\right)$ em função do total marginal $\left(n_{i .}\right)$. 


\title{
PROBABILIDADE DOS ERROS TIPO I E II DOS TESTES \\ PARA DELINEAMENTO CROSS-OVER $2 \times 2$ DE RESPOSTAS BINÁRIAS: ESTIMAÇÃO PELO MÉTODO DE MONTE CARLO
}

\author{
Autor: Antonio Luiz Rodrigues Júnior \\ Orientadora: Clarice Borges Garcia Demétrio
}

\section{RESUMO}

O delineamento "Cross-Over" $2 \times 2$ de respostas binárias é aquele que compara dois tratamentos, em dois periodos diferentes, sendo aplicados a todas as unidades experimentais observando-se as respostas categorizadas dicotômicas. Este tipo de delineamento vem sendo amplamente utilizado nas áreas biológicas, devido à sua eficiência em relação aos modelos convencionais.

O objetivo deste trabalho foi estimar as probabilidades de erros tipo I e II dos testes de McNemar, da aproximação de $\chi^{2}$ de $\mathrm{McNemar}$, dos NãoCondicionais $\left(\chi^{2}\right.$ de Pearson, $\chi^{2}$ de Verossimilhança e de Yates), de Prescott(para pequenas e para grandes amostras), de Fisher, de Armitage\&Hills e do Primeiro Período; e desenvolver um instrumento computacional, para realizar as simulações de Monte Carlo e as análises estatísticas, propiciando aos usuários do delineamento "Cross-Over" um "software" que execute os cálculos em situações reais.

Foram realizadas simulações pelo método congruencial misto, gerando amostras de distribuições multinomiais através do algoritmo de busca se- 
qüencial. Mil amostras foram geradas para cada condição paramétrica (efeito de tratamento e da interação tratamento $\times$ período), sem que houvesse efeito de periodo. As estimativas dos erros tipo I e tipo II foram feitas através do percentual de amostras que apresentavam o nível de significância inferior a de $5 \%$.

Os resultados destacam a importância da correta indicação desses métodos, pois pode haver um melhor teste, dependendo do efeito da interação tratamento $\times$ periodo. Observou-se que a presença deste efeito influiu diretamente nos resultados das probabilidades de erros tipo I e II. Também verificou-se que, nos testes de comparação de tratamentos, o tamanho da amostra diminuiu o efeito do "viés" da presença do efeito da interação. Os testes que apresentaram os melhores desempenhos foram, em ordem decrescente: o teste de McNemar para grandes amostras, os Não-Condicionais (Pearson, Verossimilhança e Yates) e o de Prescott.

Dois "softwares" foram desenvolvidos: o simxover para realizar as simulações e o xover que realiza os cálculos das análises estatísticas. Estes instrumentos computacionais permitem considerações futuras a respeito de outras condições paramétricas. 


\section{TYPE I AND II PROBABILITIES OF CROSS-OVER $2 \times 2$ DESIGNS TESTS FOR BINARY RESPONSES: ESTIMATION BY MONTE CARLO METHOD}

Author: Antonio Luiz Rodrigues Júnior Adviser: Clarice Borges Garcia Demétrio

\section{SUMMARY}

The "Cross-Over" $2 \times 2$ design for binary responses compares two treatments on two different experimental periods. It is applied to every sample unit, and dichotomic categorical data is observed. This kind of design has been widely used in Biology field because its high efficiency compared to conventional models. It uses a smaller sample size for a fixed precision.

This study aims at estimating type I and II errors probabilities from those reported tests (McNemar's, $\chi^{2}$ aproximation for McNemar, NonConditionals - Pearson, Likelihood and Yates, Prescott's - for large and small samples, Hills\&Armitage's and First Period Tests); and developing a computerized tool to perform Monte Carlo simulations and the statistical analyses. It is also worth providing the "Cross-Over" design users with a software that carry out calculations in actual samples.

Simulations by the congruencial mixed method were performed, generating samples from multinomial distributions through the sequencial search algorithm. One thousand samples were generated for each parametric condition 
(treatment and interaction treatment $\times$ period) with no period effect. Type I and II errors probabilities estimates were done through percentages of observed samples showed significant level below $5 \%$.

The results highlight the importance of correct prescription of these tests, because there can be a better method depending upon the interaction treatment $\times$ period effect. It was observed that presence of interaction effect changes type $I$ and $I I$ error probabilities and the sample size may decrease these bias. The best performances were showed by McNemar's, Non-Conditionals' (Pearson, Likelihood and Yates) and Prescott's Tests.

Two software were developed: the simxover to perform simulations, and the xover to carry out calculations. Such computerized tools provide a source for further considerations concerning to another parametric conditions. 


\section{INTRODUÇÃO}

Muitas das descobertas importantes para o Homem, no último século, foram obtidas pela observação do "acaso". Na descoberta da penicilina, por exemplo, houve várias "coincidências" no experimento de Alexander Fleming, que determinaram a inibição do crescimento bacteriano. Fleming nunca entendeu o que ocorrera com suas colônias de bactérias, pois não conseguiu reproduzir tal inibição in vitro. Entretanto, seus relatos forneceram subsídios valiosos a outros pesquisadores, que posteriormente estudaram as condições em que o experimento dele fora realizado, possibilitando a descoberta da penicilina pela observação das tais "coincidências". Exemplos como este servem para motivar a discussão a respeito do "acaso", que provoca o aparecimento da variabilidade experimental e, por conseguinte, do conceito de variável aleatória. Esse conceito é facilmente verificado por aqueles que lidam com ensaios biológicos, pois os resultados experimentais não são determinísticos. Eles variam em torno de uma média geral.

A Estatística é a área do conhecimento científico responsável pela elaboração de métodos sistemáticos de avaliação do "acaso". Cabe a ela desenvolver métodos analíticos de exploração das variáveis aleatórias, participando da co-autoria do trabalho experimental. Apesar dessa postura não ser adotada sistematicamente pela grande maioria dos usuários, os profissionais de Estatística têm 
cumprido seu papel e, idealisticamente, contribuído para a melhoria metodológica dos trabalhos científicos, deixando à disposição delineamentos bem elaborados.

Dentre os muitos delineamentos existentes, o "Cross-Over" é aquele que utiliza a mesma unidade experimental (voluntários, cobaias, parcelas etc) para avaliar resultados de tratamentos diferentes. Essa característica, supostamente, restringe a influência do "acaso", pois diminui o efeito de fatores não-controláveis das unidades experimentais, havendo a diminuição da variabilidade experimental. Então, conseqüentemente, a eficiência do método aumenta, resultando em menor demanda amostral e menor custo. Entretanto, a desvantagem de maior destaque dos delineamentos tipo "Cross-Over" é o possivel aparecimento do efeito "Carry-Over", apesar de não comprometer sua aplicabilidade.

A análise estatística desse tipo de delineamento vem sendo discutida e desenvolvida, verificando-se que, ao longo do tempo, o volume de publicações desse assunto tem aumentado. Controvérsias foram encontradas e corrigidas com o objetivo de oferecer uma metodologia compativel com a boa qualidade experimental.

Os métodos existentes para analisar o delineamento tipo "CrossOver" são específicos para cada situação. Quando se utilizam variáveis aleatórias quantitativas pode-se empregar a análise de variância ou os métodos não-paramétricos. Nos casos de variáveis aleatórias qualitativas, em especial a resposta binária, empregam-se técnicas diferentes que dependem da presença ou não de efeito de "Carry-Over".

O delineamento tipo "Cross-Over" é muito empregado nas áreas de ciência da saúde: Medicina, Odontologia, Farmácia, etc. Tem sido pouco empregado no campo da Agronomia, sendo especialmente indicado para as áreas de experimentação animal. 
O objetivo deste trabalho foi descrever as técnicas estatísticas empregadas para analisar experimentos tipo "Cross-Over" $2 \times 2$, onde respostas binárias sejam de interesse. Dados foram gerados pelo método de Monte Carlo, estudando amostras de tamanhos diferentes e com situações paramétricas variadas, permitindo obter as estimativas de sensibilidade e especificidade das técnicas empregadas. Ainda como parte deste trabalho, foram criados programas ("software"), em linguagem PASCAL, que realizam a simulação dos dados e que as análises estatísticas. 


\section{REVISÃO DE LITERATURA}

O delineamento tipo "Cross-Over" é aquele em que o pesquisador utiliza períodos diferentes, para comparar tratamentos, sendo que as unidades experimentais servem como o próprio controle recebendo todos os tratamentos (KOCH, 1972). Somente o fato das unidades experimentais receberem todos os tratamentos não caracteriza o delineamento (SENN, 1993), pois há situações em que se empregam mais de um tratamento simultaneamente, principalmente em estudos observacionais, fazendo com que todos os tratamentos sejam utilizados, mas sem ter a estrutura do delineamento "Cross-Over".

A origem deste tipo de delineamento é remota, mas há a citação do experimento realizado por Bennett Lawes como sendo um marco do desenvolvimento deste modelo. O experimento originou-se da, assim chamada, controvérsia científica do século XIX, entre Lawes e o Baron Justus von Liebig, na área Agronômica, onde ambos trabalhavam com classificação dos nutrientes vegetais em "orgânicos" ou "inorgânicos". Em seu experimento, Lawes alocou duas parcelas de trigo a uma alternância de tratamentos (sal amoniacal e minerais) em estudo, verificando que havia uma diferença entre os efeitos de acordo com a ordem de aplicação dos tratamentos às parcelas. Evidentemente, o delineamento utilizado não era formalmente um "Cross-Over" como é conceituado atualmente, 
mas este experimento foi o primeiro a questionar algumas hipóteses, que foram incorporadas no modelo recente, como o efeito residual de tratamentos já aplicados, conhecido como "Carry-Over" (*) (JONES \& KENWARD, 1989).

Ao longo do tempo, o delineamento tipo "Cross-Over" foi sendo desenvolvido, em função das necessidades de cada época, por estudiosos como Yates, Simpson, Cochran, Fisher, Patterson, Lucas e outros. Esse tipo de delineamento tem sido extensivamente empregado em experimentação animal, desde meados de 1930 (JONES \& KENWARD, 1989). Entretanto, seu emprego tem sido maior nas áreas de ensaios médicos e farmacológicos.

O delineamento tipo "Cross-Over" integra uma classe especial de modelos, conhecida como "Change-Over". PATTERSON \& LUCAS (1962) apresentaram uma forma de classificação destes delineamentos, denominando-os segundo o número de períodos e de tratamentos, conforme apresentado a seguir:

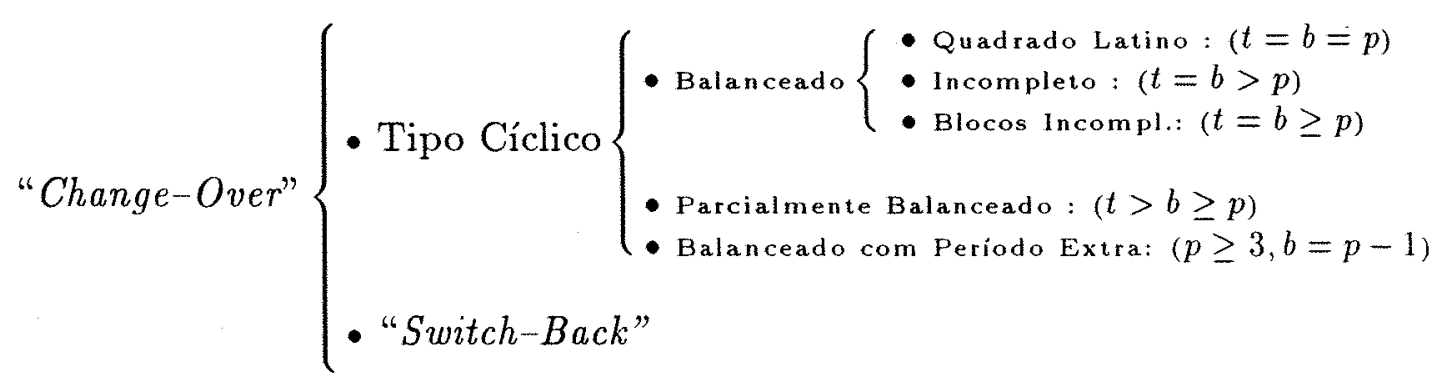

onde :

$$
\begin{aligned}
& t: \text { número de tratamentos } \\
& p: \text { número de períodos } \\
& k: \text { número de repetiçóes dos blocos experimentais } \\
& b: \text { número de blocos experimentais }
\end{aligned}
$$

$(\star)$ "Carry-Over" é definido como a persisténcia do efeito de um tratamento aplicado de um período num outro subseqũente, caracterizando uma "sobreposição" de efeitos de tratamentos. 
O delineamento "Cross-Over" é um caso especial, que pode ser descrito como um "Change-Over" balanceado do tipo cíclico, não tendo necessariamente $k=t=p=b$. O modelo mais simples possível é aquele que compara dois tratamentos em dois períodos diferentes $-2 \times 2$. Os delineamentos de mais alta ordem $(3 \times 3,4 \times 4, \cdots, n \times n)$ se caracterizam por comparar vários tratamentos.

$\mathrm{O}$ efeito do erro aleatório neste delineamento experimental pode ser decomposto em dois tipos: variação intra $\left(\sigma_{\epsilon}^{2}\right)$ e entre unidades experimentais $\left(\sigma_{\varepsilon}^{2}\right)$. A variação intra unidades é determinada pelo efeito das condições experimentais, em diferentes períodos por exemplo, pois os diferentes tratamentos são aplicados em situações distintas, podendo alterar a resposta de uma mesma unidade. Pode-se dizer que as influências do "acaso" provocam mudanças nas unidades ao longo do tempo. A variaçâo entre unidades se verifica pela aleatorização das mesmas nos grupos, no primeiro período, cujas seqüências de aplicação dos tratamentos são estabelecidas, para todo o experimento.

Uma característica interessante do delineamento "Cross-Over" é relativa à sua eficiência estatística, em relação aos testes convencionais, ou seja, a variabilidade do experimento com delineamento "Cross-Over" é menor. Tal fato procede da redução (ou eliminação) da variação intra-unidades $\left(\sigma_{\epsilon}^{2}\right)$, pela utilização da mesma unidade experimental em períodos subseqüentes, fazendo com que ela forneça informações de comparação de todos os tratamentos aplicados.

A importância disto se verifica ao se definir o tamanho da amostra, que será utilizada no experimento, pois, com uma variação menor, necessita-se de um número menor de repetições, para uma determinada eficiência. BROWN (1980) apresentou um estudo a respeito deste fato e mostrou que a razão entre as variâncias, para o delineamento tipo "Cross-Over" (CO) e o Completamente Aleatorizado (CA), é dada por : 


$$
\frac{\operatorname{Var}\left(\hat{\delta}_{C O}\right)}{\operatorname{Var}\left(\hat{\delta}_{C A}\right)}=\frac{m \sigma_{\varepsilon}^{2}}{2 n\left(\sigma_{\xi}^{2}+\sigma_{\xi}^{2}\right)}
$$

onde,

$$
\begin{aligned}
\hat{\delta} & : \text { estimativa da diferença entre tratamentos } \\
\sigma_{\varepsilon}^{2} & : \text { variaçâa entre unidades experimentais } \\
\sigma_{\tilde{\xi}}^{2} & : \text { variaçấo intra unidades experimentais } \\
m & : \text { número de repetiçòes do delineamento Complet. Aleat. (CA) } \\
n & : \text { número de repetiçôes do delineamento "Cross-Over" (CO) }
\end{aligned}
$$

Tomando-se a expressão dada por (1) igual a 1 , tem-se que

$$
n=\frac{m \sigma_{\varepsilon}^{2}}{2\left(\sigma_{\varepsilon}^{2}+\sigma_{\xi}^{2}\right)}
$$

e, portanto, pode-se verificar que quanto maior for a variação intra-unidades experimentais $\left(\sigma_{\xi}^{2}\right)$, menor será o número de repetições a serem utilizadas em um delineamento tipo "Cross-Over", para alcançar a mesma eficiência nos testes estatísticos.

Uma das conseqüências imediatas disto é a redução dos custos da experimentação, pois os valores podem chegar a $45 \%$ das despesas de um experimento do tipo convencional (CA), dependendo da variação intra unidade experimental e dos custos intrínsecos da pesquisa (BROWN, 1980). Assim, quando o experimento envolver voluntários, ou no caso de não se dispor de muitas unidades experimentais, ou de custo elevado das repetições etc, tal aspecto deve ser considerado no planejamento do experimento.

O delineamento "Cross-Over" apresenta algumas desvantagens, comparado aos modelos Completamente Aleatorizados, que não têm grandes implicações práticas. SENN (1993) aponta quatro possíveis ocorrências indesejáveis. A primeira é chamada de "drop-outs", que são aquelas unidades experimentais que "desaparecem" no meio do experimento, de alguma forma - por morte, por 
abandono, por desestímulo, etc. A segunda é a presença da interação tratamentoperíodo, que pode propiciar o aparecimento do "Carry-Over". A terceira é a inconveniência para as unidades experimentais, dado que elas permanecem mais tempo em experimentação, podendo causar o desestímulo, em delineamentos com muitos tratamentos. Por último, as dificuldades analíticas, porque apesar de se dispor de publicações no assunto em número cada vez maior, não existem algoritmos totalmente satisfatórios para solução do problema relacionado ao efeito do "Carry-Over".

O modelo matemático adotado atualmente, que foi formalizado por GRIZZLE, em 1965, incorpora os efeitos de tratamentos, de períodos, de erros intra e entre unidades experimentais e de "Carry-Over", isto é,

$$
y_{i j k}=\mu+\tau_{i}+\pi_{j}+\varphi_{d(i, j)}+\xi_{i k}+\varepsilon_{i j k}
$$

onde,

$$
\begin{aligned}
\mu & : \text { média geral } \\
\tau_{i} & : \text { efeito fixo do i-ésimo tratamento } \\
\pi_{j} & : \text { efeito fixo do j-ésimo período } \\
\varphi_{d(i, j)}: & \text { efeito fixo de "Carry-Over" em função do i-ésimo tratamento e } \\
& \text { do j-ésimo período } \\
\xi_{i k}: & \text { efeito aleatório da k-ésima unidade experimental no i-ésimo trata- } \\
& \text { mento e com } E\left(\xi_{i k}\right)=0 \text { e } E\left(\xi_{i k}^{2}\right)=\sigma_{\xi}^{2} \\
\varepsilon_{i j k}: & \text { efeito aleatório entre unidades experimentais e com } E\left(\varepsilon_{i j k}\right)=0 \text { e } \\
& E\left(\varepsilon_{i j k}^{2}\right)=\sigma_{\varepsilon}^{2}
\end{aligned}
$$

O autor faz, ainda, as seguintes considerações:

- A variância de uma observação é dada por $\sigma_{\xi}^{2}+\sigma_{\varepsilon}^{2}$;

- A covariância entre as observações da mesma unidade experimental é dada por $\sigma_{\xi}^{2}$;

- Os resultados entre unidades experimentais são independentes. 
Os métodos analíticos utilizados para variáveis aleatórias quantitativas contínuas restringem-se à aplicação do teste $t$-Student, sobre os totais e sobre as diferenças na mesma unidade experimental, para o delineamento $2 \times 2$. Quando o delineamento for tipo $n \times n(n \geq 3)$, emprega-se a tabela de análise de variância sugerida por GRIZZLE (1965), que é válida quando o número de repetições dos grupos forem iguais $\left(n_{1}=n_{2}=\ldots=n_{k}\right)$. ARMITAGE \& HILLS (1982) propõem uma modificação para a tabela proposta por GRIZZLE (1965), que vem sendo adotada como a mais adequada, pois incorpora os efeitos de tratamentos, de períodos e de "Carry-Over". Existem também os métodos bayesianos e os não-paramétricos de Mann-Whitney (ou de Wilcoxon), que são utilizados como alternativas para os casos em que a Estatística Clássica não possa ser empregada (KOCH, 1972; GART, 1969).

Entretanto, em várias situações práticas, a variável aleatória observada não é do tipo quantitativa, podendo ser do tipo categorizada (ou qualitativa). Como exemplo tem-se o tipo binomial, que é uma categorização dicotômica de possíveis resultados num experimento do tipo dose-resposta ("sim" ou "nâo", "morte" ou "sobrevivência", "sucesso" ou "falha", etc.). Para as variáveis categorizadas, os métodos de análises diferenciam-se dos descritos para varáveis contínuas, mas pode-se adotar o mesmo modelo matemático dado por GRIZZLE (1965) para a parte sistemática com algumas mod 
Para entender os testes de análise do delineamento "Cross-Over" $2 \times 2$, de respostas binárias, faz-se necessário abordar os conceitos de variável aleatória binária (2.1.), modelo logístico (2.2.), tabelas de contingência (2.3.) e modelo log-linear (2.4.). Após estes conceitos, serão estruturados os modelos matemáticos (2.5.) e as técnicas analíticas (2.6.) do delineamento "Cross-Over" para respostas binárias.

\subsection{Variável Aleatória Binária}

Em situações práticas, há casos em que os resultados de observações não são quantificáveis (mensuráveis), associando-se qualidades (categorias) aos elementos do espaço amostral $(\Omega)$, como por exemplo: os níveis de qualidade de um produto (ruim, regular, bom, ótimo, etc.) ou as cores de um evento (amarelo, azul, preto, etc.).

As variáveis categorizadas podem apresentar dois tipos de resultados: ordinais ou nominais. As variáveis qualitativas ordinais são aquelas em que as categorias apresentam uma relação ordenada; ou seja, estão dispostas de uma forma tal que dão uma noção de uma seqüência (crescente ou decrescente), em relação à característica inicial e à final, como no exemplo de níveis de qualidade de um produto. As variáveis qualitativas nominais não se apresentam numa relação seqüencial, sendo representativa somente de nomes que descrevam os resultados do evento, como no exemplo das cores.

A variável aleatória binária é um caso especial de categorização, onde há somente dois possíveis resultados, dicotômicos, usualmente denominados de "sucesso" ou de "fracasso" e conhecida como "ensaio de Bernoulli". Costuma- 
se associar o valor "0" ao resultado "fracasso" e "1" ao "sucesso" (JONES \& KENWARD, 1989). Também é conhecida como resposta quantal.

Pelo ensaio de Bernoulli, obtém-se o espaço de probabilidade $(\Omega, \Re, P)$, onde $\Re$ é a $\sigma$-álgebra do espaço amostral $\Omega$ e $P$ é a medida de probabilidade associada à variável aleatória Y (MOOD et al., 1974), dada por :

$$
\operatorname{Pr}\left(Y_{i}=1\right)=\pi_{i} \Longrightarrow E\left(Y_{i}\right)=\pi_{i} \quad \operatorname{Var}\left(Y_{i}\right)=\pi_{i}\left(1-\pi_{i}\right)
$$

Seja $\left(Y_{1}, Y_{2}, Y_{3}, \cdots, Y_{n}\right)^{T}$ um vetor de variáveis aleatórias binárias independente e identicamente distribuídas (iid), referentes a n ensaios de Bernoulli. A distribuição de probabilidade conjunta deste vetor é dada por :

$$
\operatorname{Pr}\left(Y_{1}=y_{1}, Y_{2}=y_{2}, \cdots, Y_{n}=y_{n}\right)=\pi^{z}(1-\pi)^{n-z}
$$

onde $z=\sum_{i}^{n} y_{i}$ é o número de "sucessos".

O parâmetro $\pi$ é normalmente desconhecido, podendo ser estimado $(\hat{\pi})$ pela maximização da função de verossimilhança $(L)$ dada por :

$$
L\left(\pi \mid y_{1}, y_{2}, \cdots, y_{n}\right)=\pi^{z}(1-\pi)^{n-z}
$$

e cujo logaritmo $(\ell)$ é

$$
\ell=\ln L\left(\pi \mid y_{1}, y_{2}, \cdots, y_{n}\right)=z \ln \pi+(n-z) \ln (1-\pi)
$$

(MOOD et al., 1974)

O estimador de máxima verossimilhança de $\pi$ pode ser encontrado fazendo-se a derivada de $\ell$ em relação a $\pi$ igual a zero, resultando em $\hat{\pi}=z / n$.

$\mathrm{Na}$ prática, existe interesse em relacionar a ocorrência de uma resposta binária com alguns fatores, como é feito em Modelos Lineares. Podese querer relacionar o comportamento de uma variável aleatória binária com covariáveis ou variáveis explanatórias $\left(\stackrel{x_{1}}{\sim} \underset{\sim}{\sim}, \ldots, \underset{x_{p}}{\sim}\right)$, que podem conter informações 
referentes a blocos e/ou níveis de tratamentos, como em análise de variância (McCULLAGH \& NELDER, 1989).

Se as unidades experimentais forem agrupadas, de acordo com as informações das variáveis explanatórias $\left(\stackrel{x_{1}}{\sim}, \underset{2}{\sim}, \ldots, \stackrel{x_{p}}{\sim}\right)$, obtém-se :

$$
\left[\begin{array}{c}
h\left(\pi_{1}\right) \\
h\left(\pi_{2}\right) \\
h\left(\pi_{3}\right) \\
\vdots \\
h\left(\pi_{n}\right)
\end{array}\right]=\left[\begin{array}{ccccc}
x_{11} & x_{12} & x_{13} & \cdots & x_{1 p} \\
x_{21} & x_{22} & x_{23} & \cdots & x_{2 p} \\
x_{31} & x_{32} & x_{33} & \cdots & x_{3 p} \\
\vdots & \vdots & \vdots & \ddots & \vdots \\
x_{n 1} & x_{n 2} & x_{n 3} & \cdots & x_{n p}
\end{array}\right]\left[\begin{array}{c}
\beta_{1} \\
\beta_{2} \\
\beta_{3} \\
\vdots \\
\beta_{p}
\end{array}\right]
$$

ou seja, pode haver uma relação, através de um modelo matemático, entre a probabilidade de ocorrer "sucesso" $\left(\pi_{i}\right)$ e as variáveis explanatórias $\left(\stackrel{x_{1}}{\sim}, x_{2}, \ldots, x_{p}\right)$, desde que $0<\pi_{i}\left(\underset{\sim}{x_{1}, x_{2}}, \ldots, \underset{x_{p}}{\sim}\right)<1$.

Utilizando os princípios da teoria de Modelos Lineares, pode-se supor que exista uma relação de dependência entre $h\left(\pi_{i}\right)$ e $\left(x_{i 1}, x_{i 2}, \cdots, x_{i p}\right)$, do tipo aditiva, como se segue :

$$
\begin{gathered}
h\left(\pi_{i}\right)=\eta_{i}=\sum_{j}^{p} x_{i j} \beta_{j} \Longrightarrow \pi_{i}=h^{-1}\left(\sum_{j}^{p} x_{i j} \beta_{j}\right) \\
0 \leq h^{-1}\left(\sum_{j}^{p} x_{i j} \beta_{j}\right) \leq 1
\end{gathered}
$$

onde, $h\left(\pi_{i}\right)$ é chamada de função de ligação, na teoria de Modelos Lineares Generalizados e estabelece a relação entre uma função do valor esperado do componente aleatório e o sistemático (McCULLAGH \& NELDER, 1989; AGRESTI, 1990).

Segundo McCULLAGH \& NELDER (1989), é sempre possível encontrar uma função que linearize a relação de uma variável aleatória com suas variáveis explanatórias, desde que pertençam à família exponencial. As três funções de ligação mais utilizadas são: 
i) função logística (logito) : $h_{1}\left(\pi_{i}\right)=\ln \left\{\pi_{i} /\left(1-\pi_{i}\right)\right\}$;

ii) função inversa da Normal acumulada (probito): $h_{2}\left(\pi_{i}\right)=\Phi^{-1}\left(\pi_{i}\right)$;

iii) função complemento $\log -\log : h_{3}\left(\pi_{i}\right)=\log \left\{-\log \left(1-\pi_{i}\right)\right\}$.

Dessas, a transformação logística será de maior interesse, não somente por apresentar propriedades teóricas mais simples, mas também por ser interpretada como o logaritmo da razão das chances, isto é,

$$
\ln \left(\frac{\pi_{i}}{1-\pi_{i}}\right)=\ln \left(\frac{\text { prob.sucesso }}{\text { prob.fracasso }}\right)
$$

Além disso, a transformação logística possui a vantagem de poder ser utilizada para avaliar dados de estudos observacionais retrospectivos ou de prospectivos (McCULLAGH \& NELDER, 1989; AGRESTI, 1990; FREEMAN, 1987).

\subsection{Modelo Logístico}

O modelo matemático que considera a função (2), como transformação de variável aleatória, é denominado de logístico.

Em Modelos Lineares Generalizados ela seria denominada função de ligação, a transformação, permitindo que as variáveis de resposta e explanatória possam assumir valores na escala real, considerando a restrição $0 \leq \pi_{i} \leq 1$ (McCULLAGH \& NELDER, 1989). Como conseqüência disto, verifica-se a existência de uma metodologia voltada para o estudo de associações entre respostas binárias e fatores (variável explanatória), tal qual é feito em Modelos Lineares. 
À semelhança dos outros modelos matemáticos, estas variáveis explanatórias (fatores) podem ser do tipo quantitativo ou qualitativo. Assim, podem ser aplicados os conhecimentos relacionados aos métodos de regressão, de análise de variância, de tabelas de contingência, de modelos log-lineares, etc., para analisar resultados com componentes logísticos.

AGRESTI (1990) afirma que os métodos analíticos empregados em variáveis nominais podem ser aplicados em variáveis ordinais, que, por sua vez, podem ser usados em variáveis continuas. A recíproca não é verdadeira.

No caso da função logística, o modelo é definido pelas seguintes expressões:

$$
\begin{gathered}
h\left(\pi_{i}\right)=\ln (\text { ODDS })=\operatorname{logit}\left(\pi_{i}\right)=\ln \left(\frac{\pi_{i}}{1-\pi_{i}}\right)=\sum_{j=1}^{p} x_{i j} \beta_{j} \Longrightarrow \pi_{i}=h^{-1}\left(\sum_{j=1}^{p} x_{i j} \beta_{j}\right) \\
E\left(Y_{i}\right)=\pi_{i}=\frac{\exp \left\{\sum_{j} x_{i j} \beta_{j}\right\}}{1+\exp \left\{\sum_{j} x_{i j} \beta_{j}\right\}} \\
\operatorname{Var}\left(Y_{i}\right)=\pi_{i}\left(1-\pi_{i}\right)=\frac{\exp \left\{\sum_{j} x_{i j} \beta_{j}\right\}}{\left(1+\exp \left\{\sum_{j} x_{i j} \beta_{j}\right\}\right)^{2}}
\end{gathered}
$$

O modelo logístico é a base estrutural dos métodos analíticos, dos delineamentos "Cross-Over" de resposta binária, estruturados por GART (1969) e ZIMMERMANN \& RAHLFS (1978), cujos modelos matemáticos consideram fatores aditivos, estudando os efeitos de tratamentos, de períodos e da interação tratamento $\times$ periodo.

No caso do efeito da interação tratamento $\times$ periodo, não se pode afirmar que seja somente uma dependência entre efeitos de variáveis, pois a ela podem estar embutidos ("aliased") efeitos de ordem de tratamentos e/ou de "CarryOver". 


\subsection{Tabelas de Contingência}

As tabelas de contingência são construídas para agrupar dados, apresentando as freqüências relativas e/ou absolutas, relacionando variáveis de resposta com explanatórias. São utilizadas habitualmente quando as variáveis são categorizadas, criando o que se chama de "matriz de freqüências" (LINDGREN, 1979), onde cada célula dessa matriz é definida como a combinação de categorias.

Existe uma preocupação pertinente à definição das variáveis como sendo de resposta (dependente) ou explanatória (independente, com totais conhecidos) (AGRESTI, 1990). Pode-se ter variáveis explanatórias relacionadas a uma de resposta, como nos estudos prospectivos e nos retrospectivos. A variável explanatória é conhecida a priori pelo pesquisador, quando se define a natureza do estudo.

Para ilustrar a estrutura da técnica, pode-se considerar o seguinte:

- supor que num estudo duas variáveis são consideradas: $\mathbf{U}$ e V;

- a variável $\mathbf{U}$ tem $r$ categorias: $u_{1}, u_{2}, \cdots, u_{r} ;$ e $\mathbf{V}, c$ categorias: $v_{1}, v_{2}, \cdots, v_{c} ;$

- a tabela de contingência, terá $r$ linhas e $c$ colunas, e conseqüentemente, $r \times c$ células;

- supor que os totais marginais de uma das variáveis (U, por exemplo) são conhecidos, tornando-a uma variável explanatória $\left({ }^{\star}\right)$;

- os totais de respostas $\left(u_{i}, v_{j}\right)$ são dadas por $n_{i j}(i=1,2, \ldots, r) \mathrm{e}$ $(j=1,2, \ldots, c)$, e:

$$
n_{i .}=\sum_{j}^{c} n_{i j} \quad n_{. j}=\sum_{i}^{r} n_{i j} \quad e \quad n \equiv n_{.}=\sum_{i}^{r} \sum_{j}^{c} n_{i j}
$$

(*) Em estudos observacionais, por exemplo o prospectivo, as unidades experimentais são agrupadas de acordo com uma caracteristica comum (variável $U$ ), observando as respostas (variável $V$ ), após determinado periodo de tempo. 
- as estimativas das freqüências relativas são:

$$
\hat{\pi}_{i .}=\sum_{j}^{c} \frac{n_{i j}}{n_{. .}} \quad \hat{\pi}_{. j}=\sum_{i}^{r} \frac{n_{i j}}{n_{. .}}
$$

A Tabela 1 mostra uma representação esquemática e genérica da tabela de contingência de dupla entrada, com a variável $\mathbf{U}$ explanatória, cujos totais marginais $\left(n_{i}\right)$ são fixados por delineamento, onde são apresentadas as freqüências absolutas $\left(n_{i j}\right)$ integrantes da matriz de freqüência.

TABELA 1: Esquema de uma tabela de contingência genérica, de dupla entrada, usada na análise de dados categorizados

\begin{tabular}{|c|c|c|c|c|c|c|}
\hline \multirow{2}{*}{$\begin{array}{c}\text { VARIÁVEL } \\
\mathbf{U}\end{array}$} & \multicolumn{4}{|c|}{ VARIÁVEL } & \multirow{2}{*}{$\begin{array}{l}\mathbf{V} \\
v_{c}\end{array}$} & \multirow{2}{*}{ TOTAL } \\
\hline & $v_{1}$ & $v_{2}$ & $v_{3}$ & $\ldots$ & & \\
\hline$u_{1}$ & $n_{11}$ & $n_{12}$ & $n_{13}$ & $\ldots$ & $n_{1 c}$ & $n_{1}$ \\
\hline$u_{2}$ & $n_{21}$ & $n_{22}$ & $n_{23}$ & $\ldots$ & $n_{2 c}$ & $n_{2}$ \\
\hline$u_{3}$ & $n_{31}$ & $n_{32}$ & $n_{33}$ & $\ldots$ & $n_{3 c}$ & $n_{3}$ \\
\hline$\ldots$ & $\cdots$ & $\ldots$ & $\ldots$ & $\ldots$ & $\ldots$ & $\ldots$ \\
\hline$u_{r}$ & $n_{r 1}$ & $n_{r 2}$ & $n_{r 3}$ & . . & $n_{r c}$ & $n_{r}$ \\
\hline
\end{tabular}

As tabelas de contingência contêm informaçôes importantes que, sob o aspecto probabilístico, podem ser caracterizados na forma de estudos de independência e de homogeneidade de proporções.

\subsubsection{Independência}

O conceito de probabilidade conjunta estabelece que se duas variáveis, $\mathbf{U}$ e $\mathbf{V}$, são independentes, então, $\operatorname{Pr}\left(u_{i} \cap v_{j}\right)=\operatorname{Pr}\left(u_{i}\right) \operatorname{Pr}\left(v_{j}\right)$. Este conceito é utilizado na verificação de associações entre variáveis, quando são do tipo resposta (AGRESTI, 1990). 
Segundo EVERITT (1977), para avaliar se existe, ou não, evidências de tal associação, é necessário considerar o seguinte :

i) $\pi_{i j}$ é a probabilidade de um resultado pertencer à $i$-ésima categoria de U e à j-ésima categoria de V. Então, $E\left(Y_{i j}\right)=n_{i} \pi_{i j}=m_{i j}$, assumindo que $\mathbf{U}$ é fixo;

ii) $\pi_{i .}$ e $\pi_{. j}$ são as probabilidades marginais, de forma que: $E\left(Y_{i j}\right)=n_{i} \cdot \pi_{i} \pi_{. j}$, se independentes;

iii) $\pi_{i j}$ não são parâmetros conhecidos, sendo estimados por: $\hat{\pi}_{i j}=n_{i j} / n_{i}$

iv) a freqüência absoluta esperada para cada célula é dada por: $\hat{m}_{i j}=n_{i}, \hat{\pi}_{i}, \hat{\pi}_{j}$, se independentes.

Quando as variáveis $\mathbf{U}$ e $\mathbf{V}$ são independentes, os valores das freqüências absolutas observadas $n_{i j}$ se assemelham aos esperados $m_{i j}$. Para que esta verificação seja feita quantitativamente, empregam-se métodos estatísticos que, sob a hipótese nula $\left\{H_{0}: \pi_{i j}=\pi_{i .} \pi_{j}\right\}$, buscam evidências para rejeitar a hipótese de independência de U e V. Para este fim, existem várias estatísticas baseadas na distribuição $\chi^{2}$. Os testes mais utilizados são o de $\chi^{2}$ de Pearson $\left(X^{2}\right)$ e o da razão de verossimilhança $\left(G^{2}\right)$ (FREEMAN, 1987), onde as expressões correspondentes são:

$$
\begin{aligned}
& X^{2}=\sum_{i=1}^{r} \sum_{j=1}^{c} \frac{\left(n_{i j}-m_{i j}\right)^{2}}{m_{i j}} \\
& G^{2}=2 \sum_{i=1}^{r} \sum_{j=1}^{c} n_{i j} \ln \left(\frac{n_{i j}}{m_{i j}}\right)
\end{aligned}
$$

onde, $m_{i j}=n \tilde{\pi}_{i .} \hat{\pi}_{j}$ 
Nestes testes, rejeita-se $H_{0}$ quando a estatística for maior que $\chi_{\alpha,(r-1)(c-1)}^{2}$, que é o valor crítico. Nos casos em que $H_{0}$ for rejeitado, pode-se concluir que as variáveis não são independentes, ao nível $\alpha$ de significância, que sugere a existência de algum tipo de associação entre elas.

\subsubsection{Homogeneidade de Proporções}

Existem situações em que se quer saber o quão semelhantes são os níveis da(s) variável(is) explanatória(s), com totais marginais conhecidos, comparando as respectivas distribuições. Em outras palavras, compara-se a igualdade das proporções (probabilidades) das diferentes categorias. A isto se dá o nome de estudo de homogeneidade de proporçôes, sendo baseadas nas distribuiçôes de freqüências relativas $\left(\pi_{i j}\right)$, resultantes da estratificação imposta pela definição da variável explanatória.

Para ilustrar, considere-se a seguinte tabela, que esquematiza os resultados a serem obtidos na prática, com uma variável explanatória $(\mathbf{U})$ :

TABELA 2: Esquema da tabela de contingência $2 \times 2$, utilizada quando as duas variáveis são binarias

\begin{tabular}{c|cc|c}
\hline Variável & \multicolumn{2}{|c|}{ Variável V } & Probab. \\
$\mathbf{U}$ & 0 & 1 & Marginal \\
\hline $\mathbf{0}$ & $\pi_{11}$ & $\pi_{12}$ & $\pi_{1}$ \\
$\mathbf{1}$ & $\pi_{21}$ & $\pi_{22}$ & $\pi_{2}$ \\
\hline
\end{tabular}

A verificação da homogeneidade de proporções busca constatar se as probabilidades dos níveis da variável de resposta $(\mathrm{V}$, por exemplo) são iguais, 
nos subgrupos formados pela variável explanatória (U, como exemplo), estabelecendo as seguintes hipóteses nulas:

$$
\begin{aligned}
& H_{0}: \pi_{11}=\pi_{21} \\
& H_{0}^{\prime}: \pi_{11}-\pi_{21}=0 \\
& H_{0}^{\prime \prime}: \pi_{11} / \pi_{21}=1
\end{aligned}
$$

não importando qual das formas seja utilizada, pois se uma for verdadeira, as outras também o serão (FREEMAN, 1987). Destas, a terceira é conhecida em Epidemiologia como "Risco Relativo", que é usada para avaliar resultados de estudos observacionais ("Cohort", "Caso-Controle" e "Analytical Surveys") (FREEMAN, 1987; AGRESTI, 1990). A afirmativa mais interessante é que a razâo das chances ("odds ratio" $-\psi$ ) pode ser utilizada para estimar o "Risco Relativo" (AGRESTI, 1990), cuja expressão é dada por:

$$
\psi=\frac{\pi_{11}\left(1-\pi_{21}\right)}{\pi_{21}\left(1-\pi_{11}\right)}
$$

Demonstra-se, pelo teorema de Bayes (MOOD et al., 1974), que a razâo das chances pode ser usada tanto para estudos prospectivos quanto para retrospectivos (FREEMAN, 1987), conferindo certa versatilidade ao seu emprego prático. A importância disto manifesta-se naquelas situações onde a aleatorização é impraticável, optando-se, então, pelo estudo observacional retrospectivo ou prospectivo.

A demonstração dessa propriedade utiliza as expressões de probabilidades condicionais, provenientes da probabilidade conjunta das respostas de $\mathbf{U}$ e de V, da Tabela 3. A variável U é explanatória, neste caso, caracterizando um estudo prospectivo (por exemplo), sendo, então, conhecidos os seus valores. 
TABELA 3: Esquema da tabela de contingência $2 \times 2$, considerando as probabilidades condicionais, em um estudo prospectivo (por exemplo) com totais marginais da variável $\mathrm{U}$ conhecidos.

\begin{tabular}{|c|c|c|c|}
\hline $\begin{array}{c}\text { VARIÁVEL } \\
\mathrm{U}\end{array}$ & $\begin{array}{l}\text { VARIÁVEL } \\
0\end{array}$ & $\begin{array}{l}\text { V } \\
1\end{array}$ & $\begin{array}{l}\text { Probab. } \\
\text { Marginal }\end{array}$ \\
\hline 0 & $\operatorname{Pr}(U=0 ; V=0) \quad F$ & $\operatorname{Pr}(U=0 ; V=1)$ & $\operatorname{Pr}(U=0)$ \\
\hline 1 & $\operatorname{Pr}(U=1 ; V=0) \quad F$ & $\operatorname{Pr}(U=1 ; V=1)$ & $\operatorname{Pr}(U=1)$ \\
\hline
\end{tabular}

As probabilidades conjuntas estão condicionadas aos valores dos níveis de U. Então, a hipótese nula $H_{o}^{\prime \prime}$, que é a de interesse neste tipo de estudo, por estimar o "Risco Relativo" ( $R R$ ), fica assim definida:

$$
H_{o}^{\prime \prime}: \frac{\pi_{11}}{\pi_{12}}=\frac{\operatorname{Pr}(U=0) \operatorname{Pr}(V=0 \mid U=0)}{\operatorname{Pr}(U=1) \operatorname{Pr}(V=1 \mid U=1)}=R R
$$

Agora, se as mesmas variáveis, $\mathbf{U}$ e $\mathbf{V}$, fossem estudadas por um método retrospectivo, onde os totais marginais da variável V são conhecidos, terse-ia a Tabela 4.

TABELA 4: Esquema da tabela de contingência $2 \times 2$, considerando as probabilidades condicionais, em um estudo retrospectivo com totais marginais da variável $\mathbf{V}$ conhecidos.

\begin{tabular}{c|cc}
\hline $\begin{array}{c}\text { VARIÁVEL } \\
\mathbf{U}\end{array}$ & 0 & $\mathrm{~V}$ \\
& VARIÁVEL & 1 \\
\hline $\mathbf{0}$ & $\operatorname{Pr}(V=0) \operatorname{Pr}(U=0 \mid V=0)$ & $\operatorname{Pr}(V=1) \operatorname{Pr}(U=0 \mid V=1)$ \\
$\mathbf{1}$ & $\operatorname{Pr}(V=0) \operatorname{Pr}(U=1 \mid V=0)$ & $\operatorname{Pr}(V=1) \operatorname{Pr}(U=1 \mid V=1)$ \\
\hline Tot.Marg. & $\operatorname{Pr}(V=0)$ & $\operatorname{Pr}(V=1)$ \\
\hline
\end{tabular}

A hipótese nula $H_{o}^{\prime \prime}$, que testa o "Risco Relativo", é definida por: 


$$
H_{0}^{\prime \prime}: \frac{\operatorname{Pr}(V=0) \operatorname{Pr}(U=0 \mid V=0)}{\operatorname{Pr}(V=1) \operatorname{Pr}(U=1 \mid V=0)}
$$

Através do teorema de Bayes, podem-se substituir as expressões de probabilidades conjuntas de $\mathbf{U}$ e $\mathbf{V}$, conforme segue:

$$
\begin{aligned}
& \operatorname{Pr}(U=0 \mid V=0)=\frac{\operatorname{Pr}(U=0) \operatorname{Pr}(V=0 \mid U=0)}{\operatorname{Pr}(U=0) \operatorname{Pr}(V=0 \mid U=0)+\operatorname{Pr}(U=1) \operatorname{Pr}(V=1 \mid U=1)} \\
& \operatorname{Pr}(U=1 \mid V=0)=\frac{\operatorname{Pr}(U=1) \operatorname{Pr}(V=1 \mid U=1)}{\operatorname{Pr}(U=1) \operatorname{Pr}(V=1 \mid U=1)+\operatorname{Pr}(U=0) \operatorname{Pr}(V=0 \mid U=0)}
\end{aligned}
$$

Substituindo as expressões dadas por (5) e (6) em (4), obtém-se a mesma de (3). Este resultado revela que a comparação de homogeneidade de proporções pode ser obtida tanto em estudos prospectivos quanto em retrospectivos. Nos casos em que a aleatorização é impraticável, o pesquisador tem a altenativa de escolher, de acordo com sua conveniência, o tipo de estudo observacional que melhor atenda às suas necessidades.

\subsection{Modelos Log-Lineares}

O modelo log-linear permite estudar o problema de independência e o de homogeneidade de proporçôes através de um modelo matemático aditivo, semelhante ao método de análise de variância. Como o próprio nome sugere, pode-se obter um modelo linearizado (aditivo), por meio de uma transformação logarítmica. 
Se as duas variáveis ( $\mathbf{U}$ e $\mathbf{V}$ ) são independentes, então, $\pi_{i j}=\pi_{i .} \pi_{j}$ para todo $(i, j)$ e $m_{i j}=n \pi_{i, \pi_{j}}$. O logaritmico da freqüência esperada $\left(m_{i j}\right)$ é:

$$
\ln \left(m_{i j}\right)=\ln (n)+\ln \left(\pi_{i .}\right)+\ln \left(\pi_{. j}\right)
$$

Assim sendo, o modelo utilizado para a verificação torna-se aditivo, pois a frequiência esperada, para cada célula $(i, j)$, será uma função linear dos efeitos das categorias da i-ésima linha e da j-ésima coluna (AGRESTI, 1990), permitindo a formulação da expressão anterior da seguinte forma:

$$
\ln \left(m_{i j}\right)=\alpha+\lambda_{i}^{U}+\lambda_{j}^{V}
$$

onde,

$$
\begin{aligned}
m_{i j} & : \text { valor esperado para a célula }(i, j) \\
\alpha & : \text { constante } \\
\lambda_{i}^{U} & : \text { efeito do nível } i \text { da variável } U \\
\lambda_{j}^{V} & : \text { efeito do nível } j \text { da variável } V
\end{aligned}
$$

De uma forma genérica, para abordar o problema de independência, através de modelos $\log$-lineares, inclui-se o efeito da interação $\left(\lambda_{i j}^{U V}\right)$ entre as variáveis $\mathbf{U}$ e $\mathbf{V}$, que pode ser entendida como um termo de dependência (AGRESTI, 1984), ficando a expressão (7) da seguinte forma:

$$
\ln \left(m_{i j}\right)=\alpha+\lambda_{i}^{U}+\lambda_{j}^{V}+\lambda_{i j}^{U V}
$$

As estimativas dos parâmetros do modelo acima são:

$$
\begin{aligned}
& \mu_{i j}=\ln \left(m_{i j}\right) \\
& \lambda_{i}^{U}=\mu_{i .}-\mu \\
& \lambda_{j}^{V}=\mu_{. j}-\mu
\end{aligned}
$$




$$
\begin{gathered}
\lambda_{i j}^{U V}=\mu_{i j}-\mu_{i .}-\mu_{. j}+\mu \\
\mu_{i .}=\frac{1}{c} \sum_{j}^{c} \mu_{i j}, \quad \mu_{. j}=\frac{1}{r} \sum_{i}^{r} \mu_{i j}, \quad \mu=\frac{1}{r c} \sum_{j}^{c} \sum_{i}^{r} \mu_{i j}
\end{gathered}
$$

As restrições impostas ao modelo são (AGRESTI, 1990):

$$
\sum_{i}^{r} \lambda_{i}^{U}=0, \quad \sum_{j}^{c} \lambda_{j}^{V}=0, \quad \sum_{i}^{r} \lambda_{i j}^{U V}=0, \quad \sum_{j}^{c} \lambda_{i j}^{U V}=0
$$

A Tabela 5 associa a cada célula da tabela de contingência o correspondente termo genérico (8) no modelo log-linear.

TABELA 5: Representação esquemática da tabela de contingência

\begin{tabular}{|c|c|c|c|}
\hline $\begin{array}{c}\text { VARIÁVEL } \\
\mathbf{U}\end{array}$ & $\begin{array}{l}\text { VARIÁVEI } \\
0\end{array}$ & $\begin{array}{l}\mathrm{V} \\
1\end{array}$ & $\begin{array}{l}\text { Probab. } \\
\text { Marginal }\end{array}$ \\
\hline 0 & $\alpha+\lambda_{1}^{U}+\lambda_{1}^{V}+\lambda_{11}^{U V}$ & $\alpha+\lambda_{1}^{U}+\lambda_{2}^{V}+\lambda_{12}^{U V}$ & $2 \alpha+2 \lambda_{1}^{U}$ \\
\hline 1 & $\alpha+\lambda_{2}^{U}+\lambda_{1}^{V}+\lambda_{21}^{U V}$ & $\alpha+\lambda_{2}^{U}+\lambda_{2}^{V}+\lambda_{22}^{U V}$ & $2 \alpha+2 \lambda_{2}^{U}$ \\
\hline TOTAL & $2 \alpha+2 \lambda_{1}^{V}$ & $2 \alpha+2 \lambda_{2}^{V}$ & \\
\hline
\end{tabular}
$2 \times 2$, onde as expressóes de cada célula foi obtida pelo modelo log-linear

Segundo AGRESTI (1984), pode-se verificar que existe uma relação direta entre os parâmetros do modelo log-linear e a medida razão das chances. Para tanto, é necessário considerar as restrições $\lambda_{11}^{U V}=\lambda_{22}^{U V}=-\lambda_{12}^{U V}=-\lambda_{21}^{U V}$, que resulta numa reparametrização:

$$
\lambda_{i j}^{U V}=\mu_{i j}-\mu_{i .}-\mu_{. j}+\mu=\mu_{i j}-\frac{1}{2} \sum_{i}^{r} \mu_{i j}-\frac{1}{2} \sum_{j}^{c} \mu_{i j}+\frac{1}{4} \sum_{i}^{r} \sum_{j}^{c} \mu_{i j}
$$




$$
\begin{aligned}
\lambda_{11}^{U V} & =\mu_{11}-\frac{1}{2}\left(\mu_{11}+\mu_{12}\right)-\frac{1}{2}\left(\mu_{11}+\mu_{21}\right)+\frac{1}{4}\left(\mu_{11}+\mu_{12}+\mu_{21}+\mu_{22}\right) \\
& =\frac{1}{4}\left(\mu_{11}+\mu_{22}-\mu_{12}-\mu_{21}\right) \\
& =\frac{1}{4}\left(\ln \left(m_{11}\right)+\ln \left(m_{22}\right)-\ln \left(m_{12}\right)-\ln \left(m_{21}\right)\right) \\
& =\frac{1}{4} \ln \left(\frac{m_{11} m_{22}}{m_{12} m_{21}}\right) \\
\lambda_{11}^{U V} & =\frac{1}{4} \ln \left(\psi_{U V}\right)
\end{aligned}
$$

Considerando o problema de independência, através do modelo $\log$-linear, a hipótese nula $\left\{H_{0}: \lambda_{11}^{U V}=0\right\}$ deve ser estabelecida para verificação. A expressão para a variância de $\lambda_{i j}^{U V}$ a ser considerada, é dada por:

$$
\operatorname{var}\left(\lambda_{i j}^{U V}\right)=\operatorname{var}\left[\frac{1}{4} \ln \left(\psi_{U V}\right)\right]=\frac{1}{16} \operatorname{var}\left[\ln \left(\psi_{U V}\right)\right]=\frac{1}{16} \sum_{i}^{r} \sum_{j}^{c} \frac{1}{n_{i j}}
$$

Os resultados obtidos com a transformação logística são assintoticamente normais (FREEMAN, 1987; AGRESTI, 1984). Assim, a hipótese nula $\left\{H_{0}: \psi_{U V}=1\right\}$ pode ser verificada por meio do intervalo de confiança para o $\ln \left(\psi_{U V}\right)$, cuja expressão é dada por:

$$
\frac{1}{4} \ln \left(\psi_{U V}\right) \pm z_{\frac{\alpha}{2}} \frac{1}{4} \sqrt{\sum_{i}^{r} \sum_{j}^{c} \frac{1}{n_{i j}}}
$$

Não se rejeita-se $H_{0}$ quando o valor 0 (zero) estiver contido neste intervalo.

De forma análoga, podem-se obter as expressões log-lineares para $\lambda_{1}^{U}$ e $\lambda_{1}^{V}$, resultando em:

$$
\lambda_{1}^{U}=\frac{1}{4} \ln \left(\frac{m_{11} m_{12}}{m_{21} m_{22}}\right) \quad e \quad \lambda_{1}^{V}=\frac{1}{4} \ln \left(\frac{m_{11} m_{21}}{m_{12} m_{22}}\right)
$$




\subsection{O Delineamento Cross-Over $2 \times 2$}

O delineamento "Cross-Over" $2 \times 2$, quando se utilizam variáveis aleatórias contínuas, pode ser analisado estatisticamente pelos métodos paramétri$\cos ($ teste t-Student e ANOVA) e não-paramétricos (Mann-Whitney ou Wilcoxon). Entretanto, quando a variável aleatória em questão for binária, os métodos empregados na análise estatística envolvem os conceitos de modelo logístico, modelo log-linear e tabela de contingência.

A Tabela 6 mostra um esquema da matriz de freqüências de uma tabela de contingência, referente a um delineamento "Cross-Over" $2 \times 2$, que compara dois tratamentos ( $\mathbf{A}$ e $\mathbf{B}$ ), em dois períodos ( 1 e 2), utilizando dois grupos de unidades experimentais, que recebem os tratamentos nas ordens AB e BA. Cada unidade experimental fornece um par de informações, $\left(Y_{1}, Y_{2}\right)$, que correspondem às respostas binárias do primeiro $\left(Y_{1}\right)$ e do segundo $\left(Y_{2}\right)$ período. Observam-se, também, as probabilidades associadas aos níveis da variável explanatória (grupos experimentais), que formam uma distribuição de probabilidade multinomial com parâmetros $\left(\pi_{i 1}, \pi_{i 2}, \pi_{i 3}, \pi_{i 4}, n_{i}\right)$.

TABELA 6: Representaçấo esquemática da tabela de contingência $2 \times 2$, mostrando a matriz de freqüências $\left(n_{i j}\right)$ e as probabilidades $\left(\pi_{i j}\right)$ do delineamento "Cross-Over".

\begin{tabular}{|c|c|c|c|c|c|c|}
\hline Conteúdo & $\begin{array}{l}\text { Grupo } \\
\text { Exper. }\end{array}$ & $(0,0)$ & $\begin{array}{c}\left(Y_{1}\right. \\
(0,1)\end{array}$ & $\begin{array}{l}\left.Y_{2}\right) \\
(1,0)\end{array}$ & $(1,1)$ & $\begin{array}{c}\text { Total } \\
\text { Marginal }\end{array}$ \\
\hline $\begin{array}{l}\text { Freq. } \\
\text { Abs. }\end{array}$ & $\begin{array}{l}\mathbf{A B} \\
\mathbf{B A}\end{array}$ & $\begin{array}{l}n_{11} \\
n_{21}\end{array}$ & $\begin{array}{l}n_{12} \\
n_{22}\end{array}$ & $\begin{array}{l}n_{13} \\
n_{23}\end{array}$ & $\begin{array}{l}n_{14} \\
n_{24}\end{array}$ & $\begin{array}{l}n_{1} \\
n_{2}\end{array}$ \\
\hline Prob. & $\begin{array}{l}\mathrm{AB} \\
\mathrm{BA}\end{array}$ & $\begin{array}{l}\pi_{11} \\
\pi_{21}\end{array}$ & $\begin{array}{l}\pi_{12} \\
\pi_{22}\end{array}$ & $\begin{array}{l}\pi_{13} \\
\pi_{23}\end{array}$ & $\begin{array}{l}\pi_{14} \\
\pi_{24}\end{array}$ & $\begin{array}{l}\pi_{1} \\
\pi_{2}\end{array}$ \\
\hline
\end{tabular}


Na Tabela 6, o valor $n_{11}$ corresponde ao número de unidades experimentais, do grupo I (AB), que apresentaram o par de respostas $(0,0)$. Da mesma forma, interpretam-se os outros elementos da matriz de freqüência.

GART elaborou seu modelo, baseado no método de "análise de preferência" de $\mathrm{McNemar}^{(a)}$, citado em seu artigo de 1969 , onde os pares $(0,0)$ e $(1,1)$ não contribuem para a avaliação dos efeitos, pois não há variação de respostas com as mudanças de tratamentos e de períodos. Então, utilizando somente os pares $(1,0)$ e $(0,1)$, de cada grupo de unidades experimentais (I e II), GART estruturou a tabela de contingência, conforme apresentado na tabela 7 .

TABELA 7: Tabela de contingência utilizada por GART (1969), que considera somente os pares em que $Y_{1} \neq Y_{2}$

\begin{tabular}{c|cc|c}
\hline \multirow{2}{*}{ GRUPOS } & Pares & $\left(Y_{1}, Y_{2}\right)$ & TOTAL \\
& $(0,1)$ & $(1,0)$ & \\
\hline AB & $\sum_{i \in I} y_{i b}$ & $\sum_{i \in I^{\prime}} y_{i a}$ & $n_{1 .}$ \\
\hline \multirow{2}{*}{ BA } & $\sum_{j \in J} y_{j a}^{\prime}$ & $\sum_{j \in J^{\prime}} y_{j b}^{\prime}$ & $n_{2 .}$ \\
\hline
\end{tabular}

onde:

$$
\begin{aligned}
I & =\left(i=1,2,3, \cdots, n_{1 .} \mid\left[Y_{1}=0 ; Y_{2}=1\right]=y_{i b}\right) \\
I^{\prime} & =\left(i=1,2,3, \cdots, n_{1} . \mid\left[Y_{1}=1 ; Y_{2}=0\right]=y_{i a}\right) \\
J & =\left(j=1,2,3, \cdots, n_{2}||\left[Y_{1}=0 ; Y_{2}=1\right]=y_{j a}^{\prime}\right) \\
J^{\prime} & =\left(j=1,2,3, \cdots, n_{2 .} \mid\left[Y_{1}=1 ; Y_{2}=0\right]=y_{j b}^{\prime}\right)
\end{aligned}
$$

O mesmo autor demonstrou as expressões logísticas associadas ao esquema da tabela 6, chegando à expressão da função de verossimilhança:

(a) McNEMAR, $Q$ Note on Sampling Error of the Difference between Correlated Proportions Percentages. Psychometrika 12:153-7, 1947. 


$$
L(y ; \theta)=\left[\prod_{i=1}^{n_{1}} f\left(y_{i a} ; \theta\right) f\left(y_{i b} ; \theta\right)\right]\left[\prod_{j=1}^{n_{2}} f\left(y_{j a}^{\prime} ; \theta\right) f\left(y_{j b}^{\prime} ; \theta\right)\right]
$$

que, após a substituição de $f(. ; \theta)$ pelas expressões exponenciais correspondentes do modelo $\log 1$ śtico, $L(y ; \theta)$ fica:

$$
L=\frac{\exp \left\{\sum_{i}^{n_{1}} \tau_{i}\left(y_{i a}+y_{i b}\right)+\sum_{j}^{n_{2}} \tau_{j}\left(y_{j a}^{\prime}+y_{j b}^{\prime}\right)+\phi\left(y_{. a}+y_{. a}^{\prime}-y_{. b}-y_{. b}^{\prime}\right)+\varphi\left(y_{. a}+y_{. b}^{\prime}-y_{. b}-y_{. a}^{\prime}\right)\right\}}{\left[\prod_{i}^{n_{1}}\left(1+e^{\tau_{1}} e^{\varphi} e^{\phi}\right)\left(1+e^{\tau_{i}} e^{-\varphi} e^{\phi}\right)\right]\left[\prod_{j}^{n_{2}}\left(1+e^{\tau_{i}} e^{\varphi} e^{-\phi}\right)\left(1+e^{\tau_{1}} e^{-\varphi} e^{\phi}\right)\right]}
$$

onde,

$$
\begin{aligned}
\mu & : \text { média geral } \\
\phi_{A}, \phi_{B} & : \text { efeito de tratamentos, com } \phi_{A}=-\phi_{B}=\phi \\
\tau_{1}, \tau_{2} & : \text { efeito de períodos, com } \tau_{1}=-\tau_{2}=\tau \\
\varphi_{A}, \varphi_{B} & : \text { efeito de "Carry-Over", } \operatorname{com} \varphi_{A}=-\varphi_{B}=\varphi
\end{aligned}
$$

Segundo GART (1969), para $\varphi=0$, o modelo matemático se reduz à expressão logística proposta para o teste de $\mathrm{McNemar}$, citando que as estatísticas conjuntamente suficientes são $\left(y_{. a}+y_{. a}^{\prime}-y_{. b}-y_{. b}^{\prime}\right),\left(y_{. a}+y_{. b}^{\prime}-y_{. b}-y_{. a}^{\prime}\right),\left(y_{i a}+y_{i b}\right) \mathrm{e}$ $\left(y_{j a}^{\prime}+y_{j b}^{\prime}\right)$.

ZIMMERMANN \& RAHLFS (1978) propuseram um modelo para a análise desses dados binários, estabelecendo as expressões matemáticas dos efeitos dos fatores presentes em cada tratamento e periodo, conforme segue :

$$
\begin{aligned}
& \pi_{A 1}=\pi_{13}+\pi_{14}=\mu+\phi_{A}+\tau_{1}=\alpha+\lambda_{1}^{T}+\lambda_{1}^{P} \\
& \pi_{B 1}=\pi_{23}+\pi_{24}=\mu+\phi_{B}+\tau_{1}=\alpha+\lambda_{2}^{T}+\lambda_{1}^{P} \\
& \pi_{A 2}=\pi_{22}+\pi_{24}=\mu+\phi_{A}+\tau_{2}+\varphi_{B}=\alpha+\lambda_{1}^{T}+\lambda_{2}^{P}+\lambda_{2}^{T P} \\
& \pi_{B 2}=\pi_{12}+\pi_{14}=\mu+\phi_{B}+\tau_{2}+\varphi_{A}=\alpha+\lambda_{2}^{T}+\lambda_{2}^{P}+\lambda_{1}^{T P}
\end{aligned}
$$


Os dois modelos log-lineares apresentados são semelhantes ao estabelecido por GRIZZLE (1965), para variáveis aleatórias contínuas, que pode ser representado pelas expressões da Tabela 8, seguindo a notação da Tabela 5.

TABELA 8: Representaçấo esquemática da tabela de contingência $2 \times 2$, onde os elementos foram obtidos pela proposta de ZIMMERMANN \& RAHLFS (1978)

\begin{tabular}{c|cc}
\hline GRUPOS & 0 & 1 \\
\hline AB & $\alpha+\lambda_{1}^{T}+\lambda_{1}^{P}$ & $\alpha+\lambda_{2}^{T}+\lambda_{2}^{P}+\lambda_{1}^{T P}$ \\
BA & $\alpha+\lambda_{2}^{T}+\lambda_{1}^{P}$ & $\alpha+\lambda_{1}^{T}+\lambda_{2}^{P}+\lambda_{2}^{T P}$ \\
\hline
\end{tabular}

Aplicando a transformação logística aos grupos I (AB) e II (BA), utilizando o modelo proposto por ZIMMERMANN \& RAHLFS (1978), obtém-se:

$$
\begin{aligned}
& \operatorname{Pr}\left(Y_{11 k}=1\right)=\frac{\exp \left\{\alpha+\lambda_{1}^{T}+\lambda_{1}^{P}\right\}}{1+\exp \left\{\alpha+\lambda_{1}^{T}+\lambda_{1}^{P}\right\}} \quad ; \quad \operatorname{Pr}\left(Y_{12 k}=1\right)=\frac{\exp \left\{\alpha+\lambda_{2}^{T}+\lambda_{2}^{P}+\lambda_{1}^{T P}\right\}}{1+\exp \left\{\alpha+\lambda_{2}^{T}+\lambda_{2}^{P}+\lambda_{1}^{T P}\right\}} \\
& \operatorname{Pr}\left(Y_{21 k}=1\right)=\frac{\exp \left\{\alpha+\lambda_{2}^{T}+\lambda_{1}^{P}\right\}}{1+\exp \left\{\alpha+\lambda_{2}^{T}+\lambda_{1}^{P}\right\}} \quad ; \quad \operatorname{Pr}\left(Y_{22 k}=1\right)=\frac{\exp \left\{\alpha+\lambda_{1}^{T}+\lambda_{2}^{P}+\lambda_{2}^{T P}\right\}}{1+\exp \left\{\alpha+\lambda_{1}^{T}+\lambda_{2}^{P}+\lambda_{2}^{T P}\right\}}
\end{aligned}
$$

onde $Y_{i j k}$ representa a variável de resposta da $k$-ésima unidade experimental, no $j$-ésimo período, no i-ésimo grupo experimental.

A partir das expressões probabilísticas das respostas $\left(Y_{1}, Y_{2}\right)$, os métodos de análise de dados binários, em delineamento "Cross-Over", serão restritos aos problemas de independência e homogeneidade de proporçôes. Várias técnicas foram desenvolvidas com o propósito de estabelecer o melhor método, devido à possível presença de efeito de "Carry-Over", que se confunde com o efeito da interaçấo tratamentoxperíodo e de ordem de aplicaçâo de tratamentos. 
Segundo JONES \& KENWARD (1989), pode-se supor que uma tabela de contingência $2 \times 4$, de dados de contagem $\left(n_{i j}\right)$, contém observações independentes de uma distribuição de probabilidade multinomial $\left(\pi_{i 1}, \pi_{i 2}, \pi_{i 3}, \pi_{i 4}, n_{i}\right)$, com $i=\{1,2\}$. Eles sugerem três passos a serem seguidos na construção de um modelo, do delineamento "Cross-Over":

a.) Os pares de observaçôes $\left(Y_{1}, Y_{2}\right)$ de uma unidade experimental são independentes. São usados aditivos comuns, em cada grupo $e$ período, para a esperança de $Y_{i j k}$ de ensaios $2 \times 2$, cujas expressões logísticas são:

$$
\begin{aligned}
& \operatorname{logit}\left\{\operatorname{Pr}\left(Y_{11 k}=1\right)\right\}=\ln \left\{\frac{\operatorname{Pr}\left(Y_{11 k}=1\right)}{1-\operatorname{Pr}\left(Y_{11 k}\right)}\right\}=\alpha+\lambda_{1}^{T}+\lambda_{1}^{P} \\
& \operatorname{logit}\left\{\operatorname{Pr}\left(Y_{12 k}=1\right)\right\}=\alpha+\lambda_{2}^{T}+\lambda_{2}^{P}+\lambda_{1}^{T P} \\
& \operatorname{logit}\left\{\operatorname{Pr}\left(Y_{21 k}=1\right)\right\}=\alpha+\lambda_{2}^{T}+\lambda_{1}^{P} \\
& \operatorname{logit}\left\{\operatorname{Pr}\left(Y_{22 k}=1\right)\right\}=\alpha+\lambda_{1}^{T}+\lambda_{2}^{P}+\lambda_{2}^{T P}
\end{aligned}
$$

b.) A probabilidade conjunta de $\left(Y_{i 1 k}, Y_{i 2 k}\right)$, considerando a hipótese de independência como pertinente, é:

$$
\begin{aligned}
& \operatorname{Pr}\left(Y_{11 k}=0, Y_{12 k}=0\right)=\left(1-\operatorname{Pr}\left(Y_{11 k}=1\right)\right)\left(1-\operatorname{Pr}\left(Y_{11 k}=1\right)\right) \\
& \quad=\left(1-\frac{\alpha+\lambda_{2}^{T}+\lambda_{1}^{P}}{1+\alpha+\lambda_{2}^{T}+\lambda_{1}^{P}}\right)\left(1-\frac{\alpha+\lambda_{1}^{T}+\lambda_{2}^{P}+\lambda_{1}^{T P}}{1+\alpha+\lambda_{1}^{T}+\lambda_{2}^{P}+\lambda_{1}^{T P}}\right)=\exp \left\{\xi_{1}\right\} \\
& \operatorname{Pr}\left(Y_{11 k}=0, Y_{12 k}=1\right)=\exp \left\{\xi_{1}+\alpha+\lambda_{1}^{T}+\lambda_{2}^{P}+\lambda_{1}^{T P}\right\} \\
& \operatorname{Pr}\left(Y_{11 k}=1, Y_{12 k}=0\right)=\exp \left\{\xi_{1}+\alpha+\lambda_{2}^{T}+\lambda_{1}^{P}\right\} \\
& \operatorname{Pr}\left(Y_{11 k}=1, Y_{12 k}=1\right)=\exp \left\{\xi_{1}+2 \alpha+\lambda_{1}^{T}+\lambda_{2}^{T}+\lambda_{1}^{P}+\lambda_{2}^{P}+\lambda_{1}^{T P}\right\}
\end{aligned}
$$

c.) Finalmente, devem ser incluidos nas expressões o termo de dependência, dado por:

$$
\text { se } \begin{cases}\rho_{1 k}, & \text { se } Y_{11 k}=Y_{12 k} \\ -\rho_{1 k}, & \text { se } Y_{11 k} \neq Y_{12 k}\end{cases}
$$


As expressões passam a ser:

$$
\begin{aligned}
& \operatorname{Pr}\left(Y_{11 k}=0, Y_{12 k}=0\right)=\exp \left\{\xi_{1}+\rho_{1 k}\right\} \\
& \operatorname{Pr}\left(Y_{11 k}=0, Y_{12 k}=1\right)=\exp \left\{\xi_{1}+\alpha+\lambda_{2}^{T}+\lambda_{2}^{P}+\lambda_{1}^{T P}-\rho_{1 k}\right\} \\
& \operatorname{Pr}\left(Y_{11 k}=1, Y_{12 k}=0\right)=\exp \left\{\xi_{1}+\alpha+\lambda_{1}^{T}+\lambda_{1}^{P}-\rho_{1 k}\right\} \\
& \operatorname{Pr}\left(Y_{11 k}=1, Y_{12 k}=1\right)=\exp \left\{\xi_{1}+\alpha+\lambda_{1}^{T}+\lambda_{2}^{T}+\lambda_{1}^{P}+\lambda_{2}^{P}+\lambda_{1}^{T P}+\rho_{1 k}\right\}
\end{aligned}
$$

O propósito da inclusão do termo de dependência intra unidade experimental é demonstrar que existe um desvio da média geral $(\alpha)$, caracterizando o efeito fixo da k-ésima unidade experimental do i-ésimo grupo, fazendo com que apareça o "parâmetro de perturbação": $\alpha_{i k}=\alpha \pm \rho_{i k}$ ("nuisance").

\subsection{Análise do Delineamento}

A análise do delineamento "Cross-Over" $2 \times 2$ de resposta binária é baseada em métodos comuns de tabela de contingência. Os testes descritos baseiam-se na estrutura elaborada por GART (1969) e são empregados em situações bem específicas, citadas no decorrer deste texto, conforme pode-se ver na exposição que se segue.

\subsubsection{Teste de McNemar}

Os tratamentos são aplicados aos grupos, no primeiro período, obtendo-se a resposta binária $Y_{i 1 k}$. Numa segunda etapa (período), o outro tratamento é aplicado, obtendo a resposta $Y_{i 2 k}$. O par $\left(Y_{i 1 k}, Y_{i 2 k}\right)$ pode assumir quatro combinações de resultados: $(0,0),(1,0),(0,1)$ ou $(1,1)$. 
O teste de McNemar é conhecido como "análise de preferência", por considerar somente aqueles pares de resultados que apresentam "preferência" pelo tratamento $\mathbf{A}$ ou pelo $\mathbf{B}:(1,0)$ e $(0,1)$. Os pares iguais, $(0,0)$ e $(1,1)$, não contribuem com informações comparativas, por não haver mudanças de opinião (DUNSMORE, 1981).

As suposições do teste de $\mathrm{McNemar}^{(b)}$, citadas por CAMPOS (1983), são:

- cada elemento é tomado como seu próprio controle $\left(Y_{i 1 k}, Y_{i 2 k}\right)$;

- cada um dos pares $\left(Y_{i 1 k}, Y_{i 2 k}\right)$ são mutuamente exclusivos;

- a escala de medida é ao menos nominal.

Há a restrição de se empregar o método quando não houver diferenças nos efeitos de interaçâo tratamento $\times$ período $\left(\lambda_{1}^{T P}=\lambda_{2}^{T P}\right)$ e nos de períodos $\left(\lambda_{1}^{P}=\lambda_{2}^{P}\right)$. Se houver diferenças entre algum desses efeitos, o emprego do teste de McNemar será inapropriado para avaliar os resultados (JONES \& KENWARD, 1989). Deve haver, também, a aleatorização das unidades experimentais nos grupos I e II.

O método considera o número total $\left(n_{p}=n_{.2}+n_{.3}\right)$ de unidades experimentais, que possuem alguma "preferência". Obtém-se o número de "respostas favoráveis" $\left(n_{A}=n_{13}+n_{22}\right.$ ou $\left.n_{B}=n_{12}+n_{23}\right)$, da Tabela 6 , que resulta na expressão:

$$
\hat{\pi}=\hat{\pi}_{A}=\frac{n_{A}}{n_{p}} \quad \text { ou } \quad \hat{\pi}=\hat{\pi}_{B}=\frac{n_{B}}{n_{p}}
$$

O teste estatístico consiste em verificar a existência de evidências da igualdade $\pi_{A}=\pi_{B}$, ou se $\pi=1 / 2$, considerando que a distribuição em questão é a

(b) MCNEMAR, $Q$ Note on Sampling Error of the Difference between Cor related Proportions Percentages. Psychometrika 12:153-7, 1947. 
binomial: $N_{A} \sim \mathrm{B}\left(n_{p} ; 1 / 2\right)$. O resultado, $n_{A}$ (por exemplo), é avaliado, na realidade, pelo teste binomial unilateral (CAMPOS, 1983).

A hipótese nula testada é $\left\{H_{0}: \pi_{A}=1 / 2 \mid\left[\lambda_{1}^{T P}=\lambda_{2}^{T P}\right] \cap\left[\lambda_{1}^{P}=\lambda_{2}^{P}\right]\right\}$, que será rejeitada no caso de $n_{A}>n_{\alpha}$ ou se $n_{A}<n_{1-\alpha}$, sendo que $\operatorname{Pr}\left(N_{A}>n_{\alpha}\right)=\alpha$ (JONES \& KENWARD, 1989; SENN, 1993; PRESCOTT, 1981)

Em grandes amostras, pode-se utilizar a distribuição $\chi^{2}$, para se obter uma aproximação probabilística do teste de McNemar. Sabidamente, à medida que o tamanho amostral cresce, aparecem problemas de ordem computacional que inviabilizam cálculos de combinações. Então, por convergência em probabilidade (MOOD et al., 1974), obtém-se:

$$
\frac{\left\{n_{A}-E\left(n_{A}\right)\right\}^{2}}{\operatorname{var}\left(n_{A}\right)} \stackrel{P}{\rightarrow} \chi_{1}^{2}
$$

sendo que, $\widehat{E\left(n_{A}\right)}=n_{p} \hat{\pi}_{A}$ e $\operatorname{var(n_{A})}=n_{p} \hat{\pi}_{A}\left(1-\hat{\pi}_{A}\right)$

\subsubsection{Teste de Mainland-Gart}

Na falta de evidências de que $\lambda_{1}^{P}=\lambda_{2}^{P}$, recomenda-se utilizar o teste de Mainland-Gart, que nâo requer a aleatorização das unidades experimentais nos grupos (I e II).

O teste de Mainland-Gart também é considerado uma "análise de preferência", pois, à semelhança com o de McNemar, somente utiliza as respostas $(1,0)$ e $(0,1)$, para verificar diferenças de tratamentos.

Este teste utiliza a razão das chances ("odds ratio") como estatística, comparando as chances ("odds") dos grupos AB e BA. As chances em cada grupo, revelam a diferença de efeito em favor do par de respostas $(1,0)$ em relação ao par $(0,1): \pi_{i 3} / \pi_{i 2}$. Para o grupo I, cuja ordem de aplicação de tratamentos é $\mathbf{A B}$, as chances indicam uma proporção de efeitos entre o tratamento $\mathbf{A}$ em 
relação ao B: $\pi_{13} / \pi_{12}$. No grupo II, que apresenta a ordem de aplicação de tratamentos BA, a proporção de efeitos se estabelecem do tratamento $\mathbf{B}$ em relação ao A: $\pi_{23} / \pi_{22}$. Entretanto, quando se faz a razão das chances ("odds ratio"), se estabelece uma proporção entre os efeitos do tratamento $\mathbf{A}$, em ambos os grupos, em relação ao $\mathbf{B}$, conforme segue:

$$
\psi=\frac{\frac{\text { efeito de } A(\text { grupo I })}{\text { efeito de } B(\text { grupo I })}}{\frac{\text { efeito de } B(\text { grupo II })}{\text { efeito de } A(\text { grupo II })}}=\frac{\text { ef. de } A(\text { grupo I }) * \text { ef. de } A(\text { grupo II })}{\text { ef. de } B(\text { grupo I }) * \text { ef. de } B(\text { grupo II })}
$$

Assim, a razão das chances verifica a diferença de efeito de tratamentos, considerando ambos os grupos.

A expressão da estatística deste teste $\left(\hat{\psi}_{T}\right)$ é dada por,

$$
\hat{\psi}_{T}=\frac{\hat{\pi}_{12} \hat{\pi}_{23}}{\hat{\pi}_{13} \hat{\pi}_{22}}=\frac{n_{12} n_{23}}{n_{13} n_{22}}
$$

A hipótese nula testada é $\left\{H_{0}: \psi_{T}=1 \mid\left[\lambda_{1}^{T P}=\lambda_{2}^{T P}\right]\right\}$. Utiliza-se o intervalo de confiança de $\ln \left(\psi_{T}\right)$, para realizar o teste, rejeitando a hipótese nula se $0 \in\left[\ln \left(\hat{\psi}_{T}\right) \pm z_{\alpha} \sigma_{(\ln \psi)}\right]$. A definição do intervalo de confiança é apresentada na fórmula (12).

\subsubsection{Teste Exato de FISHER}

O teste exato de Fisher é indicado para os casos em que ocorram número de contagem "muito pequeno" - menor que cinco em alguma célula (EVERITT, 1977), inviabilizando a aproximação da distribuição $\chi^{2}$. Há, também, situações em que o valor observado é zero, resultando na razão das chances ("odds ratio") nula ou indefinida. Nestas circunstâncias, o teste exato de Fisher é 
recomendado, porque se baseia na distribuição de probabilidade hipergeométrica, tendo os totais marginais fixados em cada grupo $\left(n_{i}\right)$ (FREEMAN, 1987), sendo, então, denominado de teste "condicional de homogeneidade".

O teste de Fisher se baseia no cálculo da probabilidade do arranjo dos resultados da tabela obtida. Considera-se o número de "respostas favoráveis" a um dos tratamentos $(m)$, definindo o tamanho da amostra dos dois grupos, que são utilizadas para estabelecer o total de eventos possíveis, em $n_{1}+n_{2}$ observações. Também se considera a independência dos grupo (I e II), que, com os respectivos totais marginais $\left(n_{i}\right)$, permitem obter o número total de arranjos amostrais possiveis, levando em conta os totais de respostas em cada grupo ( $w$ e $k-w)$. O termo geral do teste é dado por:

$$
\operatorname{Pr}(W=w)=\frac{\left(\begin{array}{c}
n_{1} \\
w
\end{array}\right)\left(\begin{array}{c}
n_{2} . \\
m-w
\end{array}\right)}{\left(\begin{array}{c}
n_{1 .}+n_{2} \\
m
\end{array}\right)}
$$

onde,

$$
\begin{aligned}
n_{.1}, n_{2} . & : \text { número de amostras de } \mathbf{A B} \text { e de } \mathbf{B A} \text {, respectivamente, que } \\
& \text { apresentam "preferência"; } \\
m & : \text { número total de "preferências" por um dos tratamentos; } \\
w & : \text { freq. observada de "preferências" em um dos grupos }
\end{aligned}
$$

A hipótese testada é verificar se o arranjo obtido pode ser considerado "evento raro" (probabilidade pequena) e, por isso, considerado significativo, sugerindo que os resultados não ocorreram por acaso. Como a "resposta favorável" adotada é o número de "preferências" por um dos tratamentos, A ou B, o teste verifica a existência de diferença de efeito de tratamentos (JONES \& KENWARD, 1989). 


\subsubsection{Testes Não-Condicionais}

Como foi expresso em (2.6.1.), a distribuição $\chi^{2}$ pode ser usada, para aproximar o resultado do teste de McNemar. Em essência, o que ocorre, verdadeiramente, é o emprego de uma distribuição de probabilidade de variável contínua $\left(\chi^{2}\right)$ como aproximação de uma distribuição de probabilidade discreta (multinomial), das freqüências observadas (EVERITT, 1977).

Para um tamanho de amostra $(n)$, a medida que $n \rightarrow \infty$, a freqüência esperada tende a $m_{i j}=n_{i} \pi_{i j}$. Então, os resultados assintóticos fazem com que a distribuição multinomial se aproxime de uma distribuição normal multivariada, sugerindo o emprego da distribuição $\chi^{2}$ (AGRESTI, 1990).

A semelhança dos testes anteriores, os testes não-condicionais só podem ser usados quando não houver diferença entre períodos $\left(\lambda_{1}^{P}=\lambda_{2}^{P}\right)$, apresentando somente um grau de liberdade, que é utilizado na estimativa de efeito de tratamentos.

Testes não-condicionais, como o de Pearson $\left(X^{2}\right)$ e o de verossimilhança $\left(G^{2}\right)$, podem ser empregados, realizando uma "análise de preferência", cujas expressões são dadas por:

$$
\begin{gathered}
X^{2}=\frac{\left(n_{12} n_{23}-n_{22} n_{13}\right)^{2} m}{n_{.2} n_{.3} m_{1} m_{2}} \\
G^{2}=2 \sum_{i=1}^{2} \sum_{j=2}^{3} n_{i j} \log \left(\frac{n_{i j} m_{.}}{n_{. j} m_{i}}\right)
\end{gathered}
$$

onde $m_{1}=n_{12}+n_{13}, m_{2}=n_{22}+n_{23}$ e $m=m_{1}+m_{2}$

Os resultados obtidos com o teste de Pearson e com o teste de verossimilhança são muito parecidos e não são boas aproximações do teste exato 
de Fisher (teste condicional), quando o tamanho da amostra for pequeno. Então, no caso de pequenas amostras, recomenda-se o teste não-condicional corrigido de Yates, que propicia uma melhor aproximação da distribuição $\chi^{2}$. A expressão do $\chi^{2}$ de Yates é dada por:

$$
X_{Y}^{2}=\frac{\left(\left|n_{12} n_{23}-n_{22} n_{13}\right|-\frac{1}{2} m\right)^{2} m}{n_{.2} n_{.3} m_{1} m_{2}}
$$

(JONES \& KENWARD, 1989)

Os três testes não-condicionais verificam a hipótese nula de igualdade de "preferência" de tratamentos. Usualmente, os testes de $X^{2}, G^{2}$ e $X_{Y}^{2}$ verificam a associação entre variáveis. Entretanto, no caso do delineamento "CrossOver" $2 \times 2$, eles revelam a existência de alguma relação de dependência entre tratamentos e grupos, implicando na diferença de tratamentos.

As estimativas dos testes descritos $\left(X^{2}, G^{2}\right.$ e $\left.X_{Y}^{2}\right)$ devem ser comparadas com a distribuição $\chi_{1}^{2}$. Resultados significativos implicam na rejeição da hipótese de igualdade de tratamentos $\left(\lambda_{1}^{T}=\lambda_{2}^{T}\right)$, na ausência de efeito de períodos $\left(\lambda_{1}^{P}=\lambda_{2}^{P}\right)$ e da interação $\left(\lambda_{1}^{T P}=\lambda_{2}^{T P}\right)$.

A escolha entre testes condicionais (exato de Fisher) e nâa-condicionais $\left(X^{2}, G^{2}\right.$ e $\left.X_{Y}^{2}\right)$ dependem da apreciação da diferença de tratamentos.

\subsubsection{Teste de Prescott}

Os testes descritos anteriormente dependem da ausência de efeito de períodos $\left(\lambda_{1}^{P}=\lambda_{2}^{P}\right)$ ou de ordem de aplicação de tratamentos (AB ou BA). 
Entretanto, na presença desse(s) efeito(s), o teste de Prescott é uma alternativa para o teste da diferença de efeito de tratamentos.

O teste considera todos os pares de resultados possíveis, conforme apresentado na tabela 9 .

TABELA 9: Esquema da tabela utilizada pelo teste PRESCOTT, onde sầ agrupados os pares de respostas binárias iguais

\begin{tabular}{c|ccc|c}
\hline \multirow{2}{*}{ GRUPOS } & -1 & 0 & +1 & Total \\
& $(0,1)$ & iguais $^{\star}$ & $(1,0)$ & Marginal \\
\hline AB & $n_{12}$ & $n_{11}+n_{14}$ & $n_{13}$ & $n_{1 .}$ \\
BA & $n_{22}$ & $n_{21}+n_{24}$ & $n_{23}$ & $n_{2 .}$ \\
\hline Tot. Marg. & $n_{.2}$ & $n_{.1}+n_{.4}$ & $n_{3}$ & $n_{.}$ \\
\hline
\end{tabular}

*iguais: $(1,1)$ e $(0,0)$

Ao contrário do teste de Mainland-Gart, o teste de Prescott requer a aleatorização das unidades experimentais nos grupos I e II (PRESCOTT, 1981; JONES \& KENWARD, 1989). A presença de aleatorização faz com que o resultado esperado do teste de Prescott seja mais sensível do que o de MainlandGart, devido às informações adicionais provenientes das unidades sem "preferência": $(0,0)$ e $(1,1)$.

Semelhante ao teste $t$-Student, utilizado na análise de variáveis contínuas, o teste de Prescott considera as diferenças: $d=y_{1}-y_{2}$, sendo que $d \in$ $\{-1,0,1\}$. A análise dos dados se restringe aos métodos empregados para tabelas de contingência $2 \times 3$, para variáveis ordinais $(-1,0,+1)$, caracterizando um "teste de tendência" (JONES \& KENWARD, 1989), ao invés de se empregar o teste tStudent, que é inapropriado para variáveis com distribuição discreta (PRESCOTT, 1981). 
PRESCOTT (1981) estruturou um método paramétrico, determinando sua distribuição particular - "distribution free" (JONES \& KENWARD, 1989; SENN, 1993), que é obtida pela permutação de $n$.. unidades experimentais em 2 grupos, de tamanho $n_{.1}$ e $n_{.2}$. Então, definindo-se $T=n_{13}-n_{12}$; tem-se:

$$
\begin{gathered}
E(T)=\frac{n_{1 .}\left(n_{.3}-n_{.2}\right)}{n_{. .}} \\
\operatorname{var}(T)=\frac{n_{1 .} n_{2 .}\left\{\left(n_{.3}+n_{.2}\right)-\frac{\left(n_{.3}-n_{.2}\right)^{2}}{n_{.}}\right\}}{\left.n_{. .(n . .}-1\right)} \\
z=\frac{|T-E(T)|-1 / 2}{\sqrt{\operatorname{var}(T)}}
\end{gathered}
$$

A distribuição assintótica de $Z$ é a normal, cujo teste verifica a hipótese nula $\left\{H_{0}: T=0\right\}$, que representa a ausência de efeito de tratamentos. A hipótese nula é rejeitada se $|z|>z_{\alpha / 2}$, onde $z_{\alpha / 2}$ é o valor da distribuição normal padronizada, cuja área unilateral corresponde ao nível $\alpha / 2$ de significância.

Para o caso de pequenas amostras, utiliza-se o cálculo exato de $\alpha$, usando a mesma hipótese nula citada anteriormente. Esta expressão é considerada condicional, porque é definida sobre os totais marginais, fixados a priori e é dada por:

$$
\alpha_{p}=\frac{\sum_{i=t}^{n_{3}} \sum_{j=0}^{i-t}\left(\begin{array}{c}
n_{.3} \\
i
\end{array}\right)\left(\begin{array}{c}
n_{.1}+n_{.4} \\
n_{1 .}-i-j
\end{array}\right)\left(\begin{array}{c}
n_{.2} \\
j
\end{array}\right)}{\left(\begin{array}{c}
n . . \\
n_{1 .}
\end{array}\right)}
$$

O teste de associação $\left(\chi_{2}^{2}\right)$ pode ser utilizado, considerando a tabela de contingência $2 \times 3$. Os dois graus de liberdade podem ser decompostos em: um grau de liberdade corresponde ao teste de Prescott, que compara os 
tratamentos; e o outro, que é um termo de dependência entre as respostas $Y_{1}$ e $Y_{2}$, na mesma unidade experimental. Este último pode ser considerado desprezível, quando houver aleatorização, não contribuindo significativamente para o resultado do teste de associação (JONES \& KENWARD, 1989), sendo, então, testado o efeito da diferença de tratamentos.

\subsubsection{Teste para Interação Tratamento $\times$ Periodo}

Até aqui, os teste descritos dependem da não existência de efeito da interação tratamento $\times$ periodo $\left(\lambda_{1}^{T P}=\lambda_{2}^{T P}\right)$, em qualquer tipo de forma. A sua presença, nos testes descritos, provoca o aparecimento de viés ("bias") na estimação de parâmetros e, por conseguinte, altera o resultado do teste estatístico.

Semelhante ao caso de variáveis aleatórias contínuas, há um teste para a verificar este efeito, proposto por HILLS \& ARMITAGE (1979), mas que não distingue suas origens: "Carry-Over" e/ou interação propriamente dita. Além disto, o teste para interação não é muito sensível (JONES \& KENWARD, $1989)$.

O teste utiliza as informações provenientes dos pares de resultados iguais, sem "preferência": $(1,1)$ e $(0,0)$. Em se tratando de variáveis binárias, pode-se utilizar a razão das chances ("odds ratio") - $\psi_{\varphi}$. Espera-se, em caso de igualdade, que o valor de $\psi_{\varphi}$ seja igual a um. A estatıśtica do teste é definida por:

$$
\psi_{\varphi}=\frac{n_{11} n_{24}}{n_{14} n_{21}}
$$

A hipótese nula a ser testada é $\left\{\psi_{\varphi}=1\right\}$, que representa $\lambda_{1}^{T P}=\lambda_{2}^{T P}$, sendo verificada pela estatística $\ln \left(\psi_{\varphi}\right)$. Rejeita-se a hipótese nula no caso do valor zero estar incluído no intervalo de confiança de $\ln \left(\psi_{\varphi}\right)$, conforme definido na fórmula (12). 


\subsubsection{Teste Usando o Primeiro Período}

Este, na verdade, não é um teste apropriado para delineamentos

"Cross-Over" $2 \times 2$, pois utiliza a informação referente ao primeiro período somente. Pode-se considerá-lo como sendo a última alternativa analítica, quando houver fortes evidências de existência de efeito da interação tratamento $\times$ periodo.

Pelo fato de não usar as informações intra unidades experimentais, o teste não tem a mesma eficiência, não apresentando, então, as vantagens do delineamento "Cross-Over". Ele baseia-se num reagrupamento das informações da tabela de contingência, conforme apresentado na Tabela 10.

TABELA 10: Representaçâo esquemática dos dados utilizados no teste de tratamentos, considerando o primeiro período

\begin{tabular}{c|c}
\hline $\begin{array}{c}\text { Preferência } \\
\text { por } \mathbf{A}\end{array}$ & $\begin{array}{c}\text { Preferência } \\
\text { por } \mathbf{B}\end{array}$ \\
\hline$n_{11}+n_{12}$ & $n_{13}+n_{14}$ \\
$n_{21}+n_{22}$ & $n_{23}+n_{24}$ \\
\hline
\end{tabular}

A estatística do teste é a razão das chances, aplicada sobre os dados da tabela 10, dada por:

$$
\psi_{t p p}=\frac{\left(n_{11}+n_{12}\right)\left(n_{23}+n_{24}\right)}{\left(n_{13}+n_{14}\right)\left(n_{21}+n_{22}\right)}
$$

A hipótese nula deste teste é dada por: $\left\{H_{0}: \psi_{t p p}=1\right\}$. Ela será rejeitada no caso do valor zero não estar incluido no intervalo de confiança de $\ln \left(\psi_{t p p}\right)$, conforme exposto na fórmula (12), determinando a existência de evidências estatísticas em favor da diferença entre tratamentos. 


\section{METODOLOGIA}

Em estudos de desempenho de testes estatísticos, apenas o parâmetro definido pela hipótese nula é conhecido, o que permite obter a probabilidade de erro tipo I (sensibilidade do teste). Esta é a característica de um teste de hipótese composto, que dificulta a obtenção da probabilidade de erro tipo II (especificidade do teste) e, por conseguinte, do poder do teste. O método de Monte Carlo é usado para contornar essa dificuldade. Ele se baseia em simulações de amostras, segundo distribuições previamente estruturadas, que são analisadas pelos testes estatísticos estudados, considerando a hipótese nula estabelecida. Os resultados destas simulações são avaliadas, com o propósito de se verificarem as ocorrências dos dois tipos de erros, após a conclusão adotada, através dos resultados obtidos pelos testes.

Foram criadas diversas situações paramétricas, empregando valores diferentes para o efeito de tratamentos $\left(\lambda_{i}^{T}\right)$ e para o da interação $\left(\lambda_{i j}^{T P}\right)$. O presente trabalho foi baseado no artigo de PRESCOTT (1981), que gerou mil simulações, com amostras de tamanhos iguais (cinqüenta), onde variou somente os parâmetros referentes aos efeitos de tratamentos e da interaçáo tratamentoxperíodo, considerando a ausência de efeito de períodos $\left(\lambda_{j}^{P}=0\right)$. Os valores paramétricos utilizados pelo autor foram: $(0.0,0.5,1.0)$ para o efeito da interação 
e $(0.0,0.25,0.5)$ para tratamentos.

No presente trabalho, os mesmos valores paramétricos foram considerados para o efeito da interaçâo, sendo que para tratamentos foram adotados os valores $(0.0,0.5,1.0)$, com tamanhos amostrais diferentes $(20,40$ e 60$)$, para se observar o desempenho dos testes em situaçôes de pequenas e de grandes amostras.

Para que as simulações fossem realizadas, desenvolveu-se um software, que forneceu as amostras pela geração de "números pseudo-aleatórios" (*), analisando-as e obtendo os respectivos valores de nível de significância. Foram utilizados algoritmos de aproximação de funções de distribuição, tanto para variáveis aleatórias contínuas quanto para discretas, para a obtenção destes valores.

\subsection{O Método de Monte Carlo}

O Método de Monte Carlo é uma técnica que consiste em simular dados através da geração de "números pseudo-aleatórios", por meio de algum algoritmo, que associa uma determinada distribuição de probabilidade. "Na realidade, tais seqüências não são aleatórias no sentido restrito da palavra mas, para fins práticos, comportam-se como se o fossem" (DACHS, 1988). Segundo o mesmo autor: “... esse nome (Monte Carlo) é usado atualmente com freqüência crescente, para nos referirmos ao uso de técnicas computacionais em que se geram amostras de acordo com determinadas distribuiçôes teóricas conhecidas, visando estudar novos comportamentos de diferentes técnicas estatísticas que poderiam ser

( $\star$ ) Definição: uma sequência de números "pseudo-aleatórios" ( $\left.Q_{i}\right)$ è uma sequência determinística de números em $[0,1]$, que tèm as mesmas propriedades estatísticas relevantes em uma seqüencia de números aleatórios (RIPLEY, 1987). De agora em diante, neste texto, números "pseudoaleatórios" serão referidos apenas por números aleatórios. 
empregadas num dado problema."

As situações paramétricas criadas envolveram a geração de amostras com efeitos diferentes para tratamentos $\left(\lambda_{i}^{T}=0.0,0.5\right.$ e 1.0) e para a interação $\left(\lambda_{i j}^{T P}=0.0,0.5\right.$ e 1.0$)$, combinando-os para obter as amostras simuladas. Não se considerou efeito de períodos $\left(\lambda_{j}^{P}=0\right)$, porque a maioria dos testes considerados pressupõe a ausência de tal efeito.

Os parâmetros das distribuições multinomiais $\left(\pi_{i 1}, \pi_{i 2}, \pi_{i 3}\right.$ e $\left.\pi_{i 4}\right)$ foram obtidos pela solução do sistema de equações, cujas expressões são os estimadores dos efeitos, conforme descrito nas fórmulas (9), (10) e (11), do item 2.4. deste texto, que são dadas por:

$$
\left\{\begin{array}{l}
\frac{\pi_{i 1} \pi_{i 4}}{\pi_{i 2} \pi_{i 3}}=\exp \left\{2 \lambda_{i j}^{T}\right\} \\
\frac{\pi_{i 1} \pi_{i 2}}{\pi_{i 3} \pi_{i 4}}=\exp \left\{4 \lambda_{j}^{P}\right\} \\
\frac{\pi_{i 1} \pi_{i 3}}{\pi_{i 2} \pi_{i 4}}=\exp \left\{4 \lambda_{i}^{T}\right\} \\
\pi_{i 1}+\pi_{i 2}+\pi_{i 3}+\pi_{i 4}=1
\end{array}\right.
$$

A solução encontrada para este sistema de equações é:

$$
\begin{aligned}
\pi_{i 4} & =\frac{1}{\exp \left\{2 \lambda_{i}^{T}-2 \lambda_{j}^{P}\right\}+\exp \left\{2 \lambda_{i}^{T}-\lambda_{i j}^{T P}\right\}+\exp \left\{2 \lambda_{j}^{P}-2 \lambda_{i j}^{T P}\right\}+1} \\
\pi_{i 3} & =\exp \left\{2 \lambda_{j}^{P}-\lambda_{i j}^{T P}\right\} \pi_{i 4} \\
\pi_{i 2} & =\exp \left\{2 \lambda_{i}^{T}-\lambda_{i j}^{T P}\right\} \pi_{i 4} \\
\pi_{i 1} & =\exp \left\{2 \lambda_{i j}^{T P}\right\} \frac{\pi_{i 2} \pi_{i 3}}{\pi_{i 4}}
\end{aligned}
$$

Substituindo-se os parâmetros $\lambda_{i}^{T}$ e $\lambda^{T P}$ por $\{0.0 ; 0.5 ; 1.0\}$ e $\lambda_{j}^{P}$ por zero, obtém-se os valores que definem as distribuições multinomiais, que quando combinados fornecem nove tipos de amostras simuladas, conforme mostra a Tabela 11. 
TABELA 11: Parâmetros ( $\left.\pi_{i j}\right)$ utilizados no Método de Monte Carlo, para gerar as simulaçóes do delineamento "Cross-Over"

\begin{tabular}{c|c|cccc}
\hline$\lambda_{i j}^{T P}$ & $\lambda_{i}^{T}$ & $\pi_{11}$ & $\pi_{12}$ & $\pi_{21}$ & $\pi_{22}$ \\
\hline \multirow{5}{*}{0.0} & 0.0 & 0.250 & 0.250 & 0.250 & 0.250 \\
& 0.5 & 0.443 & 0.443 & 0.060 & 0.060 \\
& 1.0 & 0.366 & 0.366 & 0.134 & 0.134 \\
\hline \multirow{5}{*}{0.5} & 0.0 & 0.312 & 0.189 & 0.189 & 0.311 \\
& 0.5 & 0.550 & 0.333 & 0.045 & 0.074 \\
& 1.0 & 0.458 & 0.276 & 0.102 & 0.167 \\
\hline \multirow{5}{*}{1.0} & 0.0 & 0.366 & 0.134 & 0.134 & 0.366 \\
& 0.5 & 0.643 & 0.236 & 0.032 & 0.087 \\
& 1.0 & 0.532 & 0.197 & 0.072 & 0.197 \\
\hline
\end{tabular}

${ }^{*} \lambda_{j}^{P}=0-$ sem efeito de periodos

Tomando esses valores como parâmetros das distribuições multinomiais, de um dos grupos experimentais, consideraram-se amostras de tamanho diferentes $\left(n_{i}=20,40\right.$ e 60$)$, que determinaram as freqüências absolutas impostas às simulações, que constam da Tabela 17 no APENDICE A.

Após a inserção dos parâmetros da simulação, as amostras foram obtidas em duas etapas: primeiro, a geração de uma seqüência de números aleatórios com distribuição uniforme entre $[0,1]$ e, segundo, a transformação na distribuição multinomial, através do algoritmo de busca sequencial (ATKINSON, 1979).

Nesta seqüência de eventos, números aleatórios com distribuição uniforme no intervalo $[0 ; 1]$ foram gerados pelo método congruencial misto (**) (DACHS, 1988; HILLIE \& LIEBERMAN, 1988; RIPLEY, 1987). Este método

(*k) O primeiro método conhecido foi o do "meio do quadrado", proposto por John von Neumann (1949). O método tem a desvantagem de convergir rapidamente para zero ou para ciclos curtos, como citado por DACHS (1988). Atualmente, com a informática, pode-se utilizar outro método, chamado de "shift-register", que manipula diretamente os "bits" de um "byte" da memória. 
consiste em aplicar uma função linear a um número "semente" - $y^{(0)}$ - e posterior divisão por $m$ (inteiro). O restante dessa divisão, que pertence a $[0,1$, é considerado como o valor gerado entre $[0, m-1]$. A expressão do método congruencial misto é:

$$
y^{(k+1)}=a y^{(k)}+b \quad(\bmod \quad m)
$$

onde $y^{(k+1)}=\{0,1,2, \cdot, m-1\}$. No caso de simulações em ambiente computacional, recomenda-se $m=2^{b}$, onde $b$ é o número de "bits" com que o "chip" do computador opera. Exemplificando, tem-se $m=2^{16}=65536$, para o PC IBM-AT (HILLIE \& LIEBERMAN, 1988). A seqüência é definida pelo número "semente" - $y^{(0)}$.

A transformação desses números com distribuição uniforme em multinomial não é imediata como nas distribuições contínuas, que usam a transformação de Box-Müller (RIPLEY, 1987). Existem vários algoritmos que efetuam esta transformação, dentre eles o método de "busca seqüencial" ("sequencial search algorithm"), que é o mais simples (ATKINSON, 1979). O algoritmo consiste em subdividir o intervalo $[0,1]$, em segmentos correspondentes às proporções das respostas $(0,0),(1,0),(0,1)$ e $(1,1)$ (ATKINSON, 1979; DACHS, 1988). Então, a distribuição multinomial é definida pela contagem dos números aleatórios, que pertençam aos subintervalos definidos em $[0 ; m-1]$.

Foram geradas mil amostras para cada situação paramétrica, analisadas estatisticamente pelos testes descritos no item 2.6., através de um software (simxover). Este programa calculou as probabilidades de erro tipo I (nível de significância) dos resultados dos testes estatísticos, cujos algoritmos são expostos no item 3.2.

Os testes usados na análise de delineamento "Cross-Over" $2 \times 2$, de respostas binárias, são específicos para situações em que haja, ou não, efeito da interação e/ou efeito de período. A maioria dos testes não devem ser aplicados 
àquelas situações em que haja evidências de efeito da interaçâo. Alguns autores não consideram o efeito de períodos, em contraposição a outros que requerem a sua ausência. Há, também, o problema do tamanho da amostra e de aleatorização. Então, o emprego de um determinado teste, para solucionar resultados da prática, deve satisfazer aos requisitos, que estão apresentados na Tabela 12.

TABELA 12: Relaçâo dos testes estatísticos utilizados na análise de delineamentos "Cross-Over" $2 \times 2$, onde constam a hipótese nula, o teste e as restriçôes

\begin{tabular}{|c|c|c|c|}
\hline Métodos* & $H_{0}$ & Rejeitar $H_{0} \mathrm{se}$ & Restrição** \\
\hline (1) & $\psi_{\varphi}=1$ & $\left|\ln \left(\psi_{\varphi}\right)\right|<z_{\alpha / 2}$ & (e) \\
\hline$(2)$ & $\psi_{t p p}=1$ & $\left|\ln \left(\psi_{t p p}\right)\right|<z_{\alpha / 2}$ & (e) \\
\hline (3) & $\pi_{A}=1 / 2$ & $n_{A}<n_{\alpha} \quad$ ou $\quad n_{A}>n_{1-\alpha}$ & $(\mathrm{abc})$ \\
\hline (4) & $\lambda_{1}^{T}=\lambda_{2}^{T}$ & $\chi_{1}^{2}>\chi_{1, \alpha}^{2}$ & $(\mathrm{abc})$ \\
\hline (5) & $\psi_{T}=1$ & $\left|\ln \left(\psi_{T}\right)\right|<z_{\alpha / 2}$ & (c) \\
\hline (6) & $\lambda_{1}^{T}=\lambda_{2}^{T}$ & $X^{2}>\chi_{1, \alpha}^{2}$ & (bc) \\
\hline (7) & $\lambda_{1}^{T}=\lambda_{2}^{T}$ & $G^{2}>\chi_{1, \alpha}^{2}$ & (bc) \\
\hline (8) & $\lambda_{1}^{T}=\lambda_{2}^{T}$ & $X_{Y}^{2}>\chi_{1, \alpha}^{2}$ & (bcd) \\
\hline (9) & $\lambda_{1}^{T}=\lambda_{2}^{T}$ & $\operatorname{Pr}(W=w)<\alpha$ & $(\mathrm{bd})$ \\
\hline (10) & $T=0$ & $\left|z_{T}\right|<z_{\alpha / 2}$ & (a) \\
\hline (11) & $\lambda_{1}^{T}=\lambda_{2}^{T}$ & $\alpha_{p}<\alpha / 2$ & (ad) \\
\hline
\end{tabular}

(*) (1) - teste da interação; (2) - teste usando oprimeiro periodo; (3) - teste de McNemar; (4)-aproximação de $\chi^{2}$ de McNemar; (5) - teste de MainlandGart; (6) - teste $\mathrm{X}^{2}$ de Pearson; (7) - teste $\mathrm{G}^{2}$ de verossimilhança, (8) teste com correção de Yates; (9) - teste exato de Fischer; (10) - teste de Prescott; (11) - teste de Prescott para pequenas amostras

(**) (a) -aleatorização, (b) - sem efeito de periodo, (c) - sem efeito da in teração, (d) - pequenas amostras, (e) - nada relatado 
Apesar do teste de períodos não ter sido abordado diretamente, recomenda-se o uso da fórmula (10).

\subsection{Programação do Computador}

Como parte dos objetivos desta dissertação, criou-se um "software" para atender as demandas computacionais daqueles que utilizam o delineamento "Cross-Over", na prática de pesquisa, que possibilite a execução dos cálculos dos testes descritos. Denominou-se de xover (leia-se cross-over) ao programa que analisa dados provenientes deste tipo de delineamento. Entretanto, no caso das simulações, foi necessário criar outro programa, que gerasse amostras simuladas e que as analisasse com o mesmo algoritmo estabelecido para o xover. Ao programa simulador deu-se o nome de simxover.

\subsubsection{Software: XOVER}

Criou-se um algorítmo computacional para que os cálculos estatísticos fossem realizados, resultando em um software de finalidade específica, que é oferecer aos pesquisadores usuário deste tipo de delineamento um instrumento auxiliar. $\mathrm{O}$ usuário insere dados e a máquina os processa, produzindo as análises estatísticas de experimentos.

Os cálculos das probabilidades de "erro tipo $T$ " de cada teste foram realizados por algoritmos computacionais, específicos para o cálculo de aprox- 
imações de integrais de funções de distribuições contínuas (normal e $\chi^{2}$ ). Utilizouse o algorítmo de MORAN (1980) ${ }^{(c)}$, citado por DACHS (1988), que possibilita uma "boa aproximação", no caso de distribuição normal. "Segundo o autor podese obter, para $|z|<z$, até nove digitos corretos com esta aproximaçäo,...". Ela é obtida pela soma parcial da série :

$$
\frac{1}{\sqrt{2 \pi}} \int_{-\infty}^{2} \exp \left\{-\frac{z^{2}}{2}\right\} d z \approx 0,5+\sum_{k=0}^{12} \frac{\sin \left\{\frac{1}{3 z(k+1)}\right\} \exp \left\{\frac{1}{9(k+1)^{2}}\right\}}{2 \pi(k+1)}
$$

O cálculo de área da distribuição $\chi_{(k)}^{2}$ foi feito pela aproximação dada pelo método de LAU ${ }^{(d)}$, citado por DACHS (1988), que é indicado para funções com menos de 10 graus de liberdade.

As distribuições de variáveis aleatórias discretas, como a hipergeométrica e a binomial, nos testes condicionais de de $\mathrm{McNemar}$, respectivamente, utilizaram a aproximação de Stirling (LINDGREN, 1979), quando se deparavam com "tamanhos de amostras grandes", pela expressão:

$$
n ! \approx \sqrt{2 \pi} n^{n+1 / 2} \exp \{-n\}
$$

Tais cálculos eram processados somente para $n>60$, no caso da binomial, e $n<100$ no caso de testes condicionais, devido às limitações computacionais. Para o teste binomial, com tamanho amostral $n>60$, empregou-se a aproximação normal, dado que $\pi=1 / 2$ no teste de McNemar.

\footnotetext{
(c) MORAN, P.A.P. Calculation of the Normal Distribution Function. Biometrika 67: $675-6,1980$.

(d) LAU, C.L. Algorithm 147. A Simple Series for the Incomplete Gamma Integral. Appl. Stat. (JRSS-C), 29:113-4, 1980 .
} 
O manuseio do programa é simples; ele não requer conhecimento prévio de informática, nem treinamentos especializados. Tudo o que se necessita é indicado na tela de entrada de informações.

O software consiste de uma tela de entrada de dados, que requisita a digitação dos dados em campos indicados. $\mathrm{O}$ usuário deve mover-se livremente pelos campos, através das teclas de movimentação $(-\uparrow \uparrow)$ e ENTER. Após completá-los, pode-se, teclando F6, executar os testes ou abortar o procedimento, através da tecla ESC. As saídas de resultados podem ser enviadas diretamente para a impressora ou para um arquivo denominado xover.log, que é gerado no padrão ASCII (texto não-documento). A seleção do destino dos resultados é feita teclando ESPACSO na tela de entrada.

A linguagem de programação utilizada no desenvolvimento do software foi o Turbo PASCAL (versão 5.0), considerando-se as técnicas de programação recomendadas pela Borland International (1988) e pela literatura disponível (NORTON, 1985, BRIEN, 1989; GRILLO, 1989).

Todos os passos de programação estão apresentados no APÊNDICE B, para que possa ser transcrito e compilado por aquele usuário de informática e de delineamento "Cross-Over" $2 \times 2$ de respostas binárias.

\subsubsection{Software: SIMXOVER}

Um outro programa (simxover.exe, APENDICE C) foi desenvolvido, para que as simulações, as análises estatísticas e os cálculos das probabilidade de erro tipo $I$ fossem viabilizados. Ele também foi criado em linguagem Turbo PASCAL e é de uso específico de pesquisadores da área de Estatística, 
por realizar simulações do delineamento "Cross-Over" $2 \times 2$ de respostas binárias.

O programa consiste, basicamente, das informações referentes às simulações por digitação. Aparece no monitor do usuário uma tela de entrada, onde os campos devem ser digitados com os parâmetros das simulações. As informações requisitadas são:

- parâmetros das distribuiçóes multinomiais: correspondente aos valores inteiros $\left(n_{i j}\right)$;

- $a, b$, semente (1) e semente (2): que são referentes à geração de números aleatórios pelo método congruencial misto, sendo que cada semente é utilizada por distribuiçôes diferentes;

- acréscimo de a e b: que modificam o modelo linear congruencial à medida que novas simulações são realizadas, com o intuito de evitar ciclos nas seqüências aleatórias;

- arquivo: onde os resultados dos níveis de significância são armazenados, com padrão ASCII (texto nâo-documento).

O programa sugere os valores de $a, b$, semente (1), semente (2), acréscimo de a, acréscimo de b e o número de simulaçôes. No entanto, todos esses campos podem ser alterados pelo usuário, através das teclas de movimentação $(-\uparrow \downarrow \rightarrow)$ e ENTER. Após completar os campos, de acordo com as características da simulação, pode-se iniciar a etapa de simulações com F6 ou abortar o procedimento com a tecla ESC.

Ao final das simulações, o programa retorna à tela de entrada no monitor, tendo armazenado os valores dos níveis de significância dos testes no arquivo determinado. 


\subsection{Os Erros Tipo I e II}

Nas simulações realizadas, a probabilidade erro tipo I (sensi-

bilidade) foi estimada pelo percentual (\%) de resultados menores que 0.05 , nas situações em que o valor paramétrico era zero. Por outro lado, a probabilidade de erro tipo II (especificidade) foi estimada pelo complementar do percentual (\%) de resultados menores que 0.05 , para os casos em que o valor paramétrico não era zero $(0.5$ e 1.0$)$.

As estimativas de sensibilidade e de especificidade foram obtidas após a geração e análise das mil amostras, dentro de cada situação paramétrica criada. Todos os resultados dos níveis de significância foram arquivados separadamente, de forma que fossem avaliados descritivamente. 


\section{RESULTADOS \& DISCUSSÃO}

Através do software (simxover) realizaram-se as análises das mil simulações, em todas as situações paramétricas consideradas. Foram 27.000 amostras geradas ao todo, em que o programa calculou os níveis de significância dos onze testes utilizados. Este fato valida o algorítmo computacional criado, que foi adotado tanto para o programa simxover, quanto para o xover. Então, pode-se recomendar o uso desses programas, que devem ser empregados de acordo com as finalidades específicas, tendo passado por um período de supervisão. O desempenho observado foi satisfatório.

No que se refere aos resultados das simulações, a Tabela 12 mostra os percentuais de amostras que apresentaram resultados $(\alpha)$ menores que 0.05 . Através deles, obtiveram-se as estimativas de sensibilidade (erro tipo I) e de especificidade (erro tipo II) dos onze testes. 
TABELA 13: Valores ghsolutos de amostras simuladas com resultados menores que 0.05 .

\begin{tabular}{|c|c|c|c|c|c|c|c|c|c|c|c|c|c|}
\hline$\lambda^{T P}$ & $\lambda^{T}$ & $n_{i}$ & (1) & (2) & (3) & (4) & $\underset{(5)}{\mathrm{TI}}$ & $\begin{array}{l}\text { STE } \\
(6)\end{array}$ & $\begin{array}{l}S^{*} \\
(7)\end{array}$ & (8) & (9) & $(10)$ & (11) \\
\hline \multirow{9}{*}{0,0} & \multirow{3}{*}{0,0} & 20 & 90 & 106 & 122 & 62 & 96 & 104 & 74 & 20 & 39 & 71 & 231 \\
\hline & & 40 & 97 & 86 & 99 & 53 & 89 & 65 & 58 & 24 & 63. & 71 & 245 \\
\hline & & 60 & 60 & 57 & 88 & 41 & 93 & 49 & 44 & 19 & 106 & 64 & 242 \\
\hline & \multirow{3}{*}{0,5} & 20 & 457 & 806 & 479 & 437 & 458 & 534 & 463 & 279 & 39 & 471 & 509 \\
\hline & & 40 & 936 & 999 & 927 & 905 & 942 & 913 & 908 & 842 & 52 & 925 & 753 \\
\hline & & 60 & 967 & 1000 & 978 & 968 & 983 & 968 & 964 & 919 & 71 & 978 & 825 \\
\hline & \multirow{3}{*}{1,0} & 20 & 401 & 789 & 989 & 988 & 412 & 992 & 987 & 950 & 3 & 988 & 847 \\
\hline & & 40 & 762 & 969 & 1000 & 1000 & 756 & 1000 & 1000 & 1000 & 18 & 1000 & 953 \\
\hline & & 60 & 967 & 999 & 1000 & 1000 & 973 & 1000 & 1000 & 1000 & 41 & 1000 & 985 \\
\hline \multirow{9}{*}{0,5} & \multirow{3}{*}{0,0} & 20 & 81 & 106 & 126 & 56 & 74 & 131 & 82 & 19 & 35 & 66 & 232 \\
\hline & & 40 & 90 & 86 & 104 & 51 & 90 & 68 & 57 & 22 & 61 & 69 & 241 \\
\hline & & 60 & 76 & 57 & 87 & 37 & 76 & 46 & 39 & 19 & 97 & 56 & 232 \\
\hline & \multirow{3}{*}{0,5} & 20 & 721 & 946 & 572 & 530 & 407 & 650 & 572 & 334 & 21 & 562 & 535 \\
\hline & & 40 & 951 & 996 & 796 & 751 & 804 & 792 & 756 & 625 & 50 & 787 & 641 \\
\hline & & 60 & 990 & 1000 & 931 & 912 & 953 & 923 & 910 & 848 & 58 & 930 & 728 \\
\hline & \multirow{3}{*}{1,0} & 20 & 405 & 789 & 928 & 914 & 377 & 957 & 919 & 751 & 6 & 925 & 727 \\
\hline & & 40 & 909 & 991 & 998 & 997 & 750 & 999 & 996 & 979 & 23 & 998 & 868 \\
\hline & & 60 & 976 & 1000 & 1000 & 1000 & 913 & 1000 & 1000 & 1000 & 29 & 1000 & 950 \\
\hline \multirow{9}{*}{1,0} & \multirow{3}{*}{0,0} & 20 & 97 & 106 & 142 & 59 & 52 & 217 & 103 & 24 & 28 & 70 & 230 \\
\hline & & 40 & 95 & 86 & 125 & 58 & 96 & 109 & 74 & 11 & 40 & 69 & 231 \\
\hline & & 60 & 75 & 57 & 94 & 32 & 73 & 49 & 36 & 11 & 41 & 51 & 199 \\
\hline & \multirow{3}{*}{0,5} & 20 & 811 & 946 & 482 & 471 & 120 & 700 & 559 & 219 & 6 & 483 & 494 \\
\hline & & 40 & 974 & 996 & 638 & 607 & 599 & 665 & 617 & 418 & 36 & 634 & 561 \\
\hline & & 60 & 1000 & 1000 & 861 & 823 & 857 & 851 & 822 & 698 & 40 & 857 & 691 \\
\hline & \multirow{3}{*}{1,0} & 20 & 789 & 928 & 491 & 471 & 126 & 725 & 568 & 203 & 5 & 490 & 493 \\
\hline & & 40 & 968 & 998 & 833 & 810 & 642 & 852 & 817 & 636 & 30 & 825 & 675 \\
\hline & & 60 & 998 & 1000 & 955 & 937 & 892 & 957 & 944 & 861 & 47 & 950 & 762 \\
\hline
\end{tabular}

* (1) - teste da interação; (2) - teste usando oprimeiro período; (3) - teste de McNemar; (4)aproximação de $\chi^{2}$ de MCNemar; (5) - teste de Mainland-Gart; (6) - teste $\mathrm{X}^{2}$ de Pearson; (7) - teste $G^{2}$ de verossimilhança; (8) - teste com correção de Yates; (9) - teste exato de Fischer; (10) - teste de Prescott; (11) - teste de Prescott para pequenas amostras

A Tabela 13 originou as estimativas de sensibilidade e de especificidade, que são apresentadas na seqüência deste texto.

As estimativas de sensibilidade do teste da interação são dadas pelos valores percentuais das amostras geradas com parâmetro $\lambda_{i j}^{T P}=0$, mesmo que $\lambda_{i}^{T}$ varie, conforme mostra a tabela 14 . A mesma tabela apresenta as estimativas 
função do tamanho da amostra $\left(n_{i}\right)$.

TABELA 14: Estimativas de sensibilidade dos testes estudados, em função dos efeitos de tratamentos $\left(\lambda_{i}^{T}\right)$ e do tamanho da amostra $\left(n_{i}\right)$

\begin{tabular}{|c|c|c|c|c|}
\hline$\lambda_{i}^{T}$ & $n_{i}$ & $\begin{array}{c}\text { erro tipo } I \\
\lambda^{T P}=0\end{array}$ & $\begin{array}{r}\text { erro } \\
\lambda_{i j}^{T P}=0.5\end{array}$ & $\begin{array}{l}\text { tipo } I I \\
\lambda_{i j}^{T P}=1.0\end{array}$ \\
\hline 0.0 & $\begin{array}{l}20 \\
40 \\
60\end{array}$ & $\begin{array}{l}9.0 \\
9.7 \\
6.0\end{array}$ & $\begin{array}{l}91.9 \\
91.0 \\
92.4\end{array}$ & $\begin{array}{l}90.3 \\
90.5 \\
92.5\end{array}$ \\
\hline 0.5 & $\begin{array}{l}20 \\
40 \\
60\end{array}$ & $\begin{array}{l}9.7 \\
9.5 \\
7.5\end{array}$ & $\begin{array}{l}27.9 \\
4.9 \\
1.0\end{array}$ & $\begin{array}{l}18.9 \\
2.6 \\
0.0\end{array}$ \\
\hline 1.0 & $\begin{array}{l}20 \\
40 \\
60\end{array}$ & $\begin{array}{l}40.1 \\
76.2 \\
96.7\end{array}$ & $\begin{array}{c}59.5 \\
8.1 \\
2.4\end{array}$ & $\begin{array}{l}21.1 \\
3.1 \\
0.2\end{array}$ \\
\hline
\end{tabular}

$* \lambda_{j}^{P}=0$ - ausência de efeito de períodos

Observa-se, pela Tabela 14, que a sensibilidade do teste da interação diminui, à medida que a magnitude do efeito de tratamentos aumenta. Isto sugere que quanto mais evidente for o efeito de tratamentos, maior será a freqüência esperada de erros tipo I. Evidentemente, a probabilidade de erro tipo II também se altera com esta condição, só que de maneira inversa.

Além disso, para o teste da interação, observou-se que o aumento do efeito da interação parece contribuir para o decréscimo da freqüência esperada de erros tipo II.

O tamanho da amostra influiu no desempenho dos testes, mas de forma irregular, isto é, decresceu em uns e aumentou em outros. Verifica-se que o aumento amostral de vinte para sessenta foi suficiente para exemplificar a melhor 
aumento amostral de vinte para sessenta foi suficiente para exemplificar a melhor propriedade de eficiência.

Os demais testes referem-se às comparações de tratamentos. A Tabela 15 apresenta as estimativas de sensibilidade destes testes, considerando a ausência de efeito de tratamentos $\left(\lambda_{i}^{T}=0\right)$, variando somente a magnitude do efeito da interação. O conteúdo desta Tabela é dado pelo percentual de amostras que apresentaram resultados dos testes menores que 0.05 .

TABELA 15: Estimativas percentuais (\%) de sensibilidade dos testes, em funçâa do efeito da interação $\left(\lambda_{i j}^{T P}\right)$ e do tamanho da amostra $\left(n_{i}\right)$, dos testes de tratamentos

\begin{tabular}{l|c|ccccccccccc}
\hline \multirow{2}{*}{$\lambda_{i j}^{T P}$} & $n_{i}$ & \multicolumn{7}{|c}{ TESTES } & DE TRATAMENTOS * & & \\
& & $\mathbf{( 2 )}$ & $\mathbf{( 3 )}$ & $\mathbf{( 4 )}$ & $\mathbf{( 5 )}$ & $\mathbf{( 6 )}$ & $\mathbf{( 7 )}$ & $\mathbf{( 8 )}$ & $\mathbf{( 9 )}$ & $\mathbf{( 1 0 )}$ & $\mathbf{( 1 1 )}$ \\
\hline \multirow{3}{*0.0}{} & 20 & 10.6 & 12.2 & 6.2 & 9.6 & 10.4 & 7.4 & 2.0 & 3.9 & 7.1 & 23.1 \\
& 40 & 8.6 & 9.9 & 5.3 & 8.9 & 6.5 & 5.8 & 2.4 & 6.3 & 7.1 & 24.5 \\
& 60 & 5.7 & 8.8 & 4.1 & 9.3 & 4.9 & 4.4 & 1.9 & 10.6 & 6.4 & 24.2 \\
\hline \multirow{3}{*}{$\mathbf{0 . 5}$} & 20 & 10.6 & 12.6 & 5.6 & 7.4 & 13.1 & 8.2 & 1.9 & 3.5 & 6.6 & 23.2 \\
& 40 & 8.6 & 10.4 & 5.1 & 9.0 & 6.8 & 5.7 & 2.2 & 6.1 & 6.9 & 24.1 \\
& 60 & 5.7 & 8.7 & 3.7 & 7.6 & 4.6 & 3.9 & 1.9 & 9.7 & 5.6 & 23.2 \\
\hline \multirow{3}{*}{$\mathbf{1 . 0}$} & 20 & 10.6 & 14.2 & 5.9 & 5.2 & 21.7 & 10.3 & 2.4 & 2.8 & 7.0 & 23.0 \\
& 40 & 8.6 & 12.5 & 5.8 & 9.6 & 10.9 & 7.4 & 1.1 & 4.0 & 6.9 & 23.1 \\
& 60 & 5.7 & 9.4 & 3.2 & 7.3 & 4.9 & 3.6 & 1.1 & 4.1 & 5.1 & 19.9 \\
\hline
\end{tabular}

* (2) - teste usando oprimeiro período; (3) - teste de McNemar; (4)- aproximação de $\chi^{2}$ de McNemar; (5) - teste de Mainland-Gart; (6) - teste $X^{2}$ de Pearson; (7) teste $G^{2}$ de verossimilhança; (8) - teste com correção de Yates; (9) - teste exato de Fischer; (10) teste de Prescott; (11)-teste de Prescott para pequenas amostras

** ausència de efeitos de tratamentos e de períodos

Esta é a Tabela de maior impostância para o presente trabalho, pois apresenta as freqüências esperadas de erro tipo $I$ dos testes recomendados, possibilitando avaliar o que acontece com esses resultados a medida que o efeito da interação aumenta em magnitude. 
tribuição $\chi^{2}$, os Não-Condicionais (de Pearson, de Verossimilhança e de Yates) e o de Prescott. Eles apresentaram os melhores desempenhos, em relação à sensibilidade, ou seja, mostraram as menores frequências esperadas de erro tipo $I$.

O tamanho da amostra influi nos resultados desses testes, implicando, tudo faz crer, na redução da probabilidade de erro tipo II.

A presença do efeito da interação $\left(\lambda_{i j}^{T P}\right)$ influi nos resultados dos testes; o seu crescimento aumenta a probabilidade de erro tipo I. Mas, tudo indica que o aumento do tamanho da amostra minimiza as conseqüencias da presença de efeito da interação, nesses testes de comparação de tratamentos.

As estimativas especificidade destes teste também estão sujeitos aos efeitos de tratamentos $\left(\lambda_{i}^{T}\right)$, da interação $\left(\lambda_{i j}^{T P}\right)$ e do tamanho da amostra $\left(n_{i}\right)$, conforme apresentado na tabela 16 . 
TABELA 16: Estimativas percentuais (\%) de especificidade dos testes, em função do efeito da interação $\left(\lambda_{i j}^{T P}\right)$ e do tamanho da amostra $\left(n_{i}\right)$, dos testes de tratamentos

\begin{tabular}{|c|c|c|c|c|c|c|c|c|c|c|c|c|}
\hline$\lambda^{T P}$ & $\lambda^{T}$ & $n_{i}$ & (2) & $\begin{array}{l}\text { TES } \\
\mathbf{( 3 )}\end{array}$ & $\begin{array}{l}T E S \\
(4)\end{array}$ & $\begin{array}{l}D E \\
(5)\end{array}$ & $\begin{array}{l}T R A \\
(6)\end{array}$ & $\begin{array}{r}T A M \\
(7)\end{array}$ & $\begin{array}{l}E N T \\
\text { (8) }\end{array}$ & $\begin{array}{l}S^{*} \\
\text { (9) }\end{array}$ & $(10)$ & (11) \\
\hline \multirow{6}{*}{0.0} & \multirow{3}{*}{0.5} & 20 & 19.4 & 52.1 & 56.3 & 54.2 & 46.6 & 53.7 & 72.1 & 96.1 & 52.9 & 49.1 \\
\hline & & 40 & 0.1 & 7.3 & 9.5 & 5.8 & 8.7 & 9.2 & 15.8 & 94.8 & 7.5 & 24.7 \\
\hline & & 60 & 0.0 & 2.2 & 3.2 & 1.7 & 3.2 & 3.6 & 8.1 & 92.9 & 2.2 & 17.5 \\
\hline & \multirow{3}{*}{1.0} & 20 & 21.1 & 1.1 & 1.2 & 58.8 & 0.8 & 1.3 & 5.0 & 99.7 & 1.2 & 15.3 \\
\hline & & 40 & 3.1 & 0.0 & 0.0 & 24.4 & 0.0 & 0.0 & 0.0 & 98.2 & 0.0 & 4.7 \\
\hline & & 60 & 0.1 & 0.0 & 0.0 & 2.7 & 0.0 & 0.0 & 0.0 & 95.9 & 0.0 & 1.5 \\
\hline \multirow{6}{*}{0.5} & \multirow{3}{*}{0.5} & 20 & 5.4 & 42.8 & 47.0 & 59.3 & 35.0 & 42.8 & 66.6 & 97.9 & 43.8 & 46.5 \\
\hline & & 40 & 0.4 & 20.4 & 24.9 & 19.6 & 20.8 & 24.4 & 37.5 & 95.0 & 21.3 & 35.9 \\
\hline & & 60 & 0.0 & 6.9 & 8.8 & 4.7 & 7.7 & 9.0 & 15.2 & 94.2 & 7.0 & 27.2 \\
\hline & \multirow{3}{*}{1.0} & 20 & 21.1 & 7.2 & 8.6 & 62.3 & 4.3 & 8.1 & 24.9 & 99.4 & 7.5 & 27.3 \\
\hline & & 40 & 0.9 & 0.2 & 0.3 & 25.0 & 0.1 & 0.4 & 2.1 & 97.7 & 0.2 & 13.2 \\
\hline & & 60 & 0.0 & 0.0 & 0.0 & 8.7 & 0.0 & 0.0 & 0.0 & 97.1 & 0.0 & 5.0 \\
\hline \multirow{6}{*}{1.0} & \multirow{3}{*}{0.5} & 20 & 5.4 & 51.8 & 52.9 & 88.0 & 30.0 & 44.1 & 78.1 & 99.4 & 51.7 & 50.6 \\
\hline & & 40 & 0.4 & 36.2 & 39.3 & 40.1 & 33.5 & 38.3 & 58.2 & 96.4 & 63.6 & 43.9 \\
\hline & & 60 & 0.0 & 13.9 & 17.7 & 14.3 & 14.9 & 17.8 & 58.2 & 96.4 & 36.6 & 43.9 \\
\hline & \multirow{3}{*}{1.0} & 20 & 7.1 & 50.9 & 52.9 & 87.4 & 27.5 & 43.2 & 79.7 & 99.5 & 51.0 & 50.7 \\
\hline & & 40 & 0.2 & 16.7 & 19.0 & 35.8 & 14.8 & 18.3 & 36.4 & 97.0 & 17.5 & 32.5 \\
\hline & & 60 & 0.0 & 4.5 & 6.3 & 10.8 & 4.3 & 5.6 & 13.9 & 95.3 & 5.0 & 23.8 \\
\hline
\end{tabular}

* (2) - teste usando o primeiro periodo; (3) - teste de McNemar; (4)- aproximação de $\chi^{2}$ de McNemar; (5) teste de Mainland-Gart; (6) teste $X^{2}$ de Pearson; (7) teste ${ }^{2}$ de verossimilhança; (8) - testecom correçãode Yates; (9) - teste exato de Fischer; (10)teste de Prescoti; (11) - teste de Prescott para pequenas amostras

* ausência de efeitos de tratamentos e de periodos 
No que se refere à probabilidade de erro tipo II, associados aos testes de comparação de tratamentos, pode-se afirmar que, na ausência do efeito da interação, há o decréscimo probabilístico desse tipo de erro, a medida que o efeito de tratamentos se torna mais evidente.

Também se verifica o efeito diminuidor da freqüência esperada de erro tipo II, quando a tamanho amostral é aumentado, reforçando a observação da propriedade principal dos delineamentos "Cross-Over".

Observa-se que a probabilidade de erro tipo II aumenta, de acordo com o efeito da interação $\left(\lambda_{i j}^{T P}\right)$. Percebe-se o efeito da presença da interação sobre os testes, que provoca o aparecimento de viés.

O aumento, em magnitude, do efeito de tratamentos $\left(\lambda_{i}^{T}\right)$, fixando um valor paramétrico para a interaçâa, sugere a diminuição da freqüência esperada de erro tipo $I I$.

Finalmente, considerando os valores paramétricos iguais para os efeitos de tratamentos e da interação $-\left(\lambda_{i j}^{T P}=\lambda_{i}^{T}=\left\{\begin{array}{lll}0.5 & \text { el. } & 1.0\end{array}\right)\right.$, observa-se que há uma diminuição da probabilidade de erro tipo II, à medida que esses valores aumentam em magnitude. As únicas exceções à esta regra foram os testes de Mainland-Gart e o exato de Fisher. 


\section{CONCLUSÕES}

As conclusões obtidas foram separadas em duas partes: as referentes ao teste da interação e aos testes de comparação de tratamentos.

\subsection{Teste da Interação Tratamento $\times$ Período}

1. - A freqüencia esperada de erros tipo $I$ aumentou, à medida que aumentou o efeito de tratamentos.

\subsection{Testes de Comparação de Tratamentos}

2. - O aumento do tamanho amostral diminuiu o "viés" causado pela presença de efeito da interação, pois o tamanho amostral influiu diretamente na freqüência esperada de erros tipo $I$ e $I I$;

3. os testes que apresentaram os melhores desempenhos foram, em ordem decrescente, os testes de McNemar para grandes amostras, 
os Nâo-Condicionais (de Pearson, de Verossimilhança e Yates) e o de Prescott;

4. - sugere-se que o aumento do efeito da interação provoca o aumento da probabilidade de erro tipo II;

5. - a freqüência esperada de erro tipo II decresceu, à medida que o efeito de tratamentos aumentou, mesmo com a presença do efeito da interação;

6. - considerando valores iguais para os efeitos de tratamentos e da interação, isto é $-\lambda_{i}^{T}=\lambda_{i j}^{T P}=\{0.5$ e 1.0$\}$, observou-se a diminuição da freqüência de erro tipo $I I$, quando essa magnitude aumentou, sendo exceções os testes de Mainland-Gart e o exato de Fisher. 


\section{REFERÊNCIAS BIBLIOGRÁFICAS}

AGRESTI, A. Analysis of ordinal categorical data. New York, John Wiley, 1984 287p.

AGRESTI, A. Categorical data analysis. New York, John Wiley, $1990558 \mathrm{p}$.

ARMITAGE,P. \& HILLS, M. The two-period crossover trials. The Statistician, Oxford, Inglaterra 31(2): 119-31, 1982.

ATKINSON, A.C. The computer generator of poisson random variables. Applied Statistics, Oxford, Inglaterra 28(1): 29-35, 1979.

BROWN, B.W. The crossover experiment for clinical trials. Biometrics, Alexandria, Estados Unidos 36: 69-79, 1980.

CAMPOS, H. Estatística experimental não paramétrica. ed.4, Piracicaba, $1983348 \mathrm{p}$.

DACHS, J.N.W. Estatística computacional. Rio de Janeiro, Livros Técnicos e Científicos, 1988 235p. 
DUNSMORE, I.R. Analysis of preference in cross-over designs. Biometrics, Alexandria, Estados Unidos 37: 575-8, 1981.

EVERITT, B.S. The analysis of contingency tables. London, Chapman \& Hall, 1977. 128p.

FREEMAN, D.H. Applied categorical data analysis. New York, Marcel Dekker, 1987 318p.

GART, J.J. An exact test for comparing matched proportions in crossover designs. Biometrika, London, Inglaterra 56(1): 75-80, 1969.

GRILLO, M.C.A. Programação e técnicas TURBO PASCAL versão 4.0. ed.2, Rio de Janeiro, Livros Técnicos e Científicos, 1989 323p.

GRIZZLE, J.E. The two-period change-over design and its use in clinical trials. Biometrics, Alexandria, Estados Unidos 21: 467-80, 1965.

HILLIE, F.S. \& LIEBERMAN, G.J. Introdução à pesquisa operacional. Rio de Janeiro, Campus, São Paulo, EDUSP, 1988 805p.

HILLS, M. \& ARMITAGE, P. The two-period cross-over clinical trial. British Journal of Clinical Pharmacology, Hampshire, Inglaterra $8: 7-20,1979$.

JONES, B. \& KENWARD, M.G. Design and analysis of cross-over designs. London, Chapman and Hall, 1989 340p.

KOCH, G.G. The use of non-parametric methods in the statistical analysis of the two-period change-over designs. Biometrics, Alexandria, Estados Unidos 28: 577-84, 1972. 
LINDGREN, B.W. Statistical theory. ed.3, New York, MacMillan Publishing, 1979 613p.

McCULLAGH, P. \& NELDER, J.A. Generalized linear models. London, Chapman and Hall, 1989 511p.

MOOD, A.M.; GRAYBILL, F.A.; BOES, D.C. Introduction to the theory of statistics. New York, McGraw-Hill, 1974 564p.

NETER, J. WASSERMAN, W. \& KUTNER, M.H. Applied linear regression models. Illinois, Estados Unidos, Richard D. Irwin, 1983 545p.

NORTON, P. The Peter Norton programmer's guide to the IBM PC. Washington, Microsoft Press, $1985426 \mathrm{p}$.

O'BRIEN, S.K. TURBO PASCAL 5.5: the complete reference. Berkeley, California, Osborne McGraw-Hill, 1989 913p.

PATTERSON, H.D. \& LUCAS, H.L. Change-over designs. Departamento de Agricultura dos Estados Unidos Tech Bul 147, september, 1962.

PRESCOTT, R.J. The comparison of success rates in cross-over trials in the presence of an order effect. Applied Statistics, Oxford, Inglaterra $\mathbf{3 0}(1)$ : 9-15, 1981.

RIPLEY, B.D. Sthocastic simulation. Chichester, John Wiley, 1987 $237 \mathrm{p}$.

SENN, S. Cross-over trials in clinical trials. Chichester, John Wiley, 1993 266p. 
ZIMMERMANN, H. \& RAHLFS, V. Testing hypotheses in the two-period change-over with binary data. Biometrical Journal, Berlin, Alemanha 20(2):133-41, 1978. 
APÊNDICE A 
TABELA 17: Parâmetros usados nas simulaçôes, para interaçâo tratamento $\times$ periodo $\left(\lambda^{T P}\right)$ e para trata. mentos $\left(\lambda^{T}\right)$ em funçâo do total marginal $\left(n_{i}\right)$.

\begin{tabular}{|c|c|c|c|c|c|c|}
\hline$\lambda^{T P}$ & $\lambda^{T}$ & $n_{i}$ & $\pi_{11}$ & $\pi_{12}$ & $\pi_{21}$ & $\pi_{22}$ \\
\hline \multirow{3}{*}{0,0} & 0,0 & $\begin{array}{l}20 \\
40 \\
60\end{array}$ & $\begin{array}{c}5 \\
10 \\
15\end{array}$ & $\begin{array}{c}5 \\
10 \\
15\end{array}$ & $\begin{array}{c}5 \\
10 \\
15\end{array}$ & $\begin{array}{c}5 \\
10 \\
15\end{array}$ \\
\hline & 0,5 & $\begin{array}{l}20 \\
40 \\
60\end{array}$ & $\begin{array}{r}7 \\
15 \\
22 \\
\end{array}$ & $\begin{array}{l}3 \\
5 \\
8 \\
\end{array}$ & $\begin{array}{l}3 \\
5 \\
8 \\
\end{array}$ & $\begin{array}{r}7 \\
15 \\
22 \\
\end{array}$ \\
\hline & 1,0 & $\begin{array}{l}20 \\
40 \\
60\end{array}$ & $\begin{array}{c}9 \\
18 \\
27 \\
\end{array}$ & $\begin{array}{c}9 \\
18 \\
27\end{array}$ & $\begin{array}{l}1 \\
2 \\
4\end{array}$ & $\begin{array}{l}1 \\
2 \\
4\end{array}$ \\
\hline \multirow{3}{*}{0,5} & 0,0 & $\begin{array}{l}20 \\
40 \\
60\end{array}$ & $\begin{array}{r}7 \\
15 \\
22\end{array}$ & $\begin{array}{l}3 \\
5 \\
8 \\
\end{array}$ & $\begin{array}{l}3 \\
5 \\
8 \\
\end{array}$ & $\begin{array}{r}7 \\
15 \\
22 \\
\end{array}$ \\
\hline & 0,5 & $\begin{array}{l}20 \\
40 \\
60\end{array}$ & $\begin{array}{l}11 \\
21 \\
32 \\
\end{array}$ & $\begin{array}{c}4 \\
8 \\
12 \\
\end{array}$ & $\begin{array}{l}1 \\
3 \\
4 \\
\end{array}$ & $\begin{array}{c}4 \\
8 \\
12 \\
\end{array}$ \\
\hline & 1,0 & $\begin{array}{l}20 \\
40 \\
60 \\
\end{array}$ & $\begin{array}{l}13 \\
26 \\
39 \\
\end{array}$ & $\begin{array}{c}4 \\
8 \\
12 \\
\end{array}$ & $\begin{array}{l}1 \\
2 \\
3\end{array}$ & $\begin{array}{l}2 \\
4 \\
6\end{array}$ \\
\hline \multirow{3}{*}{1,0} & 0,0 & $\begin{array}{l}20 \\
40 \\
60\end{array}$ & $\begin{array}{c}6 \\
12 \\
19 \\
\end{array}$ & $\begin{array}{c}4 \\
8 \\
11 \\
\end{array}$ & $\begin{array}{c}4 \\
8 \\
11 \\
\end{array}$ & $\begin{array}{c}6 \\
12 \\
19 \\
\end{array}$ \\
\hline & 0,5 & $\begin{array}{l}20 \\
40 \\
60\end{array}$ & $\begin{array}{c}9 \\
18 \\
27\end{array}$ & $\begin{array}{c}6 \\
11 \\
17\end{array}$ & $\begin{array}{l}2 \\
4 \\
6\end{array}$ & $\begin{array}{c}3 \\
7 \\
10\end{array}$ \\
\hline & 1,0 & $\begin{array}{l}20 \\
40 \\
60\end{array}$ & $\begin{array}{l}11 \\
22 \\
33\end{array}$ & $\begin{array}{c}7 \\
13 \\
20\end{array}$ & $\begin{array}{l}1 \\
2 \\
3\end{array}$ & $\begin{array}{l}1 \\
3 \\
4\end{array}$ \\
\hline
\end{tabular}


APÊNDICE B 


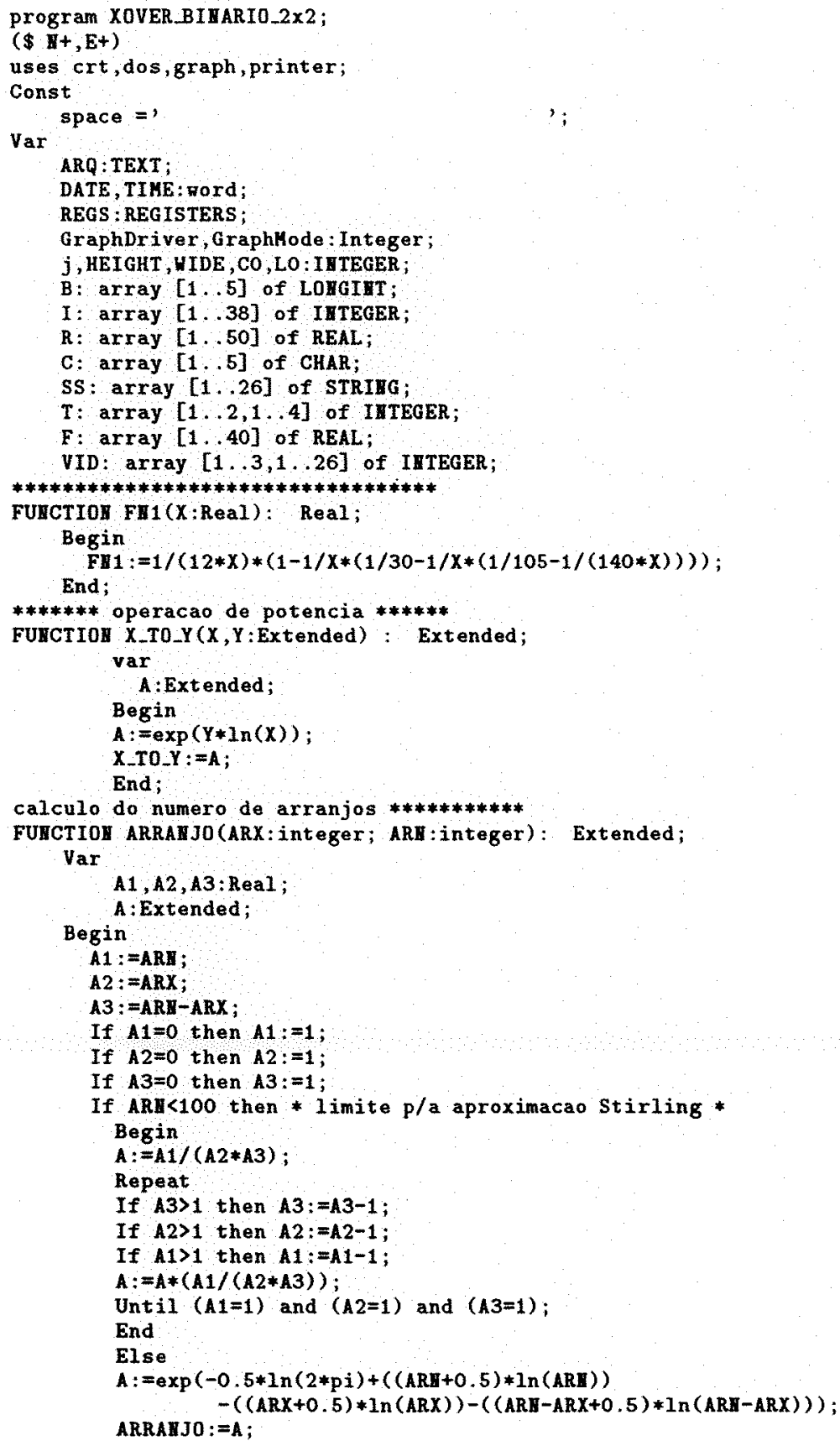




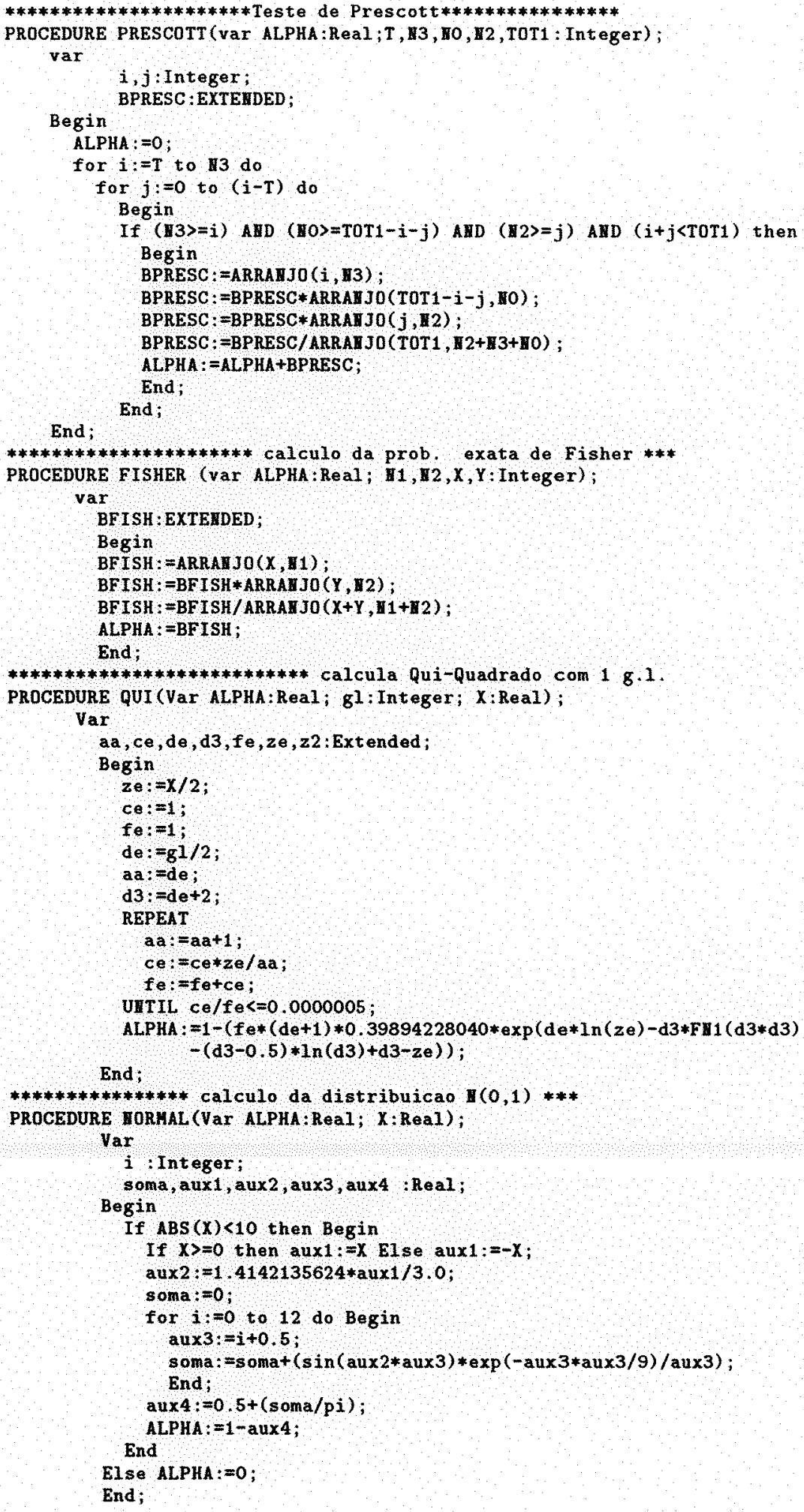




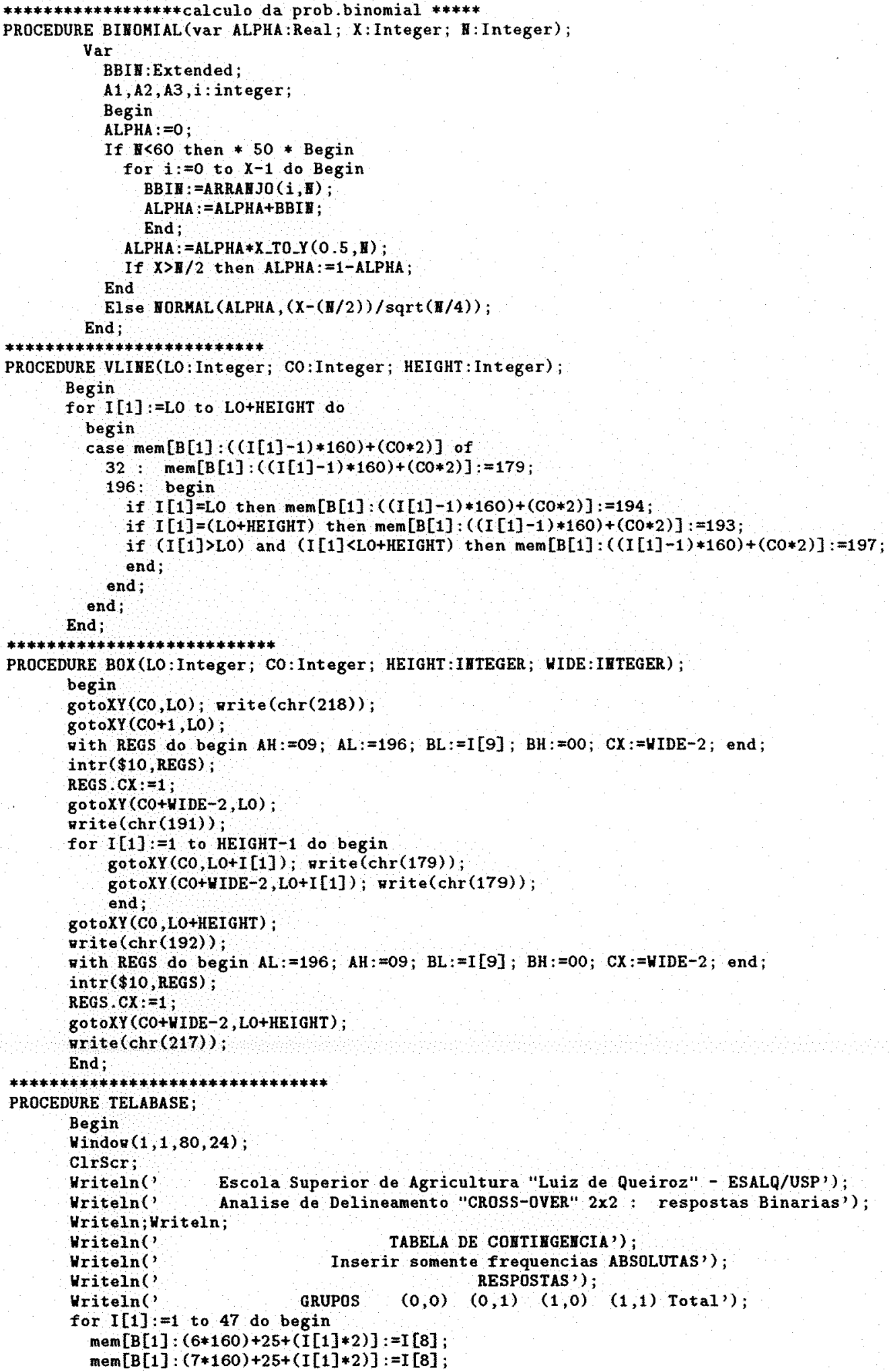


end ;
Uriteln;
$\begin{array}{ll}\text { Writeln(? } & \left.A B^{\prime}\right) \text {; } \\ \text { Writeln (? } & \left.B A^{\prime}\right) \text {; }\end{array}$
Urite (? ) ;

UITH REGS do begin AH: $=09 ; \mathrm{AL}:=196 ; \mathrm{BL}:=\mathrm{I}[9] ; \mathrm{BH}:=00 ; \mathrm{CX}:=46$; end $\operatorname{IHTR}(\$ 10, \mathrm{REGS})$

VLIBE $(9,21,3)$;

$\operatorname{VLIHE}(9,51,3)$

Writeln; Uriteln; Writeln;

Uriteln (' Tratamento A - ')

Writeln(? Tratamento $\mathrm{B}-$ ?);

Uriteln ("Tempo de "Wash-Out" - ")

Writeln(, Tempo de "Run-In" - ) )

Hriteln ('Destino da Impressao - ');

for $I[2]:=1$ to 8 do begin

$g \circ t \circ X Y(V I D[2, I[1]]+2$, VID $[1, I[1]])$;

arite (F[I $[1]]$ );

end;

for $I[1]=9$ to 13 do begin

$\operatorname{SS}[I[1]]=\operatorname{copy}(\operatorname{SS}[\mathrm{I}[1]], 1, \operatorname{VID}[3, I[1]])$

gotoXY (VID $[2, I[1]]+2, \operatorname{VID}[1, I[1]])$ :

Hrite(SS[I[1]]);

end;

for $I[1]:=1$ to 13 do begin

for $I[2]:=1$ to $\operatorname{VID}[3, I[1]]$ do begin $\operatorname{mem}[B[1]:((\operatorname{VID}[1, I[1]]-1) * 160)+((\operatorname{VID}[2, I[1]]+I[2]) * 2)+1]:=I[8]$ end;

End;

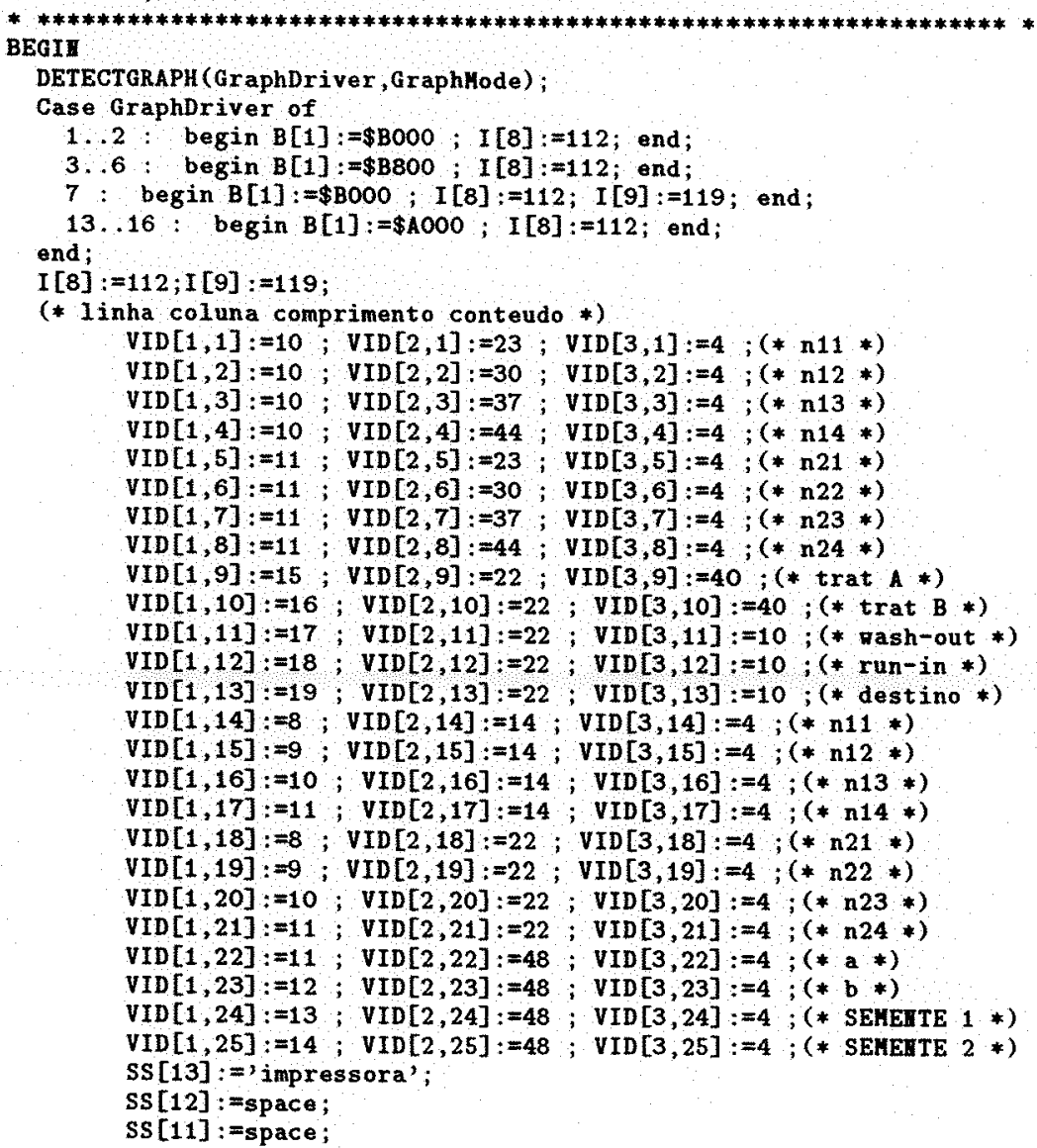




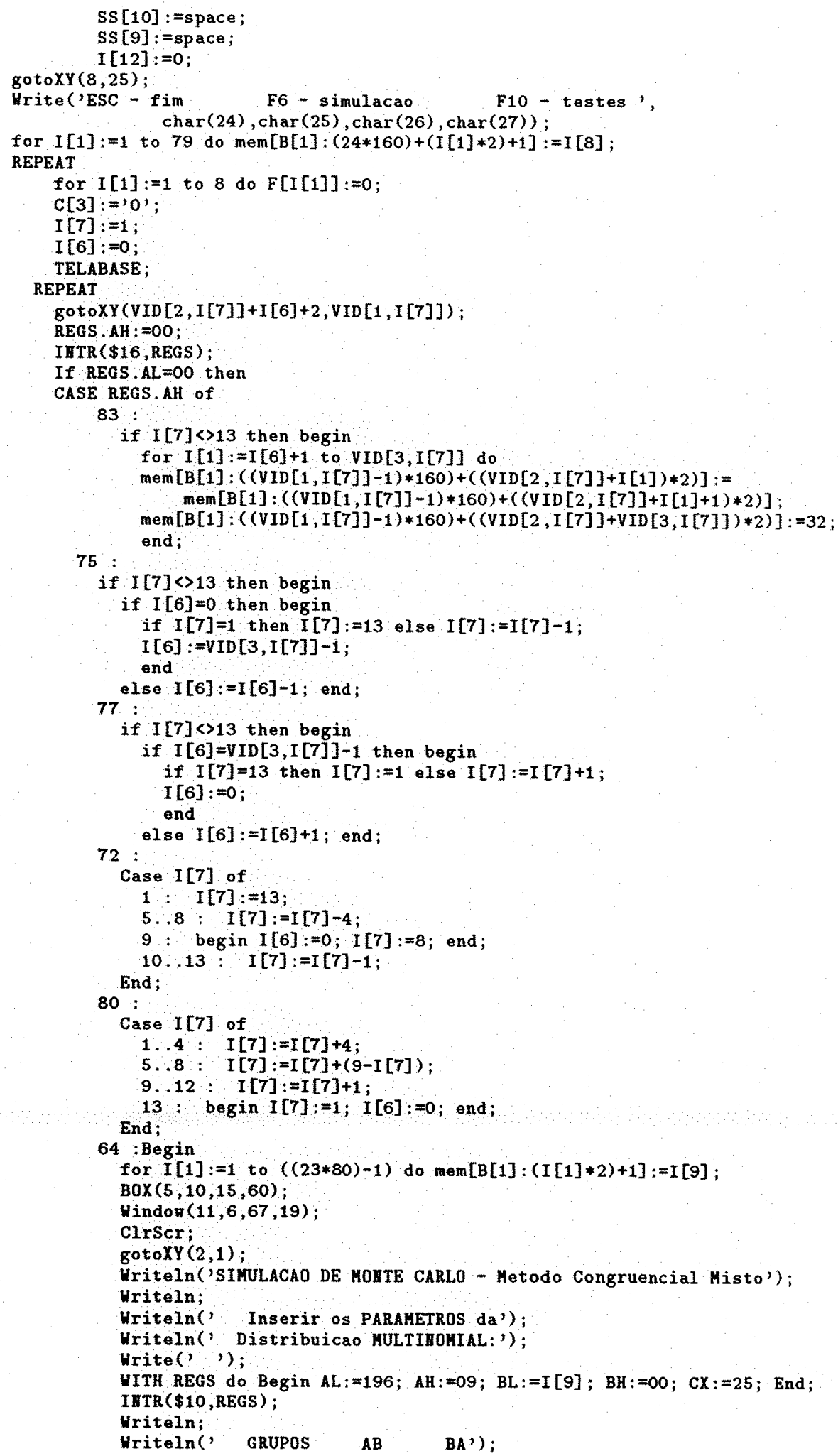




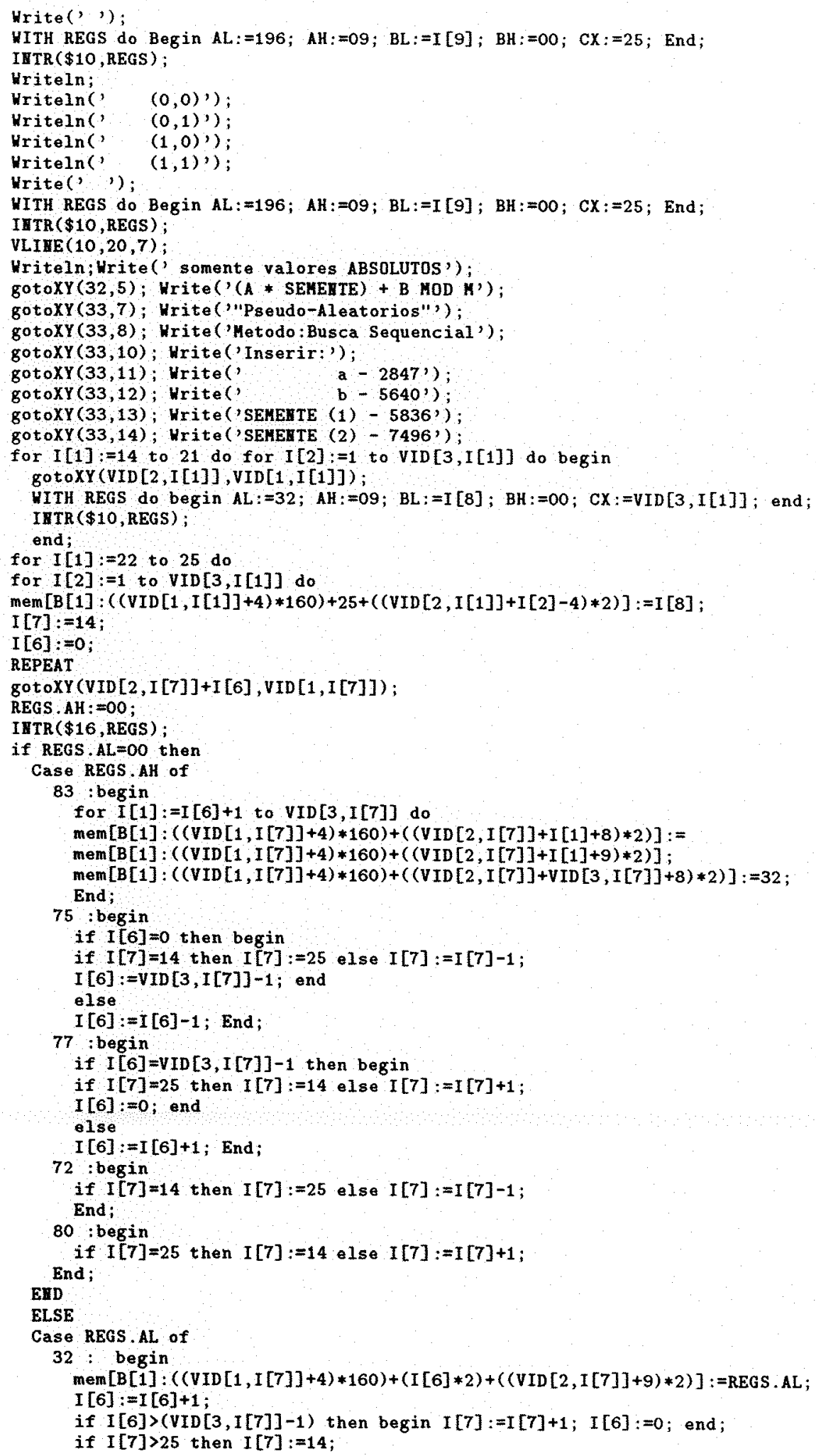




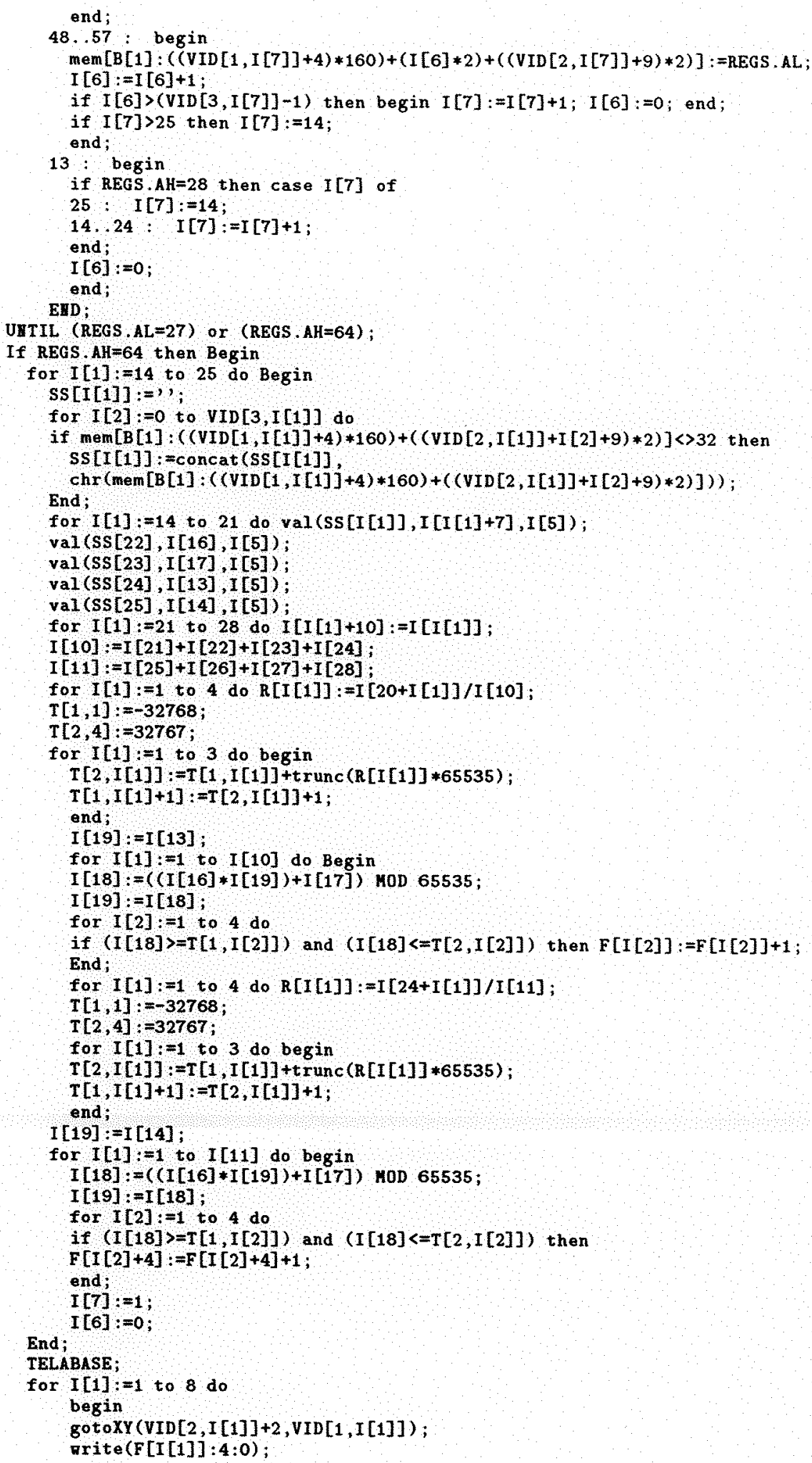




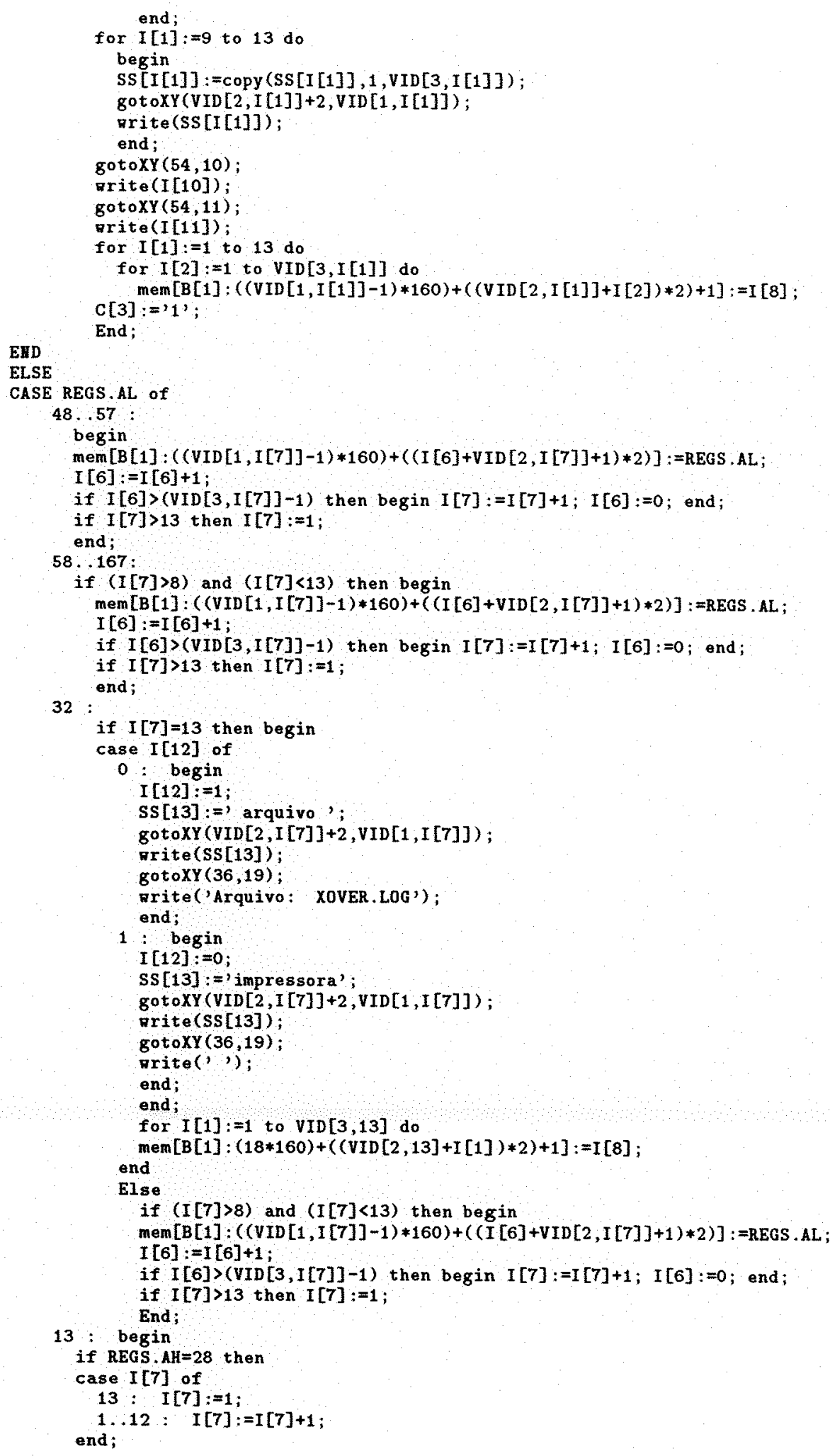


EED ;

$I[6]:=0$;

end;

UHTIL (REGS . $A L=27$ ) or (REGS. AH $=68$ );

for $I[1]:=1$ to 8 do

Begin

$\operatorname{SS}[\mathrm{I}[1]]:=$ ';

for $I[2]:=0$ to VID $[3, I[1]]$ do

Begin

if mem $[B[1]:((\operatorname{VID}[1, \mathrm{I}[1]]-1) * 160)+((\operatorname{VID}[2, \mathrm{I}[1]]+\mathrm{I}[2]) * 2)]<>32$ then

$\operatorname{SS}[I[1]]:=\operatorname{concat}(\operatorname{SS}[\mathrm{I}[1]]$.

$\operatorname{chr}(\operatorname{mem}[B[1]:((\operatorname{VID}[1, \operatorname{I}[1]]-1) * 160)+((\operatorname{VID}[2, \operatorname{I}[1]]+I[2]) * 2)]))$; End

End;

for $[1]:=1$ to 8 do

Begin

$\operatorname{val}(S S[I[1]], F[I[1]], I[5])$;

if $F[I[1]]=0$ then $F[I[1]]:=0.000001$;

$I[20+I[1]]:=\operatorname{trunc}(F[I[1]])$;

End;

$I[10]:=\operatorname{trunc}(F[1])+\operatorname{trunc}(F[2])+\operatorname{trunc}(F[3])+\operatorname{trunc}(F[4])$;

$I[11]:=\operatorname{trunc}(F[5])+\operatorname{trunc}(F[6])+\operatorname{trunc}(F[7])+\operatorname{trunc}(F[8])$;

for $I[1]=9$ to 13 do

Begin

$\operatorname{SS}[I[1]]:=" ;$

for $I[2]:=1$ to VID $[3, I[1]]$ do

Begin

SS $[I[1]]:=$ concat $(S S[I[1]]$

End ;

$\operatorname{chr}(\operatorname{mem}[B[1]:((\operatorname{VID}[1, \mathrm{I}[1]]-1) * 160)+((\operatorname{VID}[2, \mathrm{I}[1]]+\mathrm{I}[2]) * 2)]))$

End:

If (REGS AL $<>27$ ) then

Begin

$R[11]:=(F[2]+F[7]) /(F[2]+F[3]+F[6]+F[7])$;

$R[12]:=(F[2]+F[3]+F[6]+F[7]) / 2$;

$R[13]:=(F[2]+F[3]+F[6]+F[7]) / 4$;

$R[14]:=\operatorname{SQR}(F[2]+F[7]-R[12]) / R[13]$

$R[15]:=(F[2] * F[7]) /(F[3] * F[6])$;

$R[16]:=(1 / F[2])+(1 / F[7])+(1 / F[3])+(1 / F[6])$

$R[17]=F[3]-F[2]$;

$R[18]:=F[1]+F[5]$

$\mathrm{R}[19]:=\mathrm{F}[2]+\mathrm{F}[6]$

$R[20]:=F[3]+F[7]$;

$R[21]:=F[4]+F[8]$

$R[22]:=F[1]+F[2]+F[3]+F[4]$;

$R[23]:=F[5]+F[6]+F[7]+F[8]$

$R[24]:=F[2]+F[3]$

$R[25]:=F[6]+F[7]$;

$R[26]:=R[22]+R[23]$;

$R[27]:=(R[22] *(R[20]-R[19])) / R[26]$;

$R[28]:=(R[22] * R[23] *((R[20]+R[19])-(\operatorname{SQR}(R[20]-R[19]) / R[26]))) /(R[26] *(R[26]-1)) ; * \operatorname{var}(T) *$

$R[29]:=(\operatorname{ABS}(R[17]-R[27])-0.5) / R[28]$

$R[30]:=(S Q R(F[2]-((F[2]+F[3]) * R[19] /(R[24]+R[25]))) / F[2])+$

$(\operatorname{SQR}(F[3]-((F[2]+F[3])+R[20] /(R[24]+R[25]))) / F[3])+$

$(\operatorname{SQR}(F[6]-((\mathrm{F}[6]+\mathrm{F}[7]) * \mathrm{R}[19] /(\mathrm{R}[24]+\mathrm{R}[25]))) / \mathrm{F}[6])+$

$(\operatorname{SQR}(F[7]-((F[6]+F[7]) * R[20] /(R[24]+R[25]))) / F[7])$;

$R[31]:=2 *((F[2] * \ln (F[2] *(R[24]+R[25]) / R[19] / R[24]))+$

$(F[3] * \ln (F[3] *(R[24]+R[25]) / R[20] / R[24]))+$

$(F[6] * \ln (F[6] *(R[24]+R[25]) / R[19] / R[25]))+$

$(\mathrm{F}[\mathrm{T}]+\ln (\mathrm{F}[7] *(\mathrm{R}[24]+\mathrm{R}[25]) / \mathrm{R}[20] / \mathrm{R}[25])))$ )

$R[32]:=(\operatorname{SQR}(\operatorname{ABS}((F[2] * F[7])-(F[6] * F[3]))-(0.5 *(R[24]+R[25]))) *(R[24]+R[25])) /$ $(\mathrm{R}[19] * \mathrm{R}[20] * \mathrm{R}[24] * \mathrm{R}[25])$;

$R[33]:=(F[1] * F[8]) /(F[4] * F[5])$;

$R[34]:=(1 / F[1])+(1 / F[8])+(1 / F[4])+(1 / F[5])$

$R[35]:=((F[1]+F[2]) *(F[7]+F[8])) /((F[3]+F[4]) *(F[5]+F[6]))$

$R[36]:=(1 /(F[1]+F[2]))+(1 /(F[7]+F[8]))+(1 /(F[3]+F[4]))+(1 /(F[5]+F[6]))$;

UITDON $(1,1,80,25)$;

$\operatorname{BOX}(11,44,13,37)$;

HIIDOU $(45,12,78,23)$; 


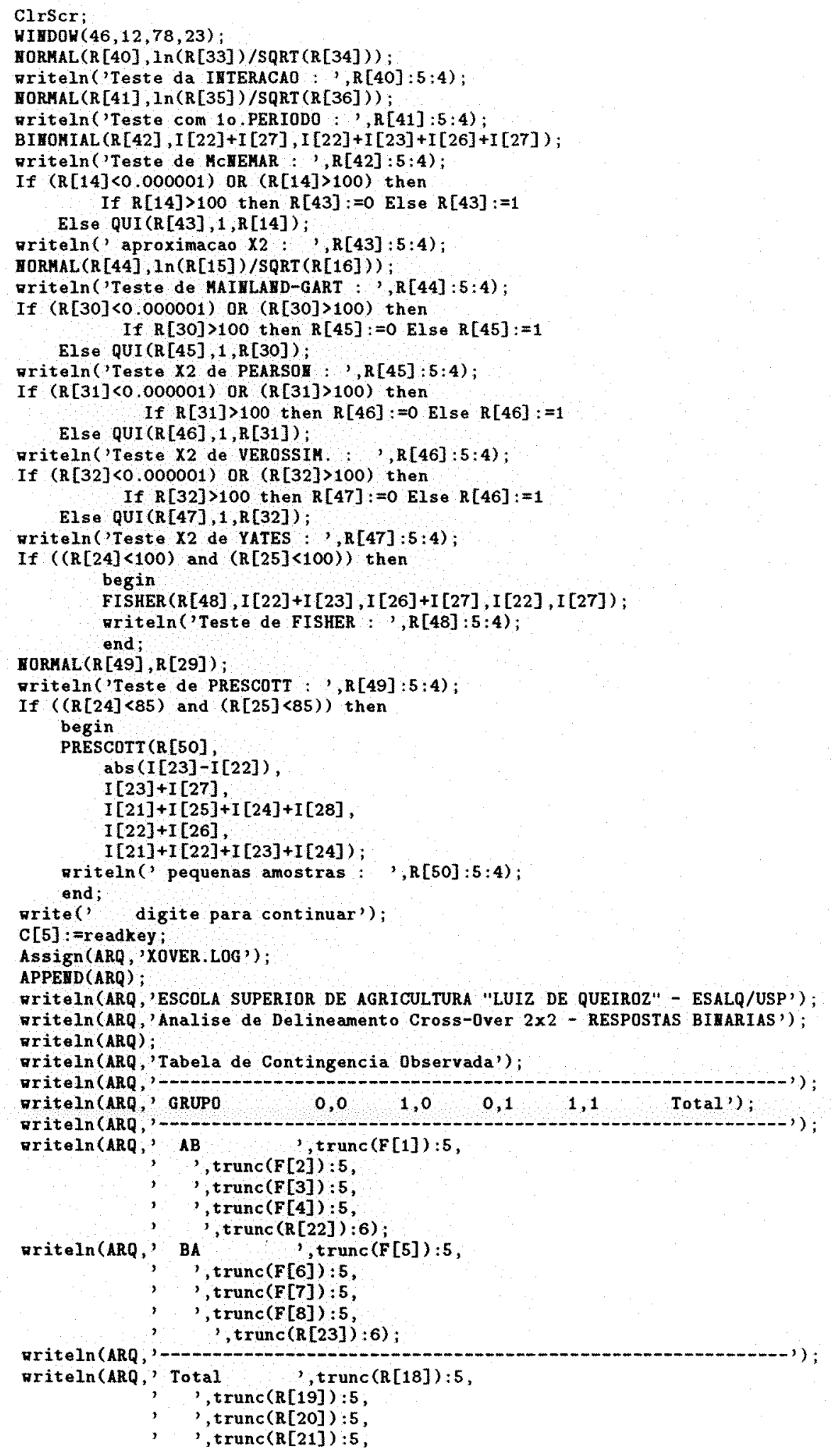




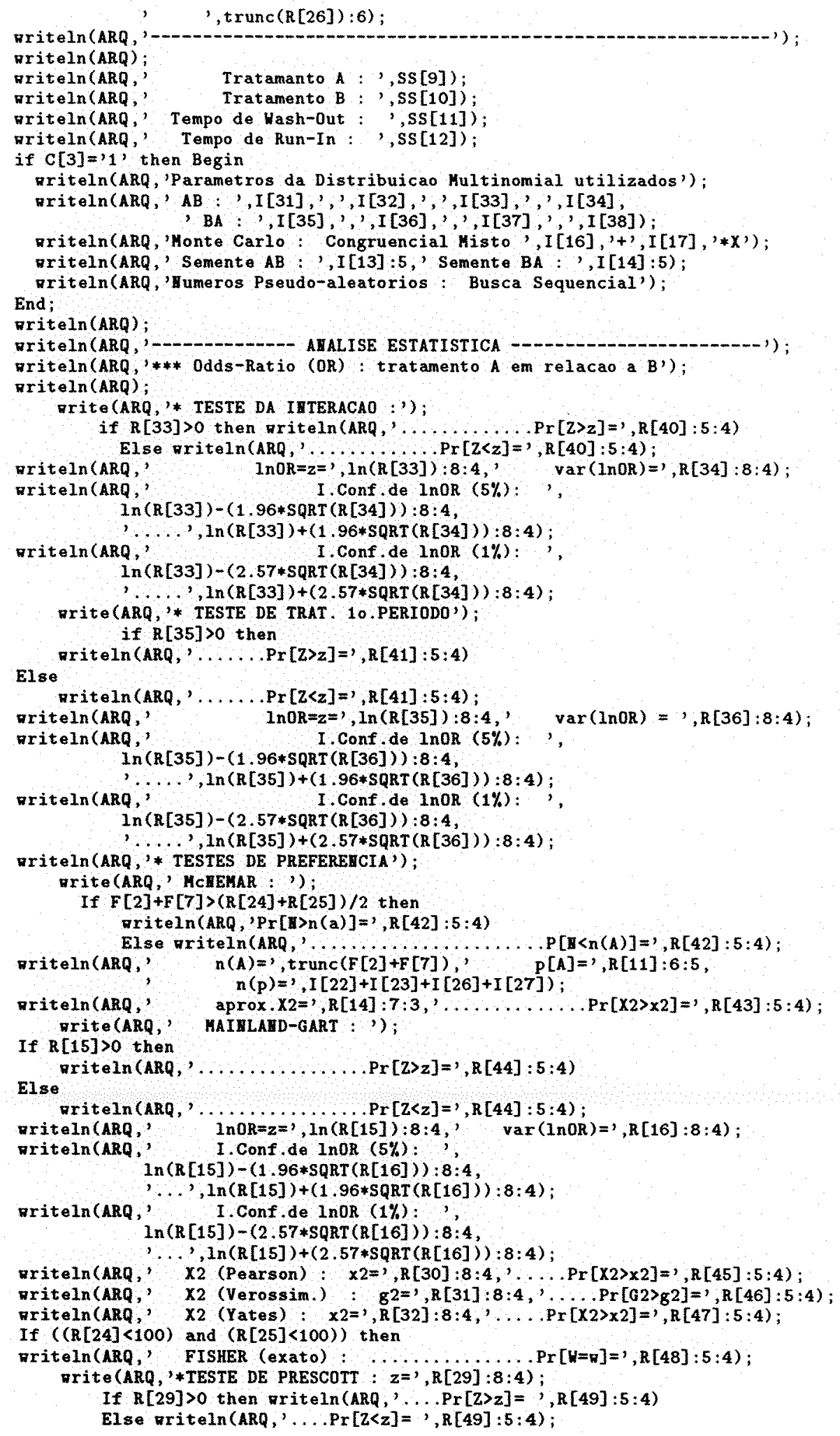




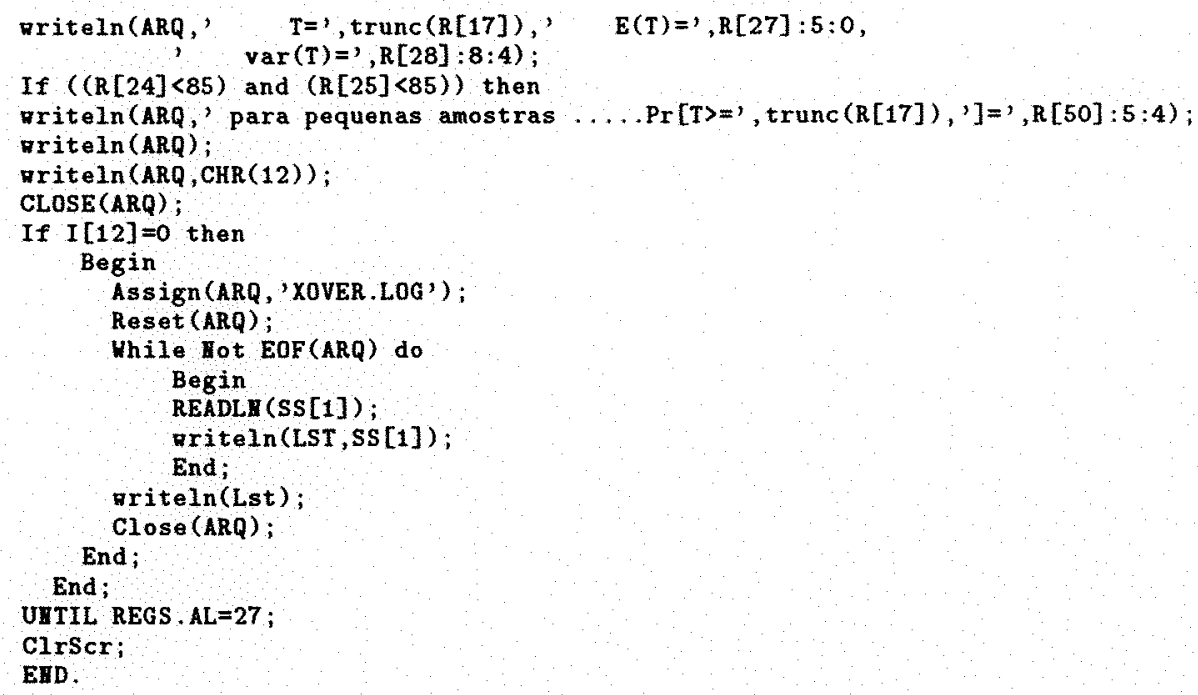


APENNDICE C 


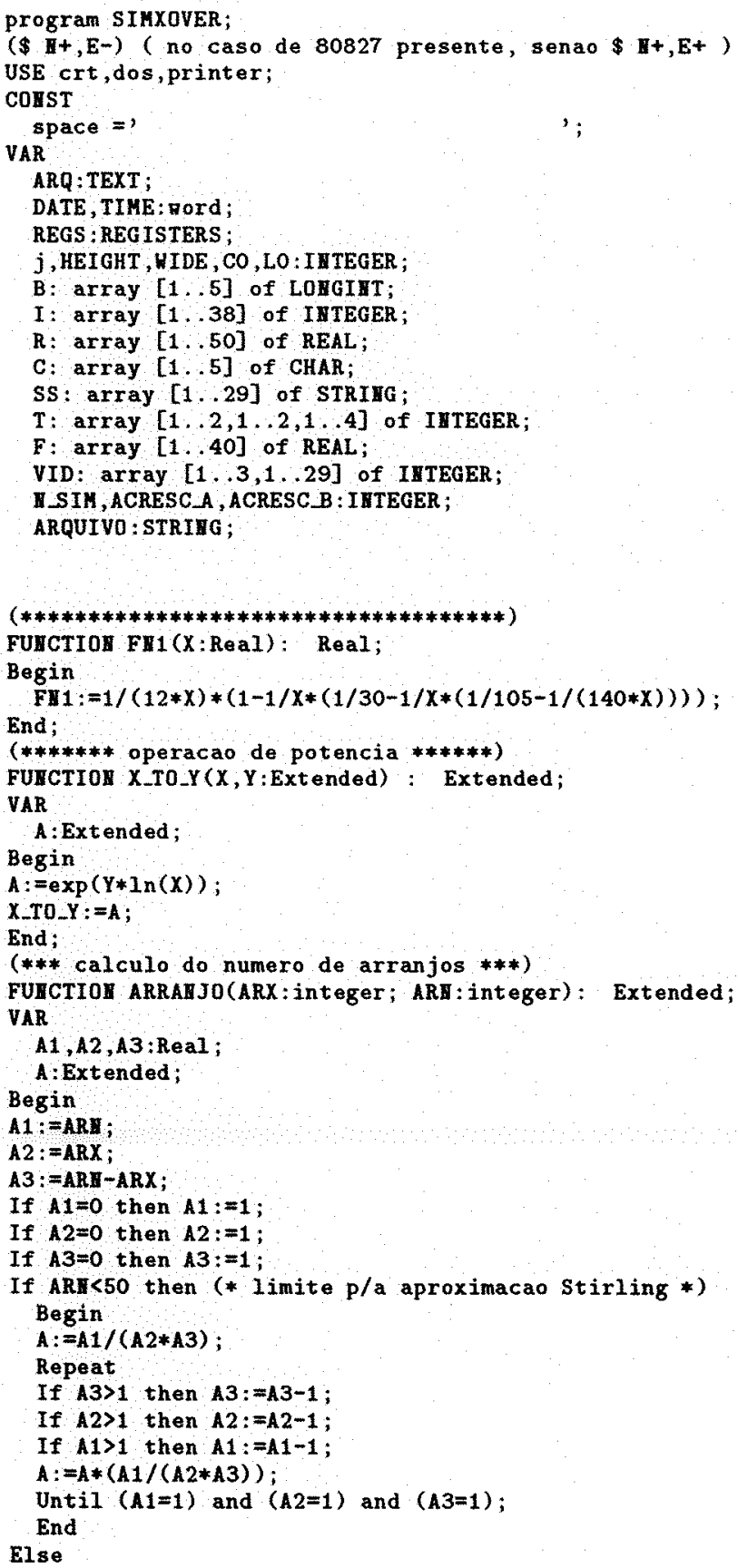




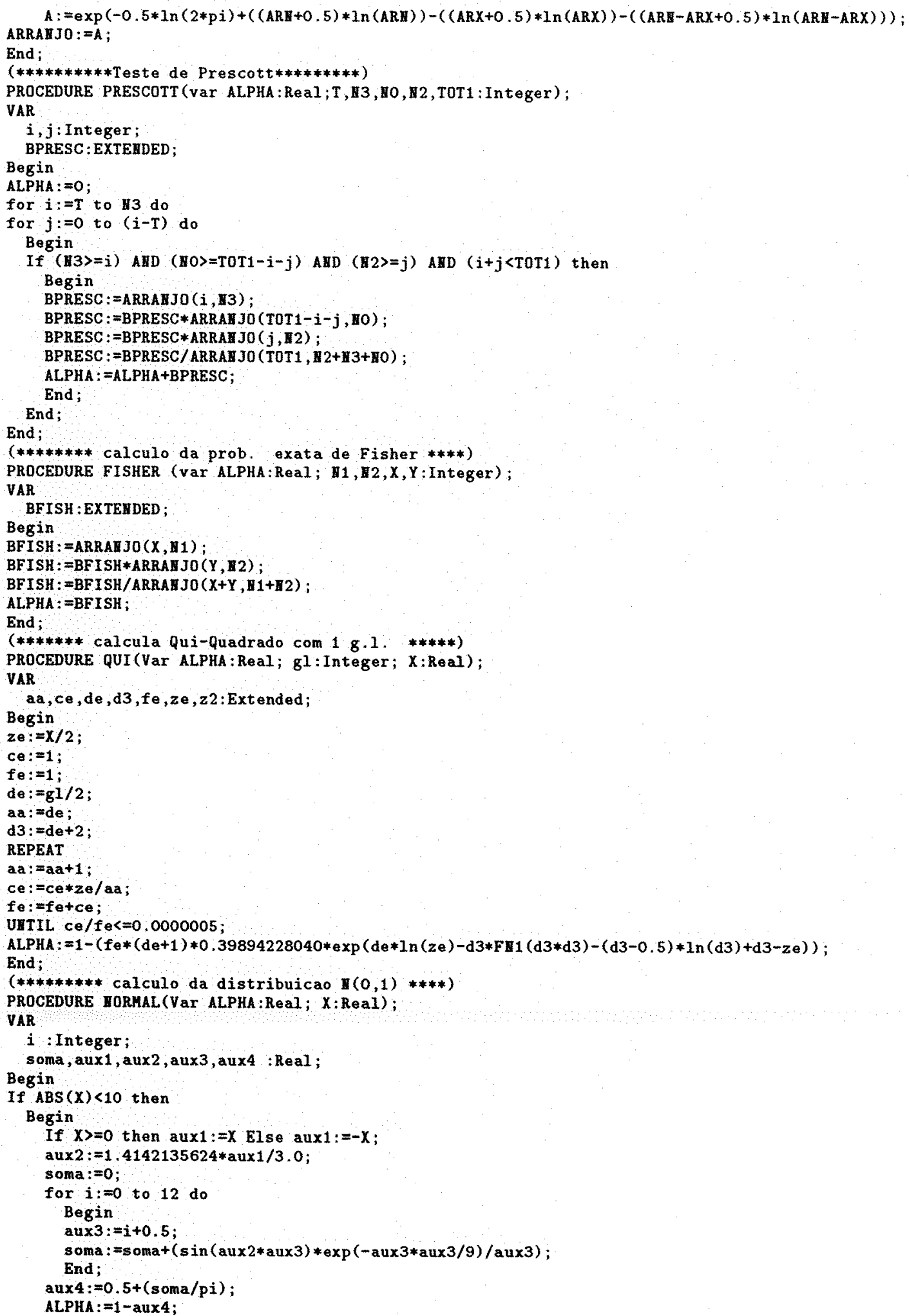




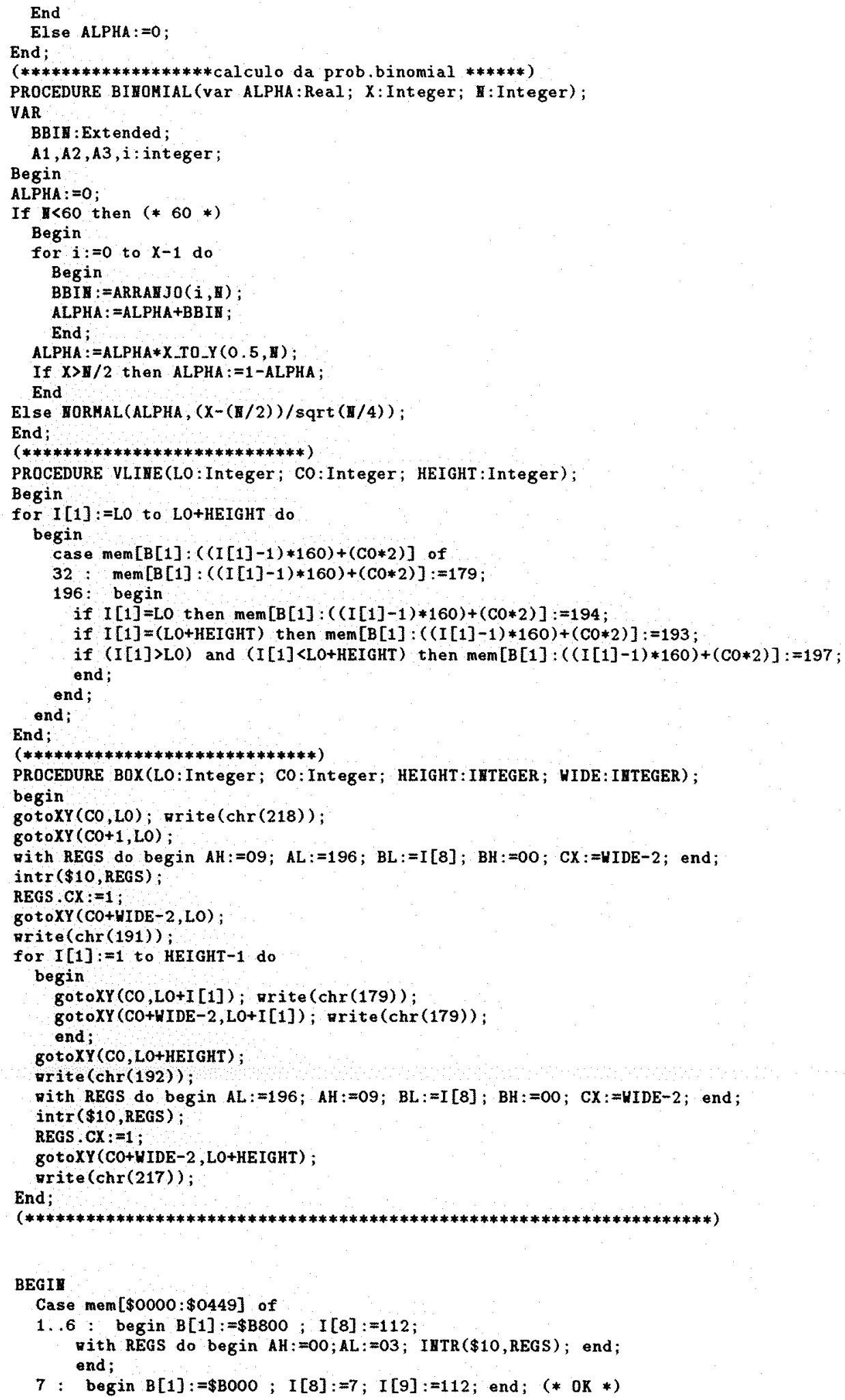




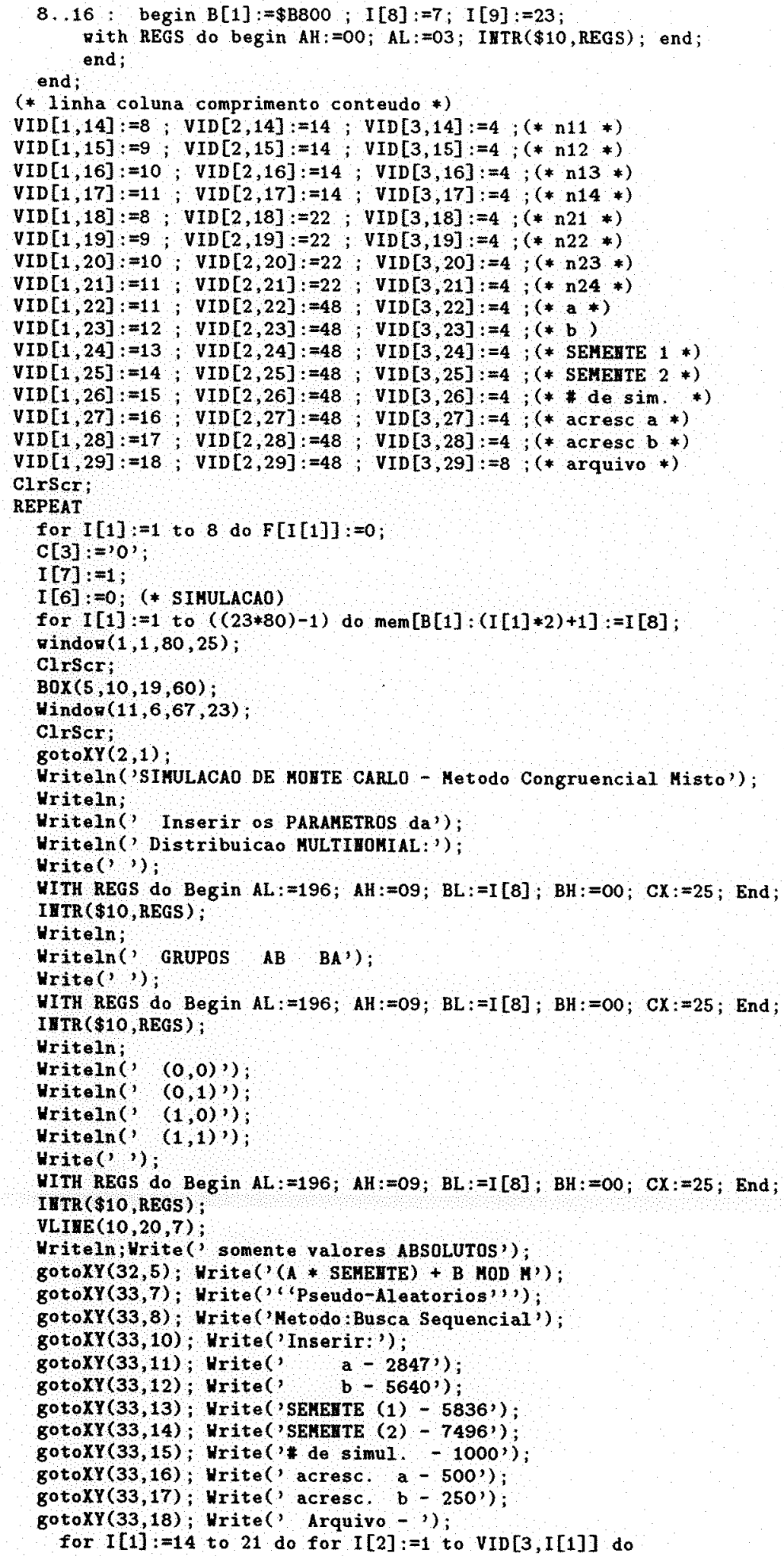




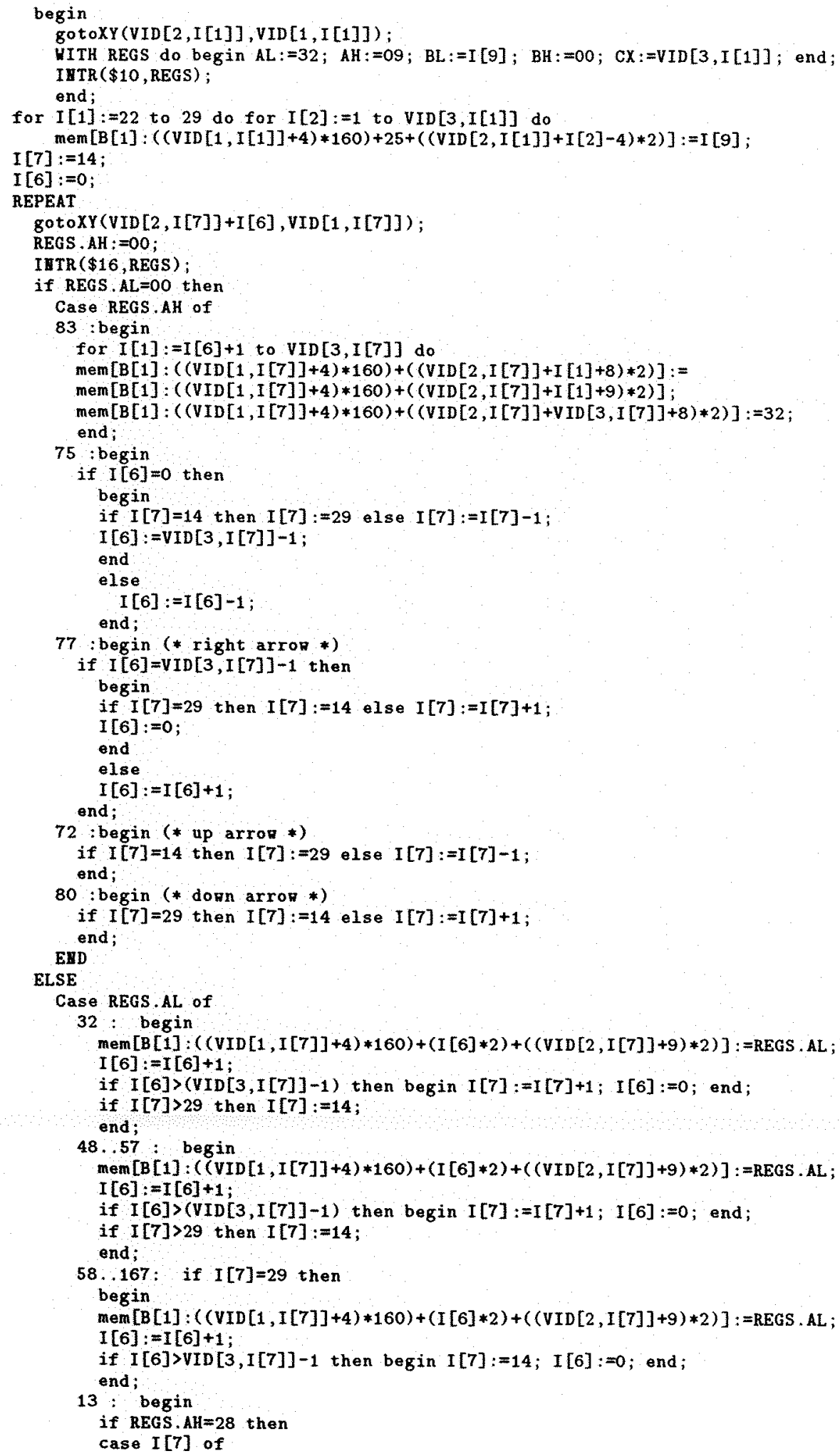




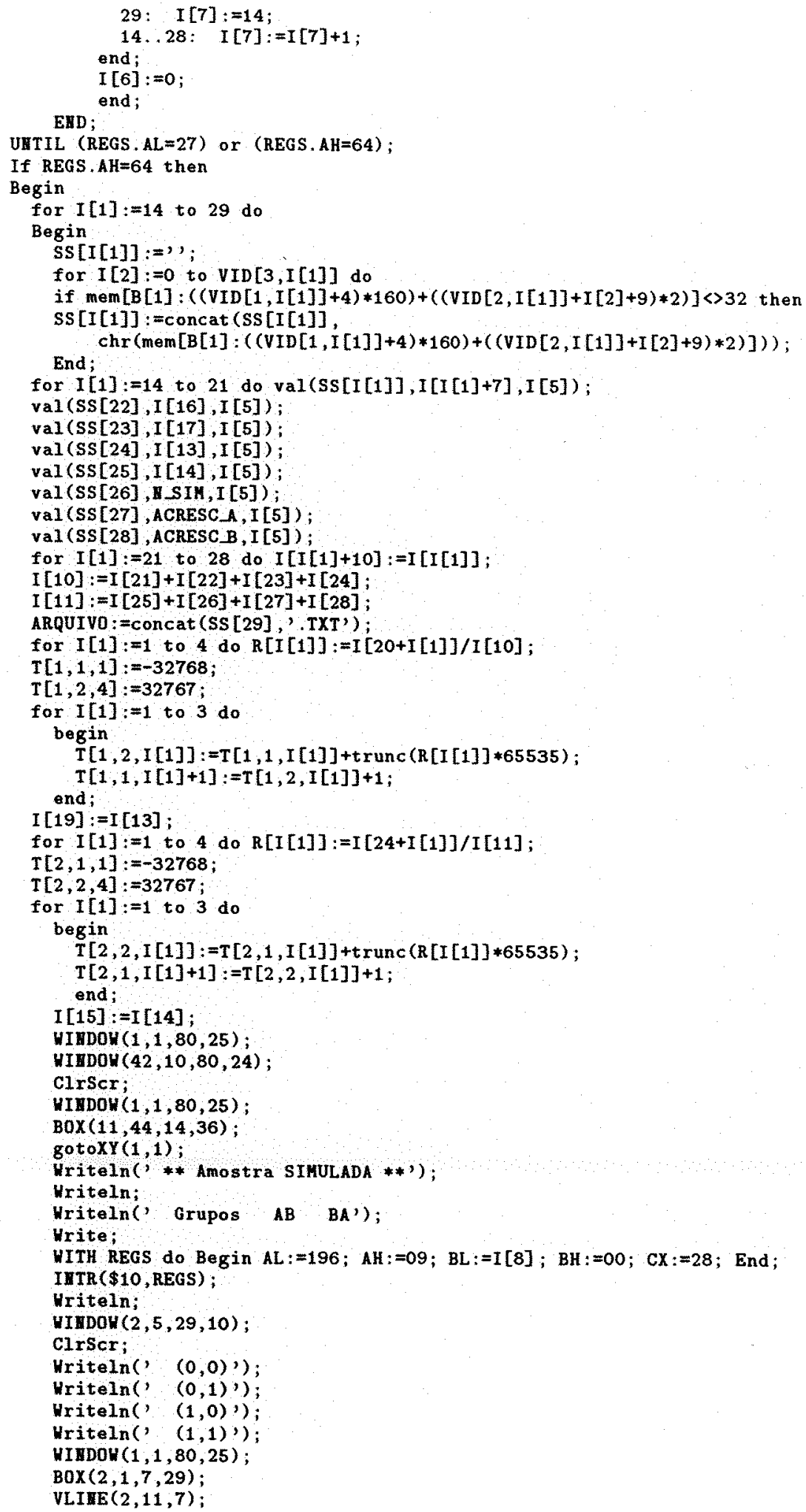


for $I[5]:=1$ to N_SIM do

Begin

for $I[1]:=1$ to 8 do $F[I[1]]:=0$;

for $I[1]:=1$ to $I[10]$ do

Begin

$I[18]:=\left(\left(\left(I[16]+\left((I[2]-1) *\right.\right.\right.\right.$ ACRESC $\left.\left.\left.\left.A_{A}\right)\right) * I[19]\right)+(I[17]+((I[2]-1) * A C R E S C B))\right)$ MOD 65535

$I[19]:=I[18]$

for $I[2]:=1$ to 4 do

if $(I[18]>=T[1,1, I[2]])$ and $(I[18]<=T[1,2, I[2]])$ then $F[I[2]] ;=F[I[2]]+1$; End ;

for $I[1]:=1$ to $I[11]$ do

begin

$I[20]:=(((I[16]+((I[2]-1) * \operatorname{ACRESCA})) * I[15])+(I[17]+((I[2]-1) * A \operatorname{CRESCB})))$ MOD 65535 $I[15]:=I[20]$;

for $I[2]:=1$ to 4 do if $(I[20]\rangle=T[2,1, I[2]])$ and $(I[20]<=T[2,2, I[2]])$ then $F[I[2]+4]:=F[I[2]+4]+1$; end;

$I[7]:=1$

$I[6]:=0$;

for $I[1]:=1$ to 8 do begin

if $F[I[1]]=0$ then $F[I[1]]:=0.000001$

$I[20+I[1]]:=\operatorname{runc}(F[I[1]])$;

end;

$I[10]:=\operatorname{trunc}(F[1])+\operatorname{trunc}(F[2])+\operatorname{trunc}(F[3])+\operatorname{trunc}(F[4])$;

$I[11]:=\operatorname{trunc}(F[5])+\operatorname{trunc}(F[6])+\operatorname{trunc}(F[7])+\operatorname{trunc}(F[8])$.

$\operatorname{HIDDOH}(1,1,80,25)$;

UIHDDU $(15,5,27,8)$;

ClrScr;

Hriteln (I $[21]: 3,,, \mathrm{I}[25]: 3)$;

Hriteln $(I[22]: 3,, I[26]: 3)$

Nriteln (I $[23]: 3, ?, I[27]: 3)$

Hrite $(\mathrm{I}[24]: 3, \cdots, \mathrm{I}[28]: 3)$;

$\mathrm{R}[11]:=(\mathrm{F}[2]+\mathrm{F}[7]) /(\mathrm{F}[2]+\mathrm{F}[3]+\mathrm{F}[6]+\mathrm{F}[7])$

$R[12]:=(F[2]+F[3]+F[6]+F[7]) / 2$;

$R[13]:=(F[2]+F[3]+F[6]+F[7]) / 4$;

$R[14]:=\operatorname{SQR}(F[2]+F[7]-R[12]) / R[13]$

$R[15]:=(F[2] * F[7]) /(F[3] * F[6])$

$R[16]:=(1 / F[2])+(1 / F[7])+(1 / F[3])+(1 / F[6])$;

$R[17]:=F[3]-F[2]$;

$R[18]:=F[1]+F[5]$

$R[19]:=F[2]+F[6]$;

$R[20]:=F[3]+F[7]$;

$R[21]:=F[4]+F[8]$;

$R[22]:=F[1]+F[2]+F[3]+F[4]$;

$R[23]:=F[5]+F[6]+F[7]+F[8]$.

$\mathrm{R}[24]:=\mathrm{F}[2]+\mathrm{F}[3]$;

$\mathrm{R}[25]:=\mathrm{F}[6]+\mathrm{F}[7]$;

$\mathrm{R}[26]:=\mathrm{R}[22]+\mathrm{R}[23]$

$R[27]:=(R[22] *(R[20]-R[19])) / R[26]$

$R[28]:=(R[22] * R[23] *((R[20]+R[19])-(\operatorname{SQR}(R[20]-R[19]) / R[26]))) /(R[26] *(R[26]-1))$

$\mathrm{R}[29]:=(\operatorname{ABS}(\mathrm{R}[17]-\mathrm{R}[27])-0.5) / \mathrm{SQRT}(\mathrm{R}[28])$

$R[30]:=(\operatorname{SQR}(F[2]-(\mathrm{F}[2]+\mathrm{F}[3]) * \mathrm{R}[19] /(\mathrm{R}[24]+\mathrm{R}[25]))) / \mathrm{F}[2])+$

$(\operatorname{SQR}(F[3]-((F[2]+F[3]) * R[20] /(R[24]+R[25]))) / F[3])+$

$(\operatorname{SQR}(\mathrm{F}[6]-(\mathrm{F}[6]+\mathrm{F}[7]) * \mathrm{R}[19] /(\mathrm{R}[24]+\mathrm{R}[25]))) / \mathrm{F}[6])+$

$(\operatorname{SQR}(F[7]-((F[6]+F[7]) * R[20] /(R[24]+R[25]))) / F[7])$

$R[31]:=2 *((F[2] * 1 \mathrm{n}(\mathrm{F}[2] *(\mathrm{R}[24]+\mathrm{R}[25]) / \mathrm{R}[19] / \mathrm{R}[24]))+$

$(F[3] * \ln (F[3] *(R[24]+R[25]) / R[20] / R[24]))+$

$(F[6] * \ln (F[6] *(R[24]+R[25]) / R[19] / R[25]))+$

$(F[7] * \ln (F[7] *(R[24]+R[25]) / R[20] / R[25])))$

$R[32]:=(\operatorname{SQR}(A B S((F[2] * F[7])-(F[6] * F[3]))-(0.5 *(R[24]+R[25]))) *(R[24]+R[25])) /$ $(\mathrm{R}[19] * \mathrm{R}[20] * \mathrm{R}[24] * \mathrm{R}[25])$

$R[33]:=(F[1] * F[8]) /(F[4] * F[5])$;

$R[34]:=(1 / F[1])+(1 / F[8])+(1 / F[4])+(1 / F[5])$

$R[35]:=((F[1]+F[2]) *(F[7]+F[8])) /((F[3]+F[4]) *(F[5]+F[6]))$;

UIRDOU $(45,12,77,24)$

ClrScr;

oriteln $\left(, * *\right.$ SIRULACAO : , I $\left.[5],, * *^{\prime}\right)$;

HORMAL (R [40], $\ln (\mathrm{R}[33]) / \operatorname{SQRT}(\mathrm{R}[34]))$; 


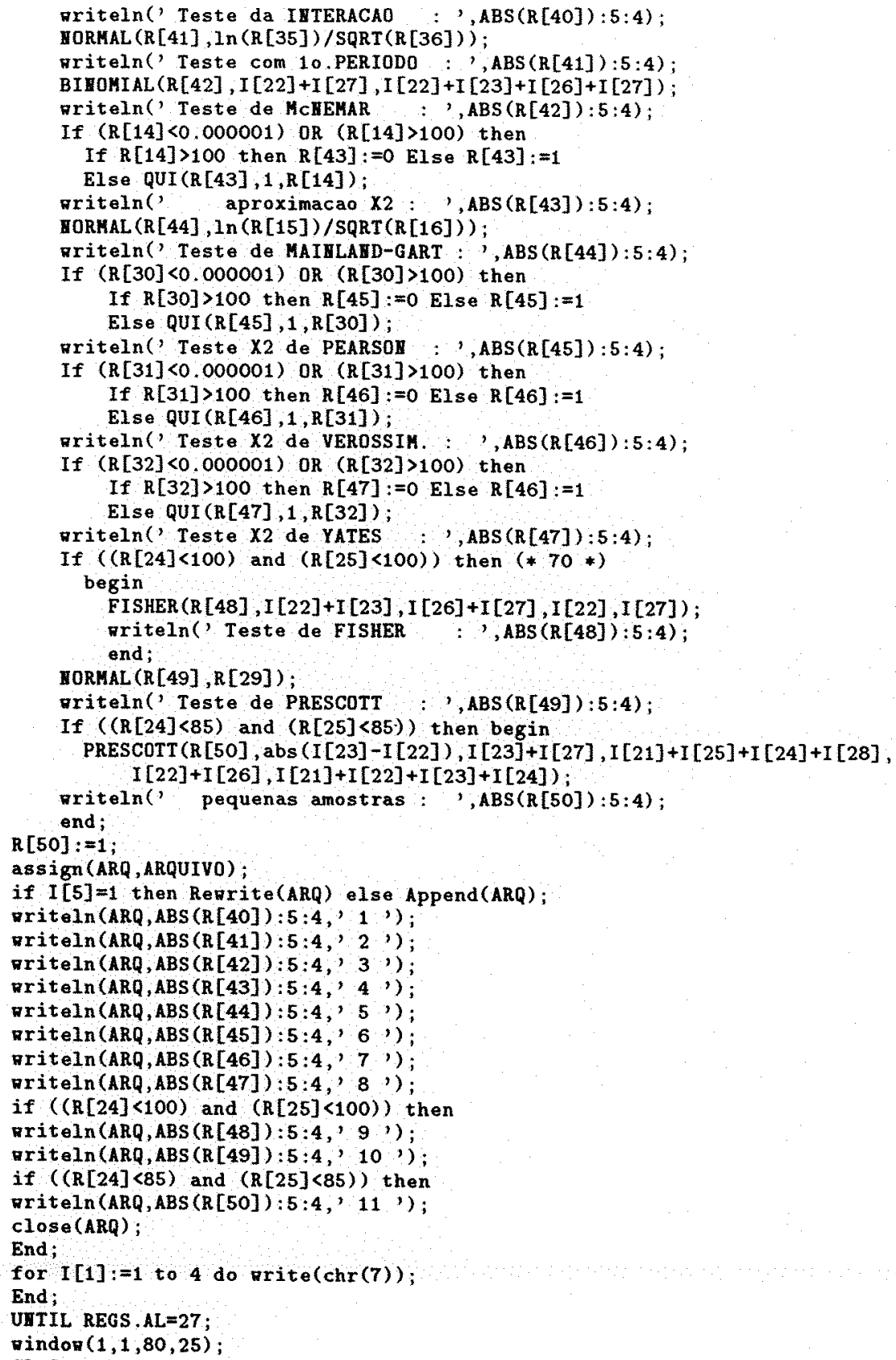

